ALEXEI GINO NAJAR JIMÉNEZ

\title{
ANÁLISES TENSÃO-DEFORMAÇÃO DE ESTRUTURAS DE SOLO GRAMPEADO
}

Dissertação apresentada à Escola Politécnica da Universidade de São Paulo para a obtenção do título de Mestre em Engenharia

São Paulo 


\section{ANÁLISES TENSÃO-DEFORMAÇÃO DE ESTRUTURAS DE SOLO GRAMPEADO}

Dissertação apresentada à Escola Politécnica da Universidade de São Paulo para a obtenção do título de Mestre em Engenharia

Área de Concentração: Engenharia Geotécnica

Orientador: Prof. Doutor Waldemar Coelho Hachich 
FICHA CATALOGRÁFICA

Najar Jiménez, Alexei Gino

Análises tensão-deformação de estruturas de solo grampeado / A.G. Najar Jiménez. -- São Paulo, 2008. $117 \mathrm{p}$.

Dissertação (Mestrado) - Escola Politécnica da Universidade de São Paulo. Departamento de Engenharia de Estruturas e Geotécnica.

1. Solos 2. Estruturas de suporte 3. Análise numérica. I.Universidade de São Paulo. Escola Politécnica. Departamento de Engenharia de Estruturas e Geotécnica II. t. 
Ao infinito amor dos meus pais, Gino e Gilda. 


\section{Agradecimentos}

Ao meu Pai, pelo exemplo que representa e por me incentivar a estudar engenharia civil desde as épocas de quando era criança;

À minha Mãe Gilda, pelo incomensurável amor, constante apoio, incentivo e dedicação;

Ao professor. doutor. Waldemar Coelho Hachich, pela constante motivação, modo dedicado e paciente de ensinar; meus sinceros agradecimentos;

Aos professores Jorge José Náder e Faiçal Massad, pelas valiosas contribuições no exame de qualificação e apoio brindado durante o desenvolvimento deste trabalho.

Aos professores Carlos Pinto e Marcos Massao; pela amabilidade com que sempre foram atendidas minhas dúvidas;

Aos meus irmãos, Adhemar e David, pelo constante apoio;

À Lissette, pelo imenso amor e compreensão brindados durante o mestrado, meu mais profundo agradecimento;

Ao Marcio, pela amizade, valiosas contribuições e revisão do texto.

Ao Henrique, pela valiosa ajuda na etapa final do trabalho.

Aos meus amigos e colegas, Arturo, Marco, Jorge e Raul, pelos bons momentos compartilhados durante o mestrado;

Aos meus colegas do mestrado, Thiago, Mariana, Flávio, Bárbara, Fernando, Rafael e Calebe, que de alguma forma contribuíram para a realização deste trabalho. 
À Sarah, pela ajuda na revisão das referências.

Aos amigos Geraldo, Lucio, Igor e Eduardo, pela amizade e contribuições ao trabalho.

Ao CNPq pela ajuda financeira durante o mestrado. 


\section{RESUMO}

Os métodos de equilíbrio limite comumente utilizados no dimensionamento de estruturas de solo grampeado não oferecem informação sobre as tensões e deformações na estrutura. No entanto, o êxito da técnica pressupõe deslocamentos para que a resistência dos grampos seja mobilizada. Portanto, seria desejável conhecer: os deslocamentos que a estrutura. sofre durante e depois de realizado o processo da escavação; os esforços mobilizados nos grampos; e a distribuição de tensões atrás da parede da escavação. A importância deste estudo é maior em situações em que a previsão do comportamento é a responsável por garantir a segurança de construções e de instalações de serviço público próximas às escavações grampeadas.

Análises bidimensionais e tridimensionais de tensão-deformação com elementos finitos foram realizadas para um melhor entendimento do comportamento da estrutura. As comparações dos resultados das modelagens numéricas permitiram conhecer várias vantagens e desvantagens de um e de outro tipo de modelagem.

Realizaram-se também comparações entre resultados de modelagens numéricas que utilizaram os seguintes modelos constitutivos: elasto-plástico (com critério de ruptura de Mohr-Coulomb), hiperbólico e elástico-linear, sendo que para este último realizou-se uma análise incremental. Para a aplicação do modelo elástico-linear foi necessária a divisão do maciço em regiões em função do tipo de trajetória de tensão. Essas comparações permitiram concluir que, desde que com a correta especificação dos parâmetros elásticos, a modelagem baseada na Teoria da Elasticidade pode representar bem o comportamento de escavações grampeadas.

Palavras-chaves: Solo Grampeado, Análise Numérica Tridimensional, Teoria da Elasticidade, Elementos Finitos, Escavações. 


\begin{abstract}
The limit equilibrium methods that are frequently used for design of soi nailing structures do not provide information about the structure's stress and strain. However, the technique's success depends on the displacements that mobilize the nails strength. Therefore it is desirable to predict the structure's displacement, during and after the excavation; the forces avting on nails; and the stress distribution behind the excavation wall. This study has its importance incresed in situations in which the prediction of the behavior is needed to guarantee the safety of adjacent buildings and municipal installations near to the excavation.
\end{abstract}

Three dimensional and two-dimensional fine element stress-strain analyses were carried out for a better understanding of the behavior of the structure. Comparisons of the results of different numerical models led to a clear picture of advantages and disadvantages of different approaches.

Numerical comparisons were also carried out between analyses with different constitutive models: elasto-plastic (Mohr-Coulomb), hyperbolic and incremental linear elastic. Application of the linear elastic model required the division of the soil mass in regions, according to stress path. Those comparisons led to the conclusion that, given correctly specified elastic parameters, Theory of Elasticity is able to correctly model the behavior of nailed excavations.

Keywords: Soil Nailing, Three-dimensional Numerical Analysis, Theory of the Elasticity, Finite Elements, Excavations. 


\section{LISTA DE FIGURAS}

Figura 1.1 - Condição típica na construção de subsolos. 1

Figura 2.1 - (a) Esquema do talude natural reforçado com grampos; (b) vista do talude natural reforçado com grampos e paramento de grama. (Pitta et al. 2003).

Figura 2.2 - (a) Esquema de uma escavação reforçada com a técnica de solo grampo; (b) vista durante a execução do sistema de contenção. (modificado de Pitta et al. 2003)

Figura 2.3 - Processo de instalação por cravação do grampo. (Soil Nail

Launcher, 2007)

Figura 2.4 - (a) Processo de instalação do grampo por perfuração; (b) perfuração do maciço de solo, (c) componentes de um grampo injetado. (modificado de Pitta et. al. 2003)

Figura 2.5 - Fase de escavação inicial mecanizada (modificado de Texeira et al. 2006)

Figura 2.6 - Fase de perfuração do solo e instalação do grampo.

Figura 2.7 - (a) Seleção dos grampos para ensaios de arrancamento; (b) instalação incorreta; (c) instalação correta do macaco hidráulico para o ensaio de arrancamento.

Figura 2.8 - Instalação da tela eletrosoldada. 10

Figura 2.9 - Lançamento do concreto projetado e instalação da placa e porca metálica

Figura 2.10 - (a) Parâmetros que influenciam a resistência da interface; (b) forças que provocam tensões de cisalhamento na interface. (modificado de Rogbeck et al. 2004)

Figura 2.11 - Correlação do valor do $q_{s} \operatorname{com} \rho_{I}$ e $N_{S P T}$ para: (a) areias; (b) argilas e siltes. (Bustamente e Doix, 1985 apud Springer, 2006)

Figura 2.12 - Curvas para a estimação do valor de $q_{s}$. (Clouterre, 1991) ....... 14

Figura 2.13 - Correlação entre $q_{s}$ e N $N_{S P T}$. (Ortigão; Zirilis e Palmeira, 1993) .. 14

Figura 2.14 - Variação do coeficiente de interface " $\alpha$ " em função da tensão normal. (Proto da Silva et al, 2006) 
Figura 2.15 - (a) Montagem do sistema de ensaio de arrancamento; (b) curva carga-deslocamento de um ensaio de arrancamento. (modificado de Springer, 2006) 16

Figura 2.16 - (a) Principio do comportamento do solo grampeado; (b) deformações que o grampo sofre; (c) forças que agem no grampo. (modificado de Rogbeck et al. 2004) 18

Figura 2.17 - (a) Talude reforçado com superfície parabólica; (b) superfície de ruptura bi-linear. (Clouterre, 1991) 19

Figura 2.18 - (a) Variação dos deslocamentos na face de taludes de solo grampeado instrumentados (Clouterre, 1991); (b) Esquema da localização dos máximos deslocamentos. (modificado de Rogbeck et al. 2004) 20

Figura 2.19 - Ruptura na face do talude. (Byrne et. al, 1998) ...................... 21

Figura 2.20 - Ruptura por arrancamento do grampo. (Byrne et. al, 1998) ..... 22 Figura 2.21 - Ruptura por insuficiente resistência a tração do reforço. (Byrne et. al, 1998)

Figura 3.1 - Disposição do comprimento dos grampos. (Shiu e Chang, 2005)28 Figura 3.2 - Deformações horizontais da parede escavada em função da profundidade. (Ho e Smith, 1993) 30

Figura 3.3 - (a) Geometria e malha de elementos finitos do modelo; (b) distribuição de deformações plásticas ao redor dos grampos. (Smith e Su 1997) 31

Figura 4.1 - Sólido deformável submetido a forças de volume, forças de superfície e deslocamentos prescritos. 35

Figura 4.2 - Limitações teoria da elasticidade (a) Incremento de $\tau$ provoca $\Delta \varepsilon_{\mathrm{v}}$;

(b) Incremento da $\Delta \gamma$ provoca decréscimo de $\sigma$. 40

Figura 4.3 - Elemento rebar em elementos sólidos. 42

Figura 4.4 - Deslocamentos verticais da superfície $A B$. 43

Figura 4.5 - (a) Recalques e Deslocamentos verticais na superfície $A B$; (b) Deslocamentos da parede escavada (superfície BC). 44

Figura 4.6 - (a) geometria e nomenclatura utilizada nas modelagens numéricas; (b) Influência do $\mathrm{K}_{\mathrm{o}}$ nos máximos deslocamentos horizontais e verticais. 
Figura 4.7 - Influencia da largura da vala (B) nos máximos deslocamentos verticais e horizontais, mantendo-se constantes $H / D=0,5$ e W $=70 \mathrm{~m}$ 46

Figura 4.8 - Influencia da relação $\mathrm{W} / \mathrm{H}$ nos máximos deslocamentos verticais e horizontais mantendo-se constantes $\mathrm{H} / \mathrm{D}=0,5$ e $\mathrm{B}=2 \mathrm{H} / 3 \ldots 47$

Figura 4.9 - Influencia da relação $H / D$ nos deslocamentos verticais e horizontais, mantendo-se constantes $\mathrm{B}=2 \mathrm{H} / 3$ e $\mathrm{W}=70 \mathrm{~m}$... 47

Figura 4.10 - Efeito do número de etapas de escavação nos deslocamentos dos pontos B e C (Christian e Wong, 1973).

Figura 4.11 - Efeito do número de etapas dos deslocamentos da face escavada (Christian e Wong, 1973) 50

Figura 4.12 - Curvas tensão-deformação para diferentes trajetórias de tensão (Lambe e Whitman, 1979).

Figura 4.13 - Comparações do módulo de elasticidade tangente para: (a) ensaios de compressão ativa e passiva, em uma argila siltosa rija; (b) ensaios de extensão ativa e compressão passiva, em uma areia densa (Medeiros e Eisenstein, 1983).

Figura 4.14 - Tipos de trajetórias de tensão no maciço na etapa final da escavação: (a) $1^{\underline{a}}$ iteração; (b) $2^{\underline{a}}$ iteração; (c) $3^{\underline{a}}$ iteração; (d) $4^{\underline{a}}$ iteração; (e) $5^{\mathrm{a}}$ iteração; (f) $6^{\mathrm{a}}$ iteração; (g) $7^{\mathrm{a}}$ iteração; (h) proposta de distribuição típica. 55

Figura 4.15 - Deslocamentos horizontais na etapa final da escavação das sete iterações e da distribuição típica na superfície BC 56

Figura 4.16 - Deslocamentos verticais na etapa final da escavação das sete iterações e da distribuição típica na superfície $A B$.

Figura 4.17 - Tipos de trajetórias tensão no maciço em uma etapa intermediária da escavação: (a) $1^{\underline{a}}$ iteração; (b) $2^{\underline{a}}$ iteração; (c)

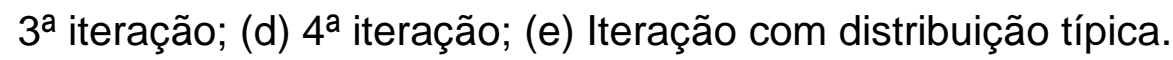

Figura 4.18 - Deslocamentos horizontais em uma etapa intermediária da escavação das sete iterações e da distribuição típica na superfície BC. 
Figura 4.19 - Deslocamentos verticais em uma etapa intermediária da escavação das sete iterações e da distribuição típica na superfície AB.

Figura 4.20 - Distribuição típica de trajetórias de tensão no maciço de solo ao redor da escavação. 59

Figura 4.21 - Regiões de trajetórias de tensão ao redor da escavação

(Eisenstein e Medeiros, 1983). 60

Figura 4.22 - Geometria e malha de elementos finitos utilizada. 61

Figura 4.23 - Influência de $v$ nos deslocamentos verticais da superfície AB. . 62

Figura 4.24 - Influência de $v$ nos deslocamentos horizontais da superfície BC. 62

Figura 4.25 - Geometria e características do maciço de solo ao redor da escavação.

Figura 4.26 - Comparação dos resultados de deslocamentos horizontais na face BC.

Figura 4.27 - Comparação dos resultados de recalques na superfície $A B$..... 64

Figura 5.1 - Geometria do modelo e condições de contorno utilizadas na modelagem numérica tridimensional.

Figura 5.2 -Campos de tensões inicias do modelo tridimensional: (a) direção z; (b) direção y; (c) direção $x$. 68

Figura 5.3 -Divisão do modelo tridimensional em regiões para modificação dos parâmetros elásticos durante o processamento computacional.

Figura 5.4 - Aspecto do modelo tridimensional deformada na última etapa de escavação.

Figura 5.5 - Campo de deslocamentos horizontais obtidos no modelo 3D. ... 70

Figura 5.6 - Campo de deslocamentos verticais obtidos no modelo 3D........ 71

Figura 5.7 - Distribuição dos deslocamentos verticais obtidos no modelo 2D.71

Figura 5.8 - Distribuição dos deslocamentos verticais obtidos no modelo 2D.72

Figura 5.9 - Comparação dos perfis de deslocamentos horizontais obtidos no modelo 3D e no trabalho realizado por Lima et. al (2002). ..... 73

Figura 5.10 - Comparação dos perfis de recalques obtidos no modelo 3D e no trabalho realizado por Lima et. al (2002). 73 
Figura 5.11 - Características do solo escavado: (a) perfil do solo encontrado nas sondagens; (b) resultados de ensaios de laboratório em amostras representativas.

Figura 5.12 - Geometria e características do modelo físico de Shen et. al

Figura 5.13 - Configuração da malha de elementos finitos e fases de construção: (a) Malha e estado inicial; (b) primeira fase; (c) segunda fase; (d) terceira fase; (e) quarta fase; (f) fase final.. 76

Figura 5.14 -Campos de tensões inicias nas direções $z$, y e x respectivamente. 78

Figura 5.15 -Divisão do maciço de solo em regiões para atualização dos parâmetros elásticos durante o processamento computacional.

Figura 5.16 - Aspecto da deformada da escavação grampeada na última etapa de escavação. 80

Figura 5.17 - Campo de deslocamentos horizontais................................... 80

Figura 5.18 - Campo de deslocamentos verticais.......................................... 81

Figura 5.19 - Comparação dos perfis de deslocamentos horizontais. ............ 82

Figura 5.20 - Comparação dos perfis de recalques .................................. 83

Figura A.1 - Modelo tridimensional de uma escavação e localização dos elementos estudados. 


\section{LISTA DE TABELAS}

Tabela 2.1 - Altura das etapas de escavação em função ao tipo de solo.

(Gässler, 1990 apud Lima, 2007).

Tabela 2.2 - Número de ensaios de arrancamento em função da área reforçada. (Clouterre, 1991)... 10

Tabela 2.3 - Fatores que aumentam a resistência por atrito unitário. (Rogbeck et al. 2004)

Tabela 2.4 - Estimativa preliminar de valores de qs (Mitchell et al., 1987 apud Byrne et. al, 1998).

Tabela 2.5 - Resumo de correlações empíricas (Lima, 2007)........................ 17

Tabela 2.6 - Estimação empírica dos deslocamentos (Clouterre, 1991) ......... 20

Tabela 2.7 - Deslocamentos horizontais em muros de solo grampeado.

(Springer, 2006)

Tabela 2.8 - Características dos métodos de cálculo para estruturas de solo grampeado (adaptado de Abramson et al., 1996 apud Lima, 2006).

Tabela 3.1 - Resumo de modelagens numéricas. 33

Tabela 4.1 - Módulos de elasticidade para diferentes trajetórias de tensão. .. 52

Tabela 4.2 - Parâmetros utilizados nas iterações das etapas final e intermediária.

Tabela 4.3 - Parâmetros utilizados nas modelagens numéricas. 63

Tabela 5.1 - Parâmetros utilizados na modelagem numérica. .66

Tabela 5.2 - Parâmetros do modelo hiperbólico (Shen et. al, 1981). 77

Tabela 5.3 - Valores de módulos de elasticidade utilizados a diferentes profundidades para cada trajetória de tensão. 


\section{LISTA DE SÍMBOLOS}

\begin{tabular}{|c|c|}
\hline$\sigma_{i j}$ & Componente do tensor das tensões \\
\hline$\sigma_{o c t}$ & Tensão octaédrica \\
\hline$\sigma_{N}$ & Tensão normal \\
\hline$\sigma_{n}^{\prime}$ & Tensão normal efetiva \\
\hline$\sigma_{v}$ & Tensão vertical \\
\hline$\sigma_{h}$ & Tensão horizontal \\
\hline$\sigma_{v o}$ & Tensão de vertical inicial \\
\hline$\varepsilon_{i j}$ & Componentes do tensor de deformação \\
\hline$\varepsilon_{V}$ & Deformação volumétrica \\
\hline$v$ & Coeficiente de Poisson \\
\hline$c$ & Coesão \\
\hline$c^{\prime}$ & Coesão efetiva \\
\hline$\phi$ & Ângulo de atrito do solo \\
\hline$\phi^{\prime}$ & Ângulo de atrito efetivo do solo \\
\hline$\delta$ & Ângulo de atrito da interface solo-grampo \\
\hline$\theta$ & Perímetro do grampo \\
\hline$\rho_{l}$ & Pressão limite do pressiômetro Ménard \\
\hline$N_{S P T}$ & Número de golpes do ensaio SPT \\
\hline$q_{s}$ & Resistência ao cisalhamento no contato solo-grampo \\
\hline$k_{b}$ & Rigidez do grampo \\
\hline$L$ & Comprimento do grampo \\
\hline$L_{i}$ & Comprimento do grampo na zona passiva \\
\hline$H$ & Altura da escavação \\
\hline$K_{o}$ & Coeficiente de empuxo em repouso \\
\hline$S_{v}, S_{h}$ & Espaçamento vertical e horizontal entre grampos \\
\hline$f_{b}$ & Força de volume \\
\hline$f_{s}$ & Força de superfície \\
\hline$I_{i}, J_{i}$ & Invariantes de tensão \\
\hline
\end{tabular}




\begin{tabular}{|c|c|}
\hline$E$ & Módulo de elasticidade \\
\hline$E_{c c}$ & Módulo de elasticidade em compressão por carregamento \\
\hline$E_{C D}$ & Módulo de elasticidade em compressão por descarregamento \\
\hline$E_{E D}$ & Módulo de elasticidade em extensão por descarregamento. \\
\hline$E_{E C}$ & Módulo de elasticidade em extensão por carregamento. \\
\hline$C_{i j}$ & Matriz elástica \\
\hline$P_{N}$ & Carga no grampo \\
\hline$P$ & Componente longitudinal da carga no grampo \\
\hline$P_{P}$ & Componente transversal da carga no grampo \\
\hline$\delta$ & Deslocamento de um ponto no grampo \\
\hline$\delta_{L}$ & Componente de deslocamento transversal \\
\hline$\delta_{a x}$ & Componente de deslocamento longitudinal \\
\hline$T_{\max }$ & Tração máxima no grampo \\
\hline$G$ & Módulo de cisalhamento \\
\hline$T$ & Tensor das tensões \\
\hline$D$ & Tensor das deformações \\
\hline$S$ & Tensor das tensões desviadoras \\
\hline$V$ & Volume \\
\hline$n$ & Vetor normal \\
\hline$u$ & Vetor deslocamento \\
\hline
\end{tabular}




\section{SUMÁRIO}

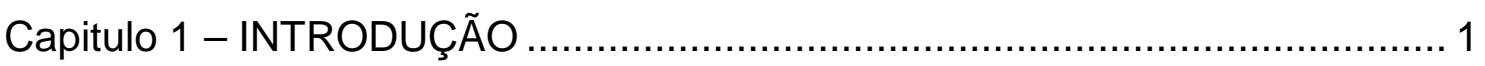

Capitulo 2 - SOLO GRAMPEADO, MECANISMO E COMPORTAMENTO ....... 4

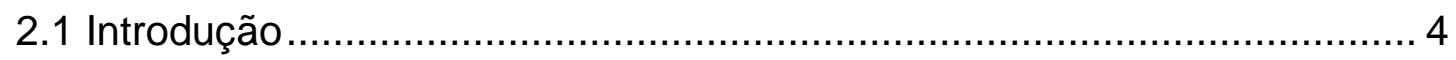

2.2 O Sistema de Estabilização e Contenção com Solo Grampeado .............. 4

2.3 Procedimento Construtivo................................................................. 7

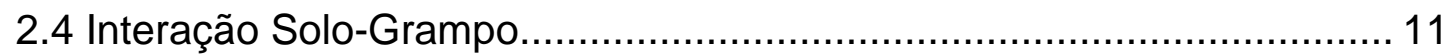

2.5 Mecanismo do Comportamento da Estrutura ...................................... 18

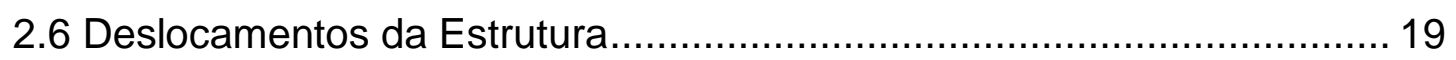

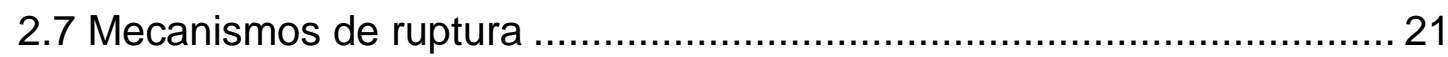

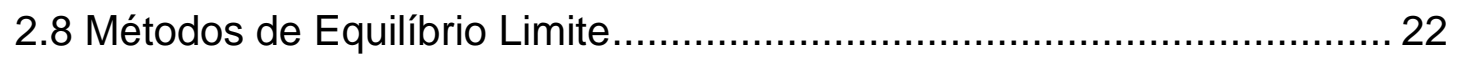

Capitulo 3 - MODELAGENS NUMÉRICAS DE ESTRUTURAS DE SOLO

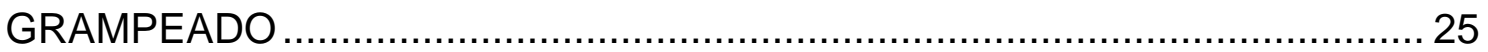

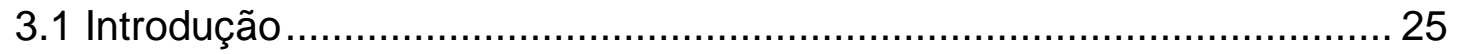

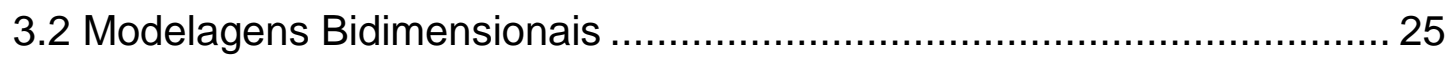

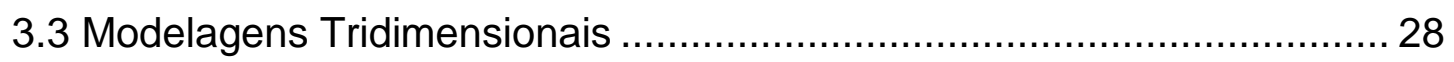

Capitulo 4 - ANÁLISES EFETUADAS UTILIZANDO MODELOS NUMÉRICOS BASEADOS NA TEORIA DA ELASTICIDADE............................................... 34

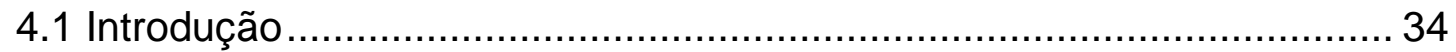

4.2 Teoria da Elasticidade Linear ......................................................... 34

4.3 Limitações da Teoria de Elasticidade ………….................................. 39

4.4 Programas Computacionais Utilizados ................................................... 41

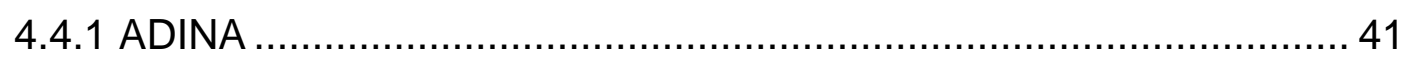

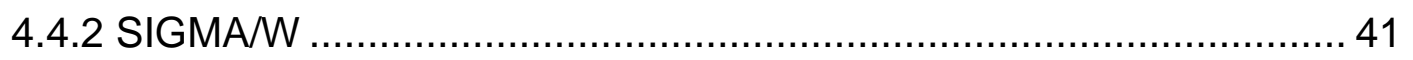

4.5 Tipos de Elementos Finitos Utilizados nas Modelagens Numéricas ....... 41

4.6 Problemas em Modelagens Numéricas que Utilizam a Teoria da

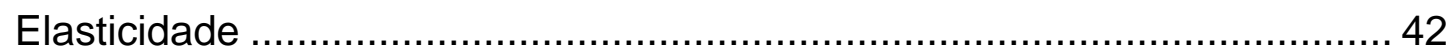

4.7 Influência do $K_{\circ}$ nos Máximos Deslocamentos ....................................... 44

4.8 Influência da Proximidade das Condições de Contorno nos Máximos

Deslocamentos Horizontais e Verticais........................................................ 46

4.9 Influência do Número de Etapas de Escavação ...................................... 48

4.10 Módulos de Elasticidade para Diferentes Trajetórias de Tensão .......... 51

4.11 Trajetórias de Tensões no Maciço ao Redor da Escavação .................. 54 
4.12 Influência da Variação do Coeficiente de Poisson ................................... 60

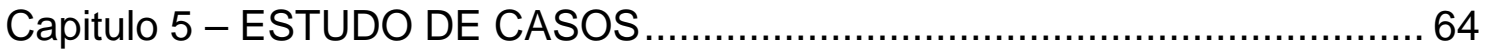

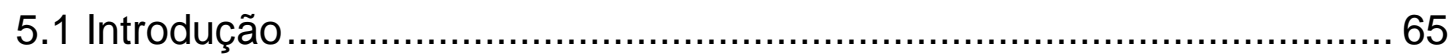

5.2 Caso Hipotético - Escavação Grampeada de Lima et. al (2002) ........... 65

5.3 Caso da Escavação Instrumentada pelo Programa de Estudo Davis.... 74

Capitulo 6 - CONCLUSÕES E RECOMENDAÇÕES ………......................... 84

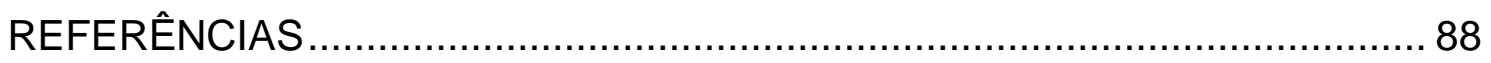

Apêndice A - TENSORES DE TENSÃO EM ELEMENTOS PRÓXIMOS A UMA

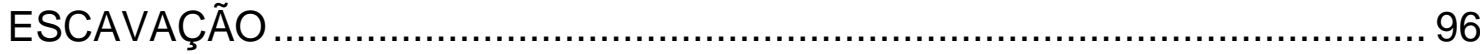

Anexo A - EQUAÇÕES DO MODELO HIPERBÓLICO DE DUNCAN E CHANG

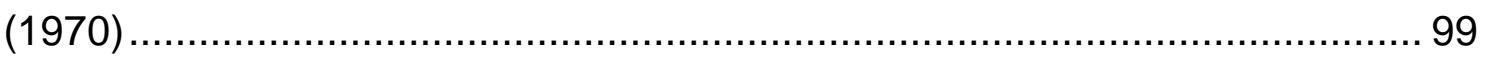




\section{Capitulo 1 - INTRODUÇÃO}

A importância de uma análise tensão-deformação de um talude escavado e reforçado com a técnica de solo grampeado fica mais evidente em situações em que o conhecimento das deformações da estrutura é responsável por garantir a segurança das construções e utilidades próximas às escavações (ver Figura 1.1).

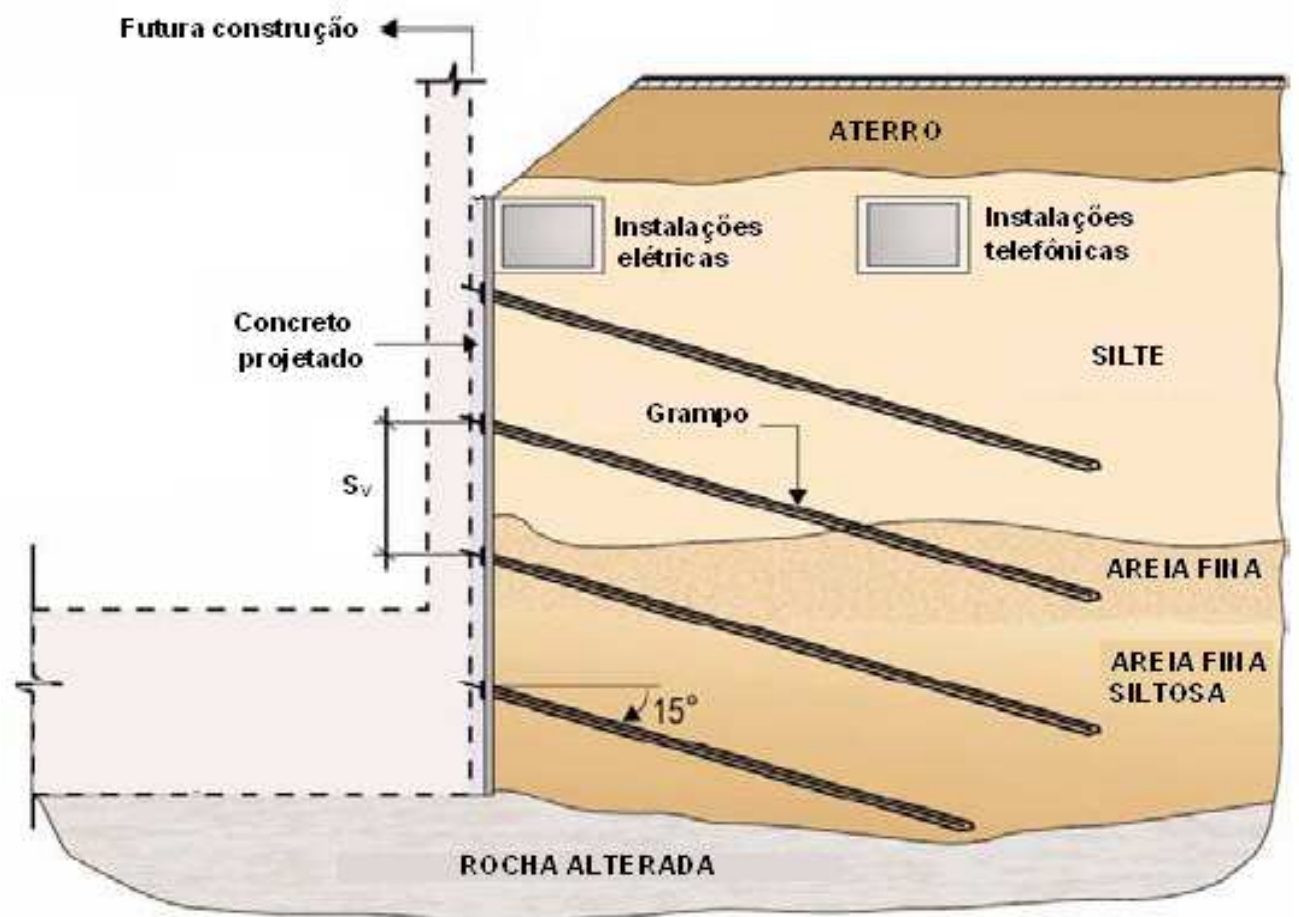

Figura 1.1 - Condição típica na construção de subsolos.

Essas situações são por vezes tratadas com reforços ativos (e.g. tirantes), mas a utilização de solo grampeado pode ser economicamente mais atraente, em que pese a conveniência de se proceder à previsão dos deslocamentos, já que os grampos são elementos passivos que requerem deformações para mobilizar a resistência.

Os métodos numéricos apresentam-se como uma ferramenta útil para estimar os deslocamentos que poderiam ocorrer em uma escavação reforçada com a técnica de solo grampeado, como por exemplo hoje em dia o método dos 
elementos finitos (MEF), que ultimamente vem sendo utilizado para obter melhores previsões do comportamento das escavações grampeadas. Ainda que essa análise proporcione uma valiosa informação, apresenta também algumas deficiências, particularmente na especificação dos parâmetros do solo e no tipo de modelo adotado. Uma análise tensão-deformação em condição bidimensional não é totalmente fiel à situação real de solicitação do grampo, pois este é representado como um elemento continuo na direção perpendicular à seção analisada, o que não é realista em termos geométricos. Torna-se portanto desejável uma análise numérica tridimensional, já que esta considera cada grampo como um elemento de barra.

A vantagem de utilizar um modelo numérico tridimensional de uma estrutura de solo grampeado é que permite criar uma distribuição geométrica adequada dos grampos para a obtenção dos deslocamentos da face escavada e do terrapleno, possivelmente conduzindo a vantagens em termos de riscos e de custos.

Modelos constitutivos de fácil aplicação em modelagens numéricas, como o elástico-linear, podem talvez representar adequadamente o comportamento das escavações grampeadas. Porém, em vista o fato de que cada região do maciço de solo ao redor da escavação apresenta diversos tipos de trajetórias de tensão, seria mais realista considerar a respectiva variação dos parâmetros elástico do solo, o que normalmente não é levando em consideração nos modelos constitutivos mais simples.

O presente trabalho tem como objetivos: (1) discutir os requisitos para a utilização correta da Teoria da Elasticidade em modelagens numéricas de escavações a céu aberto; (2) comparar resultados de análises numéricas bidimensionais com tridimensionais de escavações grampeadas que utilizam a Teoria da Elasticidade para representar o comportamento do maciço de solo, bem como, na medida do possível, comparar essas análises com casos de obra instrumentados. 
No Capitulo 2 é apresentada uma revisão bibliográfica dos principais conceitos da técnica de solo grampeado, tais como: processo construtivo, mecanismo do comportamento, mecanismos de ruptura, correlações empíricas para a estimativa do valor da resistência ao arrancamento dos grampos e uma menção aos métodos de calculo por equilíbrio limite.

O Capitulo 3 apresenta um resumo de diversas modelagens numéricas bidimensionais e tridimensionais de escavações grampeadas, encontradas na bibliografia técnica.

No Capitulo 4 são apresentados alguns aspectos básicos da Teoria da Elasticidade, fatores que influenciam os resultados das análises numéricas de escavações a céu aberto que aplicam o modelo elástico-linear, revisão bibliográfica sobre módulos de elasticidade para diferentes trajetórias de tensão e trajetórias de tensões no maciço ao redor da escavação.

O capitulo 5 apresenta dois casos de estudo analisados com modelagens numéricas bidimensionais e tridimensionais que aplicam o modelo elásticolinear para simular o comportamento do maciço de solo. Os resultados dessas análises foram comparados entre si e com a utilização de modelo constitutivo elasto-plástico e elástico não-linear, bem como uma comparação com algumas medidas de campo disponíveis na literatura.

Finalmente, no Capitulo 6 são apresentadas as conclusões e recomendações decorrentes dos estudos do presente trabalho. 


\section{Capitulo 2 - SOLO GRAMPEADO, MECANISMO E COMPORTAMENTO}

\subsection{Introdução}

O presente Capítulo apresenta uma revisão bibliográfica sobre a técnica de solo grampeado, onde são descritos alguns aspectos importantes como: processo construtivo, mecanismos de ruptura e métodos de dimensionamento. Neste capitulo também são apresentadas correlações empíricas para estimativa da resistência ao arrancamento nos grampos, em função de diversos fatores, tais como o valor do número de golpes do ensaio do SPT (Standart Penetration Test).

\subsection{O Sistema de Estabilização e Contenção com Solo Grampeado}

O solo grampeado é uma técnica que melhora a estabilidade de taludes naturais e escavados mediante a inserção de reforços passivos no maciço de solo. Portanto, o maciço reforçado age como se fosse um material com propriedades mecânicas melhoradas, como a capacidade de resistir esforços de tração.

Existem diversas definições para a técnica de solo grampeado, no presente texto será utilizada a seguinte conceituação:

"Uma estrutura de solo grampeado apresenta elementos de reforços passivos de pequeno diâmetro instalados no maciço de solo com inclinações que variam entre $10^{\circ}$ a $45^{\circ}$ com horizontal. Estes reforços trabalham principalmente a esforços de tração e com uma pequena contribuição da resistência à flexão e ao cisalhamento que normalmente são desconsideradas" (Rogbek et al., 2004, p. 5, tradução nossa). 
As principais aplicações desta técnica de reforço de taludes são duas:

- Incrementar o fator de segurança em taludes naturais. (ver Figura 2.1)

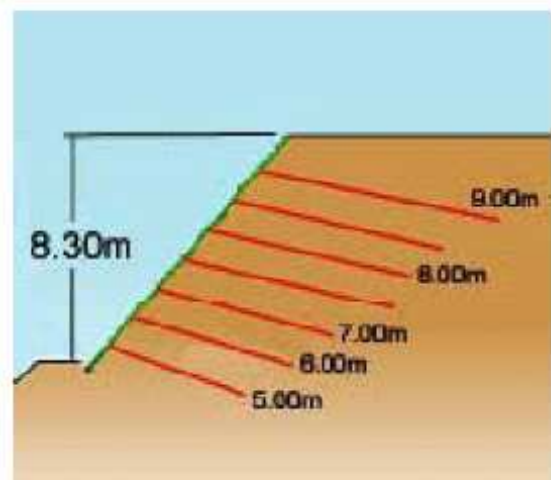

(a)

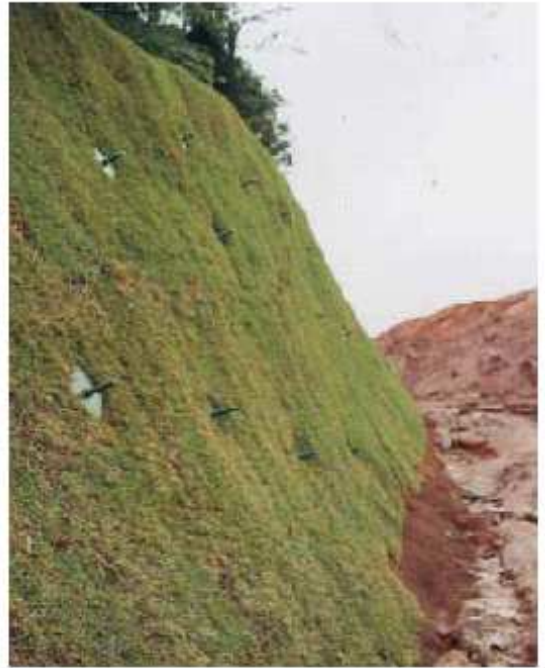

(b)

Figura 2.1 - (a) Esquema do talude natural reforçado com grampos; (b) vista do talude natural reforçado com grampos e paramento de grama. (Pitta et al. 2003)

- Como sistema de contenção de taludes escavados mediante a instalação de grampos durante a escavação. (ver Figura 2.2)

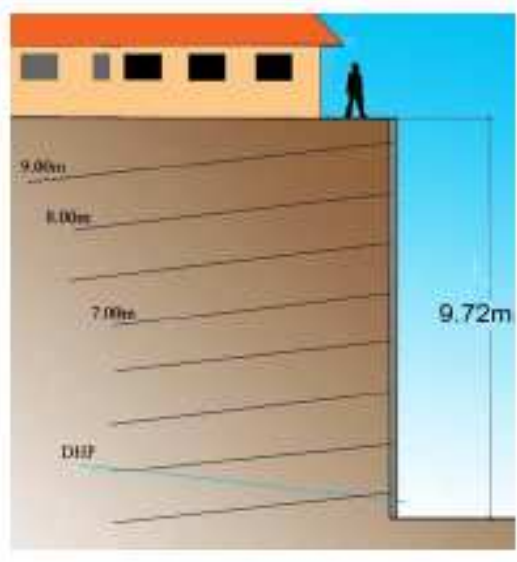

(a)

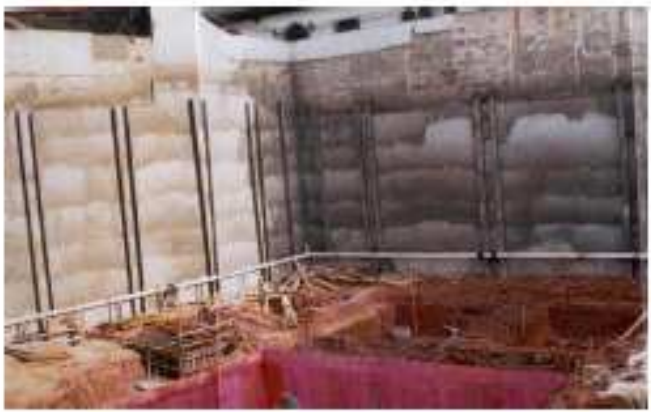

(b)

Figura 2.2 - (a) Esquema de uma escavação reforçada com a técnica de solo grampo; (b) vista durante a execução do sistema de contenção. (modificado de Pitta et al. 2003)

$\mathrm{Na}$ técnica de solo grampeado há duas formas de instalação de grampos no maciço de solo, como seguem: (1) percussão; e (2) perfuração e injeção de calda de cimento. 
A metodologia de instalação de grampos por percussão é realizada mediante um processo de cravação de barras ou perfis metálicos esbeltos com um martelete pneumático. Segundo Ortigão et. al (1993) este tipo de instalação oferece uma resistência por atrito na interface solo-grampo geralmente baixa (valores da ordem de 30 a $40 \mathrm{kPa}$ em solos arenosos), os autores também mencionam que o processo de instalação não pode ser utilizado quando há presença de pedregulhos ou solos arenosos muito resistentes, porém a vantagem principal deste processo de instalação é sua rapidez construtiva. A Figura 2.3 mostra o processo de instalação de grampos cravados na reconstrução de um tramo de uma rodovia, onde a metodologia de instalação por percussão trouxe benéficios no tempo de execução e no custo da obra.

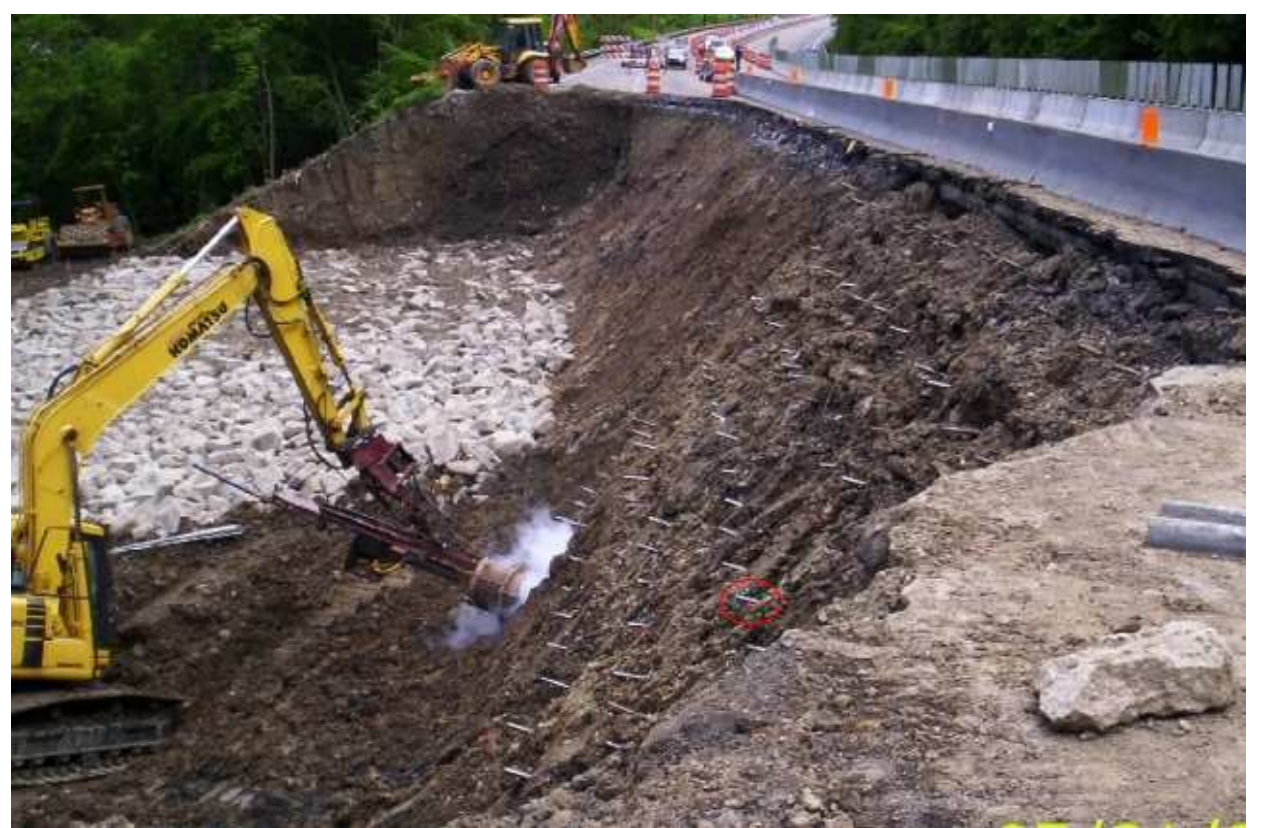

Figura 2.3 - Processo de instalação por cravação do grampo. (Soil Nail Launcher, 2007)

A segunda metodologia de instalação é realizada mediante a perfuração do maciço de solo prosseguido pela introdução de uma barra de aço e injeção da calda de cimento a baixas pressões (inferiores a $100 \mathrm{kPa}$ ). Ortigão et. al (1993). afirmam que a instalação de grampos mediante esta metodologia de instalação não é recomendada em caso da ocorrência de argilas porosas ou solos que apresentem elevados porcentagens de pedregulhos. 
Na Figura 2.4a pode-se observar a instalação do grampo por processo de perfuração na construção de uma obra de contenção com solo grampeado. Nota-se que a largura da vala é bastante estreita e que a perfuração foi realizada com uma perfuratriz compacta elétrica. Nas Figuras $2.4 \mathrm{~b}$ e $2.4 \mathrm{c}$ apresentam-se esquemas do processo de perfuração do maciço de solo e os componentes de um grampo perfurado respectivamente.

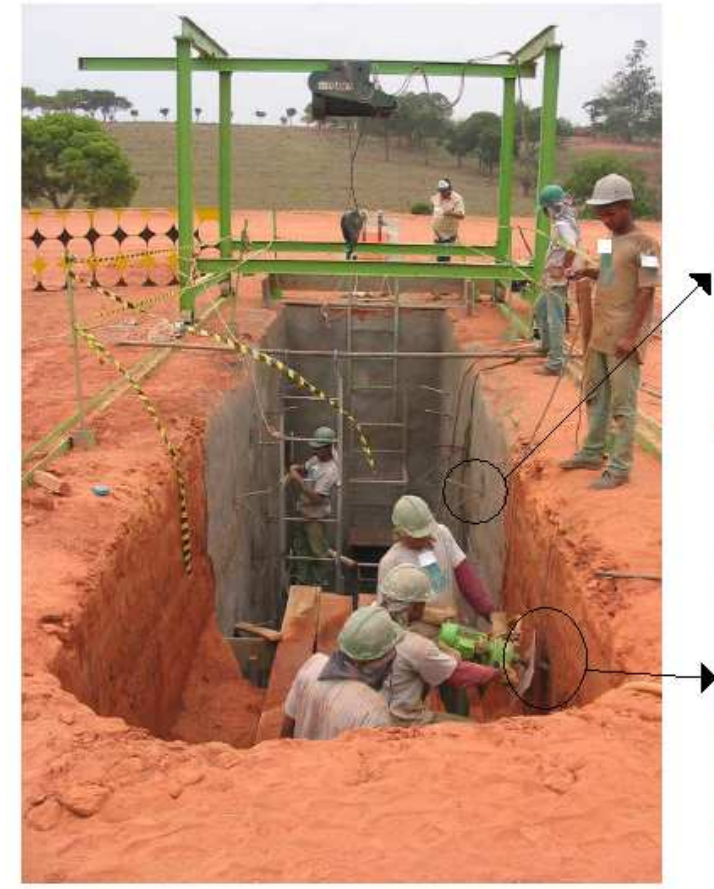

(a)

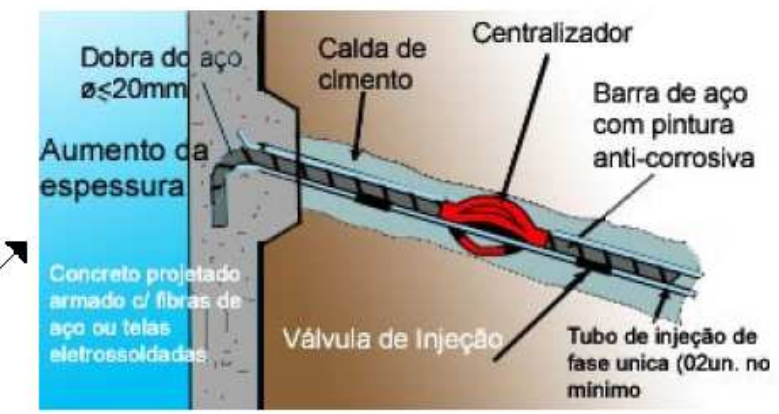

(c)

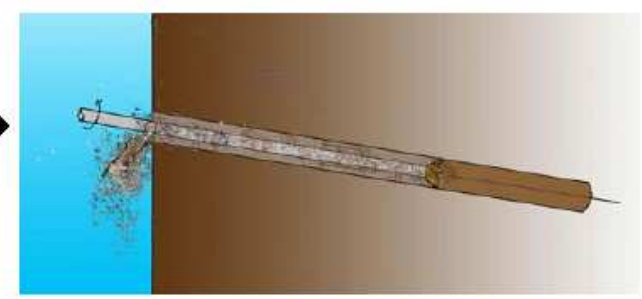

(b)

Figura 2.4 - (a) Processo de instalação do grampo por perfuração; (b) perfuração do maciço de solo, (c) componentes de um grampo injetado. (modificado de Pitta et. al. 2003)

\subsection{Procedimento Construtivo}

1) Escavação da primeira etapa segundo a geometria do projeto (ver Figura 2.5). A altura de escavação em cada etapa depende do tipo de solo; Gässler (1990) apud Lima (2007) recomenda alturas de escavação em função do tipo de solo (ver Tabela 2.1). 
$1^{2}$ Fase - escavação inicial mecanizada

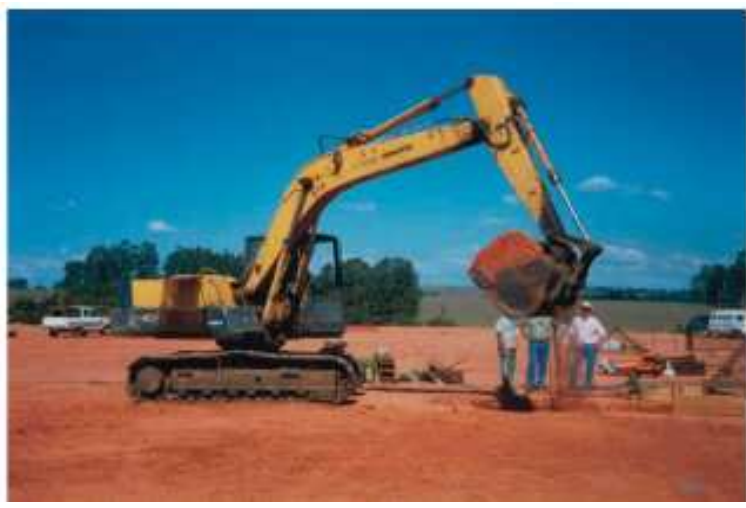

Figura 2.5 - Fase de escavação inicial mecanizada (modificado de Texeira et al. 2006).

Geralmente nesta etapa ocorrem problemas de instabilidade local que podem ser evitados por meio da redução do angulo de inclinação da parede de escavação com a vertical ( 5 a 10) ou com a realização de uma escavação com bermas de equilíbrio.

Tabela 2.1 - Altura das etapas de escavação em função ao tipo de solo. (Gässler, 1990 apud Lima, 2007)

\begin{tabular}{|c|c|c|c|}
\hline Tipo de Solo & \multicolumn{3}{|c|}{ Altura de Escavação (m) } \\
\hline Pedregulho & \multicolumn{2}{|c|}{0,5 (com coesão aparente) } & 1,5 (solo com cimentação) \\
\hline Areia & $\begin{array}{c}1,2 \text { (medianamente } \\
\text { compacta, com coesão } \\
\text { aparente) }\end{array}$ & $\begin{array}{c}1,5 \text { (compacta, com } \\
\text { coesão aparente) }\end{array}$ & $\begin{array}{c}2,0 \text { (com } \\
\text { cimentação) }\end{array}$ \\
\hline Silte & 1,2 & 2,0 (função do teor de umidade) \\
\hline Argila & 1,5 (normalmente consolidada) & 2,5 (sobreadensada) \\
\hline
\end{tabular}

2) A segunda fase consiste na instalação do reforço. No caso dos grampos injetados é realizada a perfuração do maciço de solo (com diâmetros de 70 e $120 \mathrm{~mm}$ geralmente) seguida da inserção da barra de aço e injeção da calda de cimento. Normalmente são consideras varias fases de reinjeção (ver Figura 2.6). Lima (2007) apresenta tipos, características e propriedades mecânicas das barras usualmente utilizadas no Brasil, Europa e América do Norte. A instalação dos grampos por percussão é um processo de execução rápido, no entanto, apresentam a desvantagem de requerer um cuidado especial para evitar a corrosão com recobrimentos de resina ou pintura anticorrosiva. 

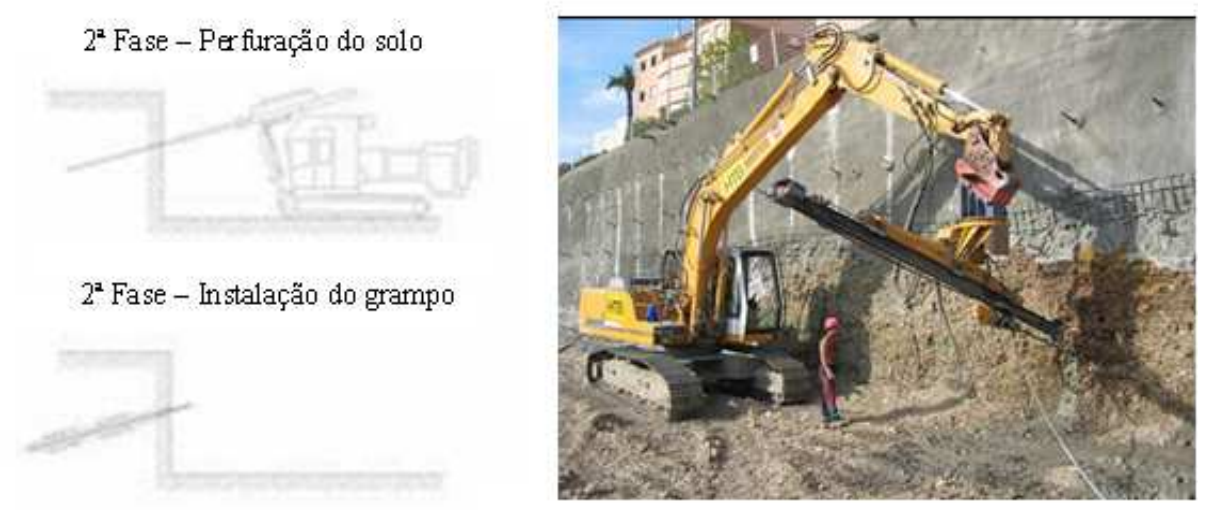

Figura 2.6 - Fase de perfuração do solo e instalação do grampo.

3) $\mathrm{Na}$ terceira fase são selecionados os grampos para os ensaios de arrancamento a serem realizados para conferir os valores da resistência ao arrancamento utilizados no projeto. (ver Figura 2.7a)

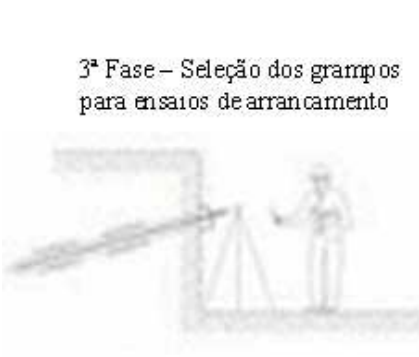

(a)

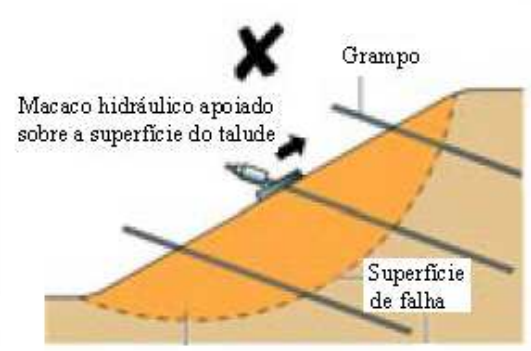

(b)

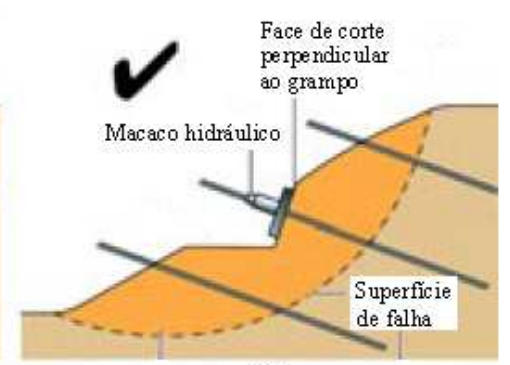

(c)

Figura 2.7 - (a) Seleção dos grampos para ensaios de arrancamento; (b) instalação incorreta; (c) instalação correta do macaco hidráulico para o ensaio de arrancamento.

A Figura 2.7c mostra a correta orientação que deve ter o macaco hidráulico em relação à orientação do grampo durante os ensaios de arrancamento, já que uma orientação errada do macaco hidráulico (ver Figura 2.7b) gera erros na interpretação dos resultados dos ensaios.

A tabela 2.2 apresenta o número de ensaios recomendado por Clouterre (1991) para qualquer tipo de solo em função da área a ser reforçada. Para o caso de inspeções de áreas reforçadas de até $1.000 \mathrm{~m}^{2}$ devem ser realizados cinco ensaios para cada camada de solo e um para cada fase de escavação, para áreas maiores aumenta-se um ensaio cada $200 \mathrm{~m}^{2}$. 
Tabela 2.2 - Número de ensaios de arrancamento em função da área reforçada. (Clouterre, 1991)

\begin{tabular}{|c|c|}
\hline $\begin{array}{c}\text { Área Reforçada } \\
\left(\mathbf{m}^{\mathbf{2}} \mathbf{)}\right.\end{array}$ & $\begin{array}{c}\text { Número de } \\
\text { ensaios }\end{array}$ \\
\hline Até 800 & 6 \\
\hline 800 a 2.000 & 9 \\
\hline 2.000 a 4.000 & 12 \\
\hline 4.000 a 8.000 & 15 \\
\hline 8.000 a 16.000 & 18 \\
\hline 16.000 a 40.000 & 25 \\
\hline
\end{tabular}

4) A quarta fase consiste na colocação da proteção superficial (para evitar problemas de erosão e ou instabilidade local), instalação de sistemas de drenagem superficial e profundo. Para a proteção superficial são utilizadas telas eletrosoldadas (ver Figura 2.8) que servem de armação à parede de concreto projetado. Alternativamente, são utilizados como paramento de proteção os seguintes: concreto projetado com fibras metálicas ou fibras sintéticas de polipropileno, painéis pré-fabricados, malha de arame de aço de alta resistência e revestimento com grama pregada quando o talude apresenta inclinações menores a 45․ (Pitta et al. 2003)

$4^{2}$ Fase - Colocação da tela eletrosoldada

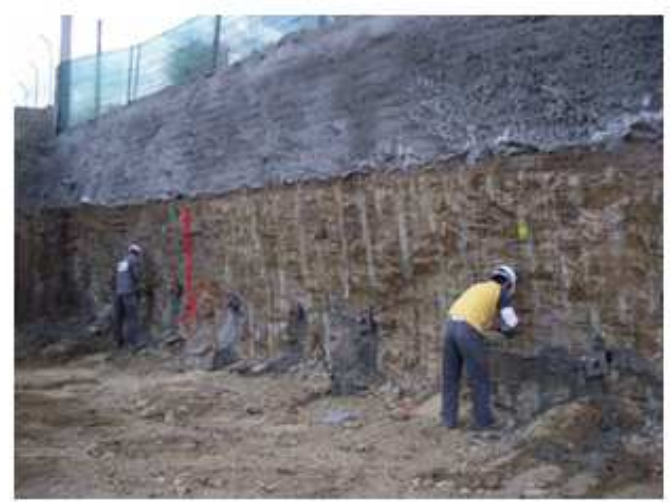

Figura 2.8 - Instalação da tela eletrosoldada.

Na prática usual no Brasil é utilizado um revestimento de concreto projetado (com $10 \mathrm{~cm}$ de espessura) com tela metálica eletrosoldada. A espessura do paramento é função do espaçamento vertical e horizontal entre grampos. Durante o lançamento do concreto pode-se provocar neste uma compactação (ganho de resistência) e um adensamento da capa superficial 
de solo (Lima, 2007). Depois de colocada a proteção superficial procede-se à instalação da placa e porca metálica no extremo livre do grampo. (ver Figura 2.9)
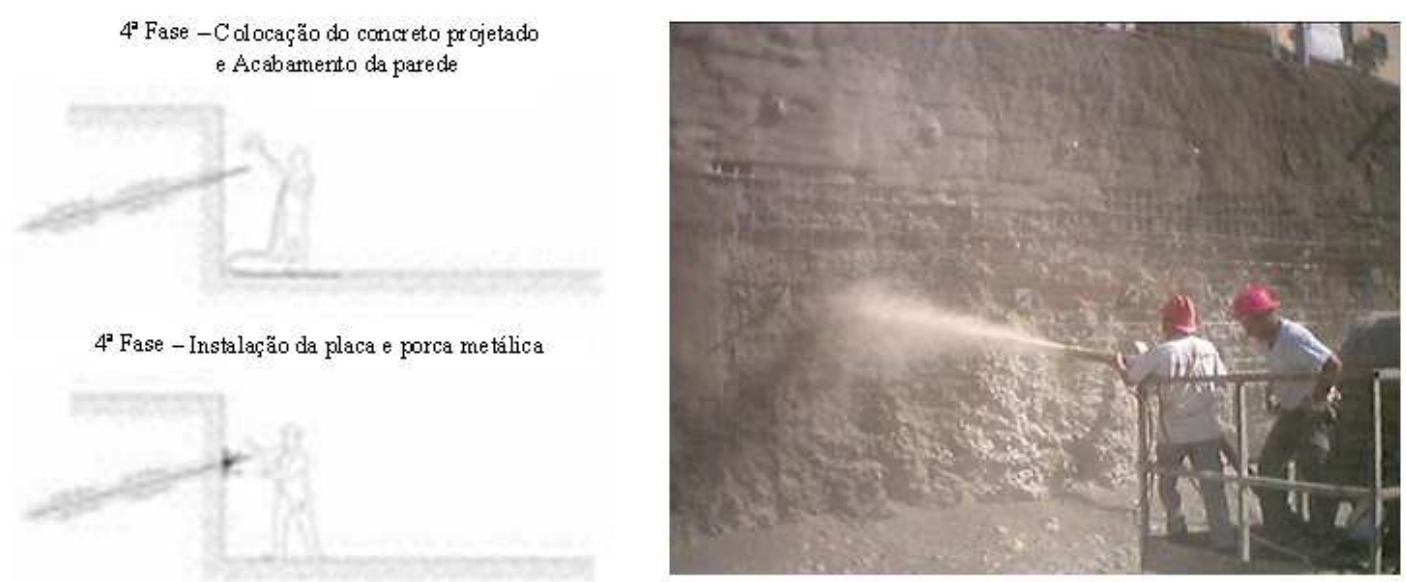

Figura 2.9 - Lançamento do concreto projetado e instalação da placa e porca metálica.

Rogbeck et. al (2004) comenta que com grandes espaçamentos é necessária a colocação de uma face rígida para uma melhor distribuição das forças nos grampos, sendo que o máximo espaçamento horizontal entre grampos é de dois metros.

\subsection{Interação Solo-Grampo}

A interação entre o maciço de solo e grampo é causada principalmente por dois fatores: (1) desenvolvimento de tensões de cisalhamento na superfície do contato solo-grampo que se transformam em tensões de tração no reforço; (2) contribuição da rigidez a flexão e corte dos grampos, que somente é mobilizada na região por onde passa a superfície de deslizamento (Clouterre, 1991). Na maioria das aplicações praticas a bibliografia técnica sugere que a contribuição da resistência por corte e flexão mobilizada no grampo seja desconsiderada (Rogbeck et. al, 2004).

A capacidade do grampo para resistir às tensões de cisalhamento na interface solo-grampo depende principalmente de três fatores: forças de atrito, tensão 
normal e área da superfície de contato. A Figura 2.10 mostra os parâmetros que influênciam a resistência do grampo e as forças de cisalhamento desenvolvidas na interface solo-grampo.

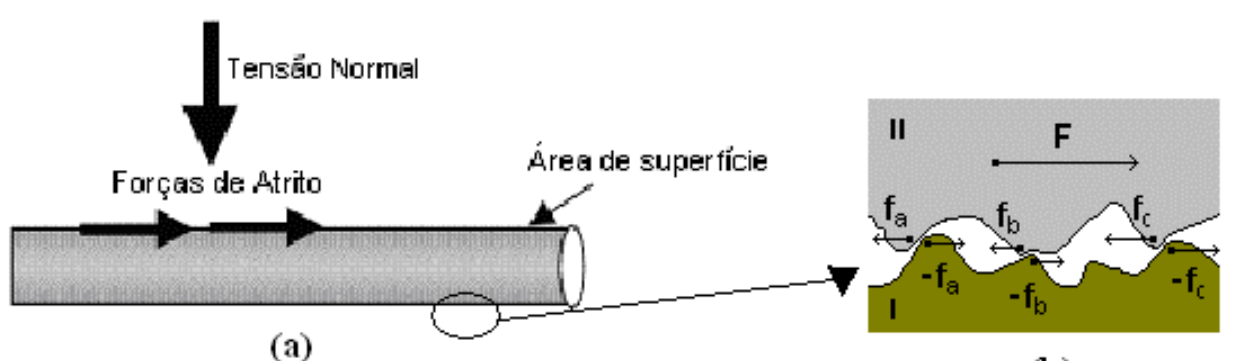

(a)

(b)

Figura 2.10 - (a) Parâmetros que influenciam a resistência da interface; (b) forças que provocam tensões de cisalhamento na interface. (modificado de Rogbeck et al. 2004)

Rogbeck et. al (2004), apresentaram a tabela 2.3 onde são mostrados os fatores que incrementam ou diminuem a resistência por atrito unitário.

Tabela 2.3 - Fatores que aumentam a resistência por atrito unitário. (Rogbeck et al. 2004)

\begin{tabular}{|c|c|c|c|c|c|c|}
\hline \multirow{2}{*}{ a) Parâmetros do solo } & \multicolumn{3}{|c|}{ Cravad os } & \multicolumn{3}{|c|}{ Injetados } \\
\hline & $\sigma_{N}^{\prime}$ & $\tan \delta$ & $\theta$ & $\sigma_{N}^{\prime}$ & $\tan \delta$ & $\theta$ \\
\hline densidade relativa & $\uparrow$ & $\uparrow$ & - & $\uparrow$ & $\uparrow$ & $\downarrow$ \\
\hline ângulo interno de atrito & $\uparrow$ & $\uparrow$ & - & $\uparrow$ & $\uparrow$ & - \\
\hline coesão - conteúdo de argila & - & $\downarrow$ & - & - & $\downarrow$ & $\downarrow$ \\
\hline teor de umidade - pressão neutra & $\downarrow$ & $\downarrow^{2}$ & - & $\downarrow$ & $\downarrow$ & - \\
\hline coeficiente de uniformidade, $C_{U}$ & - & $\uparrow$ & - & - & $\uparrow$ & $\downarrow$ \\
\hline tensão de sobrecarga & $\uparrow \downarrow$ & $\uparrow \downarrow$ & - & $\uparrow \downarrow$ & $\uparrow \downarrow$ & - \\
\hline modulo de deform abilidade & $\uparrow$ & $\uparrow$ & - & $\uparrow$ & $\uparrow$ & $\downarrow$ \\
\hline \multirow{2}{*}{ b) Parâmetros do grampo } & \multicolumn{3}{|c|}{ Cravad os } & \multicolumn{3}{|c|}{ Injetados } \\
\hline & $\sigma_{N}^{\prime}$ & $\tan \delta$ & $\theta$ & $\sigma_{N}^{\prime}$ & $\tan \delta$ & $\theta$ \\
\hline deslocamentos do solo & $\bar{\uparrow}$ & - & $\widehat{\uparrow}$ & $\bar{\uparrow}$ & - & $\uparrow$ \\
\hline superficie rugosa & $\uparrow$ & $\uparrow$ & - & $\uparrow$ & $\uparrow$ & - \\
\hline textura da superficie incluindo al gum a & $\uparrow$ & $\uparrow$ & $\uparrow$ & $\uparrow$ & $\uparrow$ & $\uparrow$ \\
\hline $\begin{array}{l}\text { gregu de expansão } \\
\text { graut }\end{array}$ & $\uparrow$ & - & $\uparrow$ & n. a. & n. a. & n. a. \\
\hline pressão de injeção & n. a. & n. a. & n. a. & $\uparrow$ & - & $\uparrow$ \\
\hline relação água-cimento da calda & n. a. & n. a. & n. a. & - & - & $\uparrow$ \\
\hline porcentagem de sólidos na calda & n. a. & n. a. & n. a. & - & - & $\uparrow$ \\
\hline
\end{tabular}

$\uparrow$ aumenta e $\downarrow$ diminui resistência pơ arrancamento, n. a. não aplicável,- efeito não determinado

2 pouca influência na interface areia-aço (P otyondy, 1961)

$\theta$ é o perím etro do grampo 
Existem diversas correlações empíricas que relacionam o valor da resistência ao arrancamento do grampo $\left(\mathrm{q}_{\mathrm{s}}\right)$ em função do número de golpes obtido pelo ensaio SPT (Standart Penetration Test). Bustamente e Doix (1985) apud Springer (2006) apresentaram correlações empíricas para areias, argilas e siltes (ver Figura 2.11). Acredita-se que valores elevados do $\mathrm{N}_{\text {SPT }}$ correspondem a materiais granulares como pedregulhos com matriz arenosa.

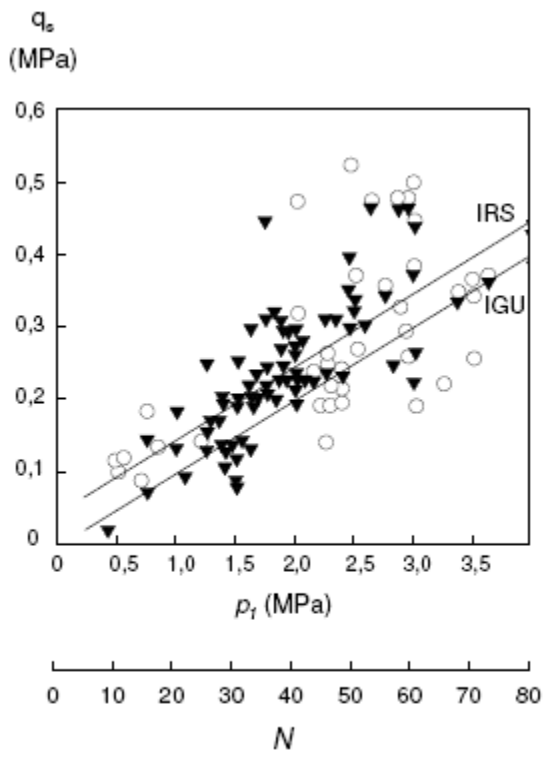

a) Areias

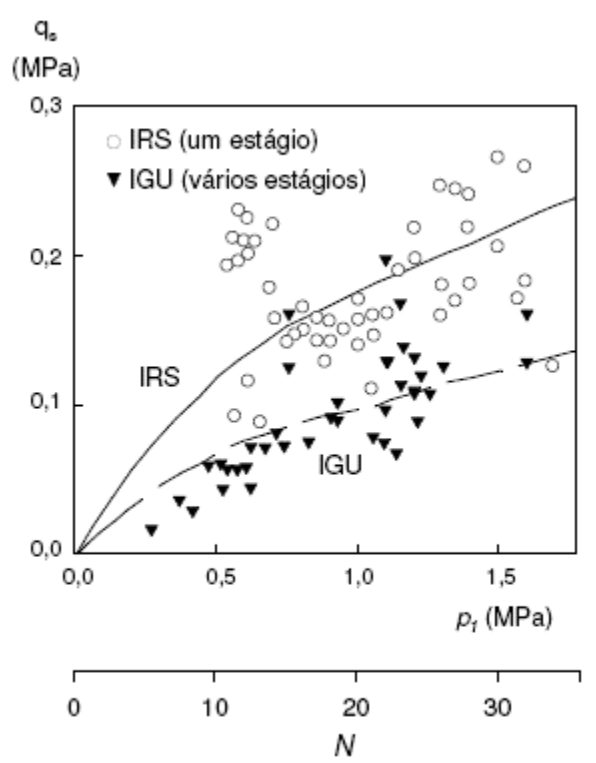

b) Argilas e siltes

Figura 2.11 - Correlação do valor do $q_{s} \operatorname{com} \rho_{l}$ e $N_{S P T}$ para: (a) areias; (b) argilas e siltes. (Bustamente e Doix, 1985 apud Springer, 2006)

Tabela 2.4 - Estimativa preliminar de valores de $\mathrm{q}_{\mathrm{s}}$ (Mitchell et al., 1987 apud Byrne et. al, 1998)

\begin{tabular}{|l|l|c|}
\hline \multicolumn{1}{|c|}{ Método de instalação } & \multicolumn{1}{|c|}{ Tipo de solo } & qs $\left(\mathbf{k N} / \mathbf{m}^{2}\right)$ \\
\hline \multirow{2}{*}{ Perfuração rotativa } & areia siltosa & 30 a 60 \\
& silte & 18 a 24 \\
\hline \multirow{5}{*}{ Escavação com revestimento } & areia & 80 \\
& areia/pedregulho denso & 115 \\
& morrena densa & 115 a 175 \\
& colúvio - areia & 30 a 60 \\
& colúvio - argila & $15-30$ \\
\hline \multirow{2}{*}{ Injeção } & areia & 115 \\
& areia/pedregulho & 290 \\
\hline \multirow{5}{*}{ Cravação } & argila & 6 a 9 \\
& argila rija & 12 a 17 \\
& silte argiloso & 15 a 30 \\
& argila siltosa & 60 a 90 \\
& areia siltosa - aterro & 6 a 9 \\
\hline
\end{tabular}


A tabela 2.4 também apresenta valores de resistência ao arrancamento do grampo propostos por Mitchell et al., (1987) apud Byrne et. al, (1998) que podem ser utilizados na etapa de pré-dimensionamento da estrutura.

Schlosser et al. (1991) apud Clouterre (1991) propõem gráficos para estimar valores de resistência por atrito unitário baseados em 450 ensaios de arrancamento realizados em 87 lugares diferentes no sul da França. Os valores foram classificados segundo o tipo de solo e grampo (ver Figura 2.12).
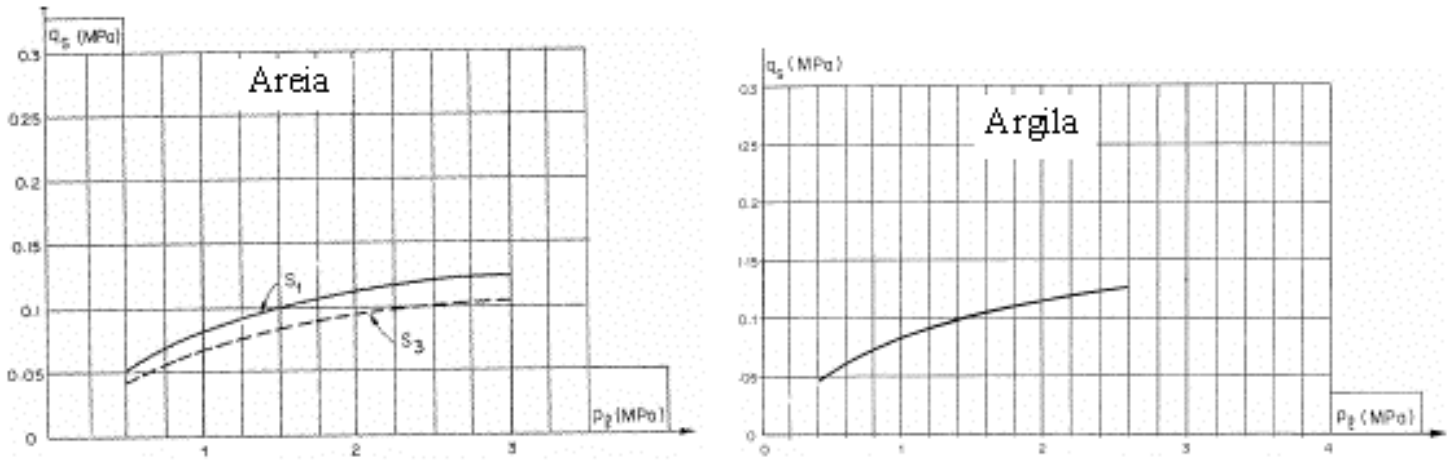

$$
\begin{aligned}
& \text { S1 - Grampos injetados. } \\
& \text { S2 - Grampos cravados. }
\end{aligned}
$$

Figura 2.12 - Curvas para a estimação do valor de $q_{s}$. (Clouterre, 1991)

Resultados de ensaios de arrancamento em grampos com diâmetros entre 75 a $150 \mathrm{~mm}$ com injeção de uma calda de cimento sem pressão, realizados em São Paulo, Rio de Janeiro e Brasília foram analisados por Ortigão et. al (1993); os autores propuseram uma correlação empírica entre o valor do $q_{s}$ e $N_{S P T}$. (ver Figura 2.13)

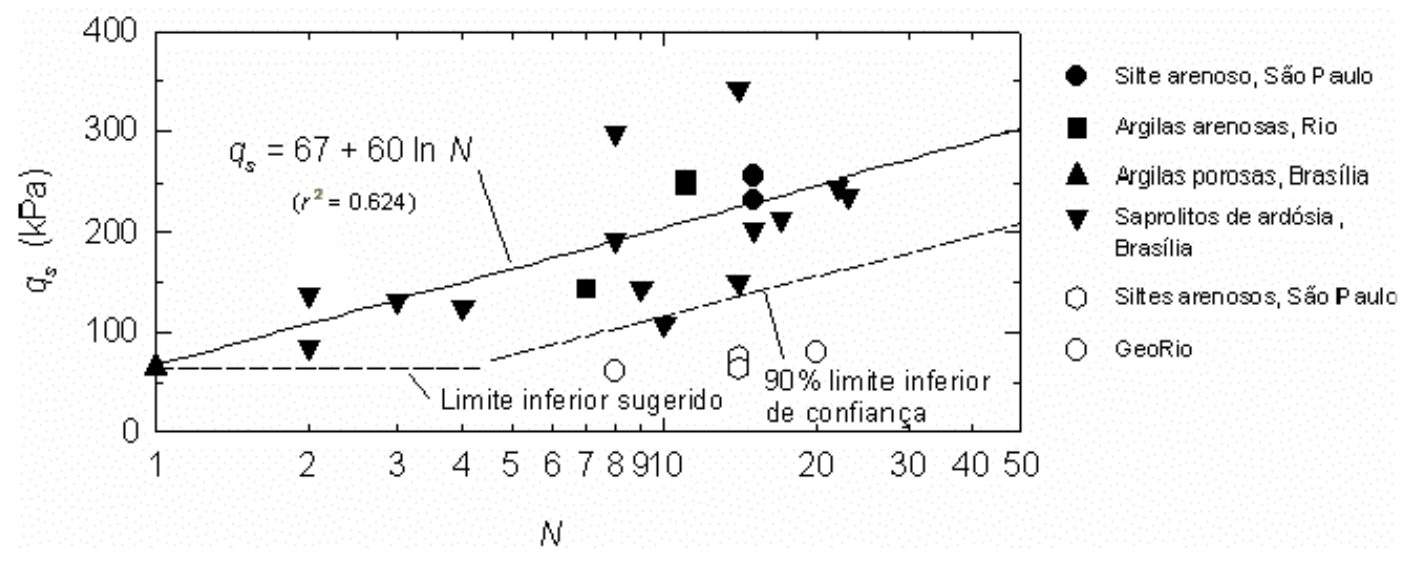

Figura 2.13 - Correlação entre $q_{s}$ e $N_{S P T}$. (Ortigão; Zirilis e Palmeira, 1993) 
Springer (2006) acredita que a dispersão da correlação empírica apresentada por Ortigão et. al (1993) é devida aos diferentes procedimentos em que foram executados os grampos analisados.

Proto da Silva et. al (2006), propõem uma correlação semi-empírica para a estimativa da resistência ao arrancamento dos grampos baseados em resultados de ensaios de cisalhamento na interface solo/nata de cimento e na hipótese de que o deslizamento ocorre no contato solo-grampo. Os autores igualaram as resistências encontradas em ensaios de arrancamento com as dos ensaios de cisalhamento direto na interface solo/nata de cimento realizadas em laboratório, obtendo-se assim um coeficiente de interface $\alpha$ que relaciona os parâmetros de resistência da interface com os da resistência do solo. (Eq. 2.1)

$$
\tau=\alpha .\left(c^{\prime}+\sigma^{\prime}{ }_{n} \cdot \operatorname{tag} \phi^{\prime}\right)
$$

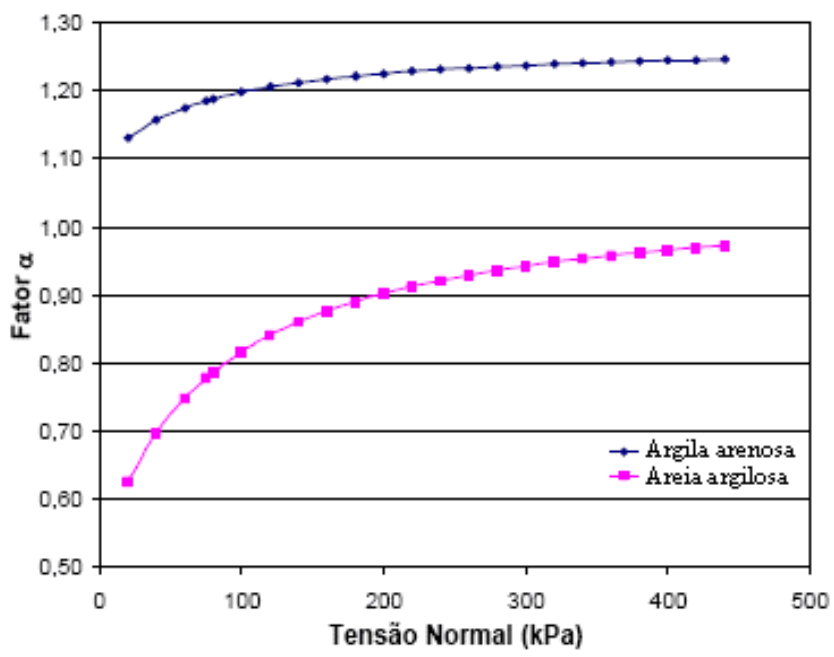

Figura 2.14 - Variação do coeficiente de interface " $\alpha$ " em função da tensão normal. (Proto da Silva et al, 2006)

A Figura 2.14 apresenta valores de $\alpha$ para um solo residual maduro (argila arenosa) e um solo residual jovem (areia argilosa). 
Springer (2006) também apresenta uma correlação de $q_{s}$ em função do $N_{S P T}$, baseado em diversos ensaios de arrancamento realizados em solo residual de gnaisse. A eq. 2.2 apresenta a correlação empírica obtida pela autora.

$$
q_{s}=45,12 \ln \left(N_{S P T}\right)-14,99
$$

A resistência ao cisalhamento no contato solo-grampo é semelhante ao comportamento de estacas, pois são necessários pequenos deslocamentos relativos entre o grampo e o solo (valores da ordem de milímetros) para mobilizar sua resistência; este comportamento foi confirmado nos estudos realizados por Plumelle $(1979,1984)$ apud Clouterre (1991).

Springer (2006) na sua tese de doutorado apresenta procedimentos, recomendações para a realização de ensaios de arrancamento e comportamento de grampos executados em solo residual (maduro e jovem) e rocha alterada de gnaisse. A autora conclui que o arrancamento de grampos re-injetados, executados em solo residual maduro, fornece em media uma resistência 37 \% superior à dos grampos com uma injeção. Na Figura 2.15a é mostrada a montagem do sistema de ensaio de arrancamento.

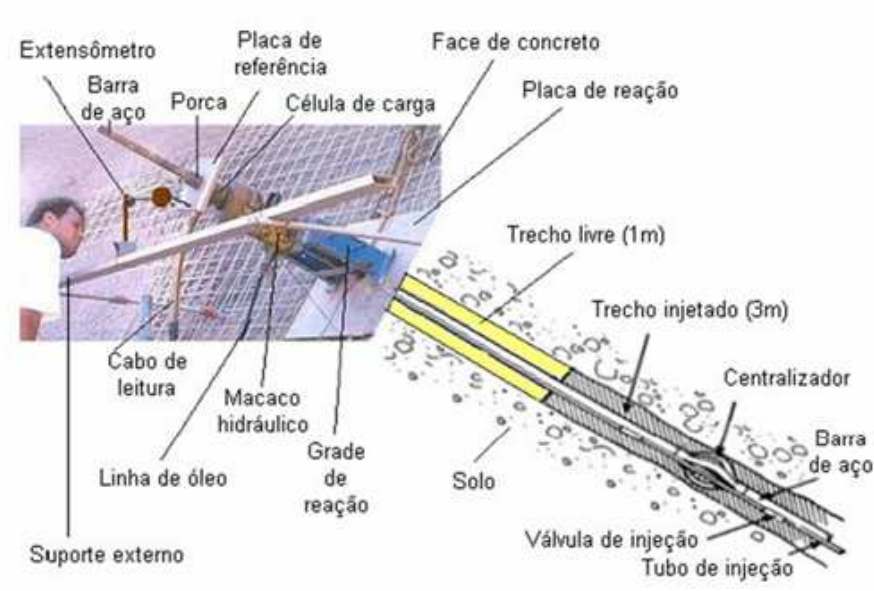

(a)

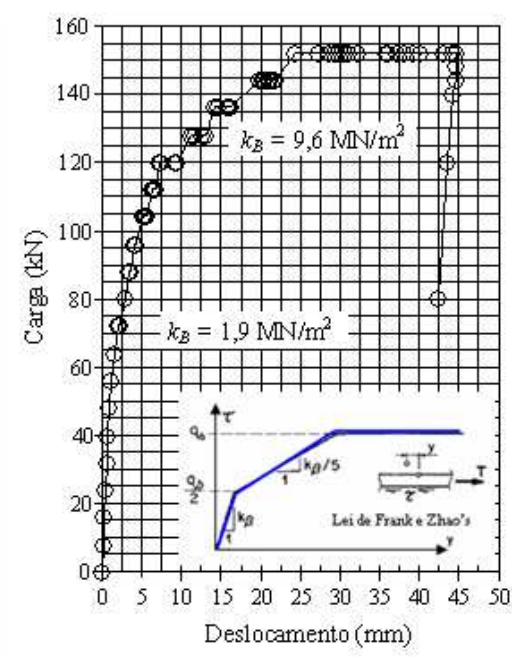

(b)

Figura 2.15 - (a) Montagem do sistema de ensaio de arrancamento; (b) curva cargadeslocamento de um ensaio de arrancamento. (modificado de Springer, 2006) 
A relação bi-linear (ver Figura 2.15b) apresentada por Frank e Zhao (1982) apud Clouterre (1991) é utilizada para interpretar a mobilização da resistência por atrito unitário durante os ensaios de arrancamento analisados por Clouterre (1991). Pode-se observar que a curva carga-deslocamento apresenta quatro retas bem definidas: A primeira até $64 \mathrm{kN}$ correspondente a uma fase de ajuste do sistema, a segunda até $120 \mathrm{kN}$ (limite da resistência por adesão), a terceira até $152 \mathrm{kN}$ (limite da resistência por atrito) e a última em que a carga se mantém em $152 \mathrm{kN}$ (limite de resistência por cisalhamento), porém o grampo continua a deslocar-se com carregamento constante, definindo-se a fase de cisalhamento. A autora menciona que o valor da rigidez do ajuste do sistema não tem significado prático, pois cada ensaio tem seu próprio ajuste.

Springer (2006) também mostrou que grampos submetidos a duas fases de injeção apresentaram rigidezes maiores $\left(k_{b} / 2\right)$ do que os grampos com somente uma fase de injeção $\left(k_{b} / 6\right)$, este último valor é próximo a $k_{b} / 5$ que é o proposto por Frank e Zhao (1982) apud Clouterre (1991).

Lima (2007) apresenta uma tabela resumo de varias correlações empíricas onde são comparados valores de resistência por atrito unitário para um solo com $N_{S P T}$ de dez golpes. Os resultados da aplicação das correlações empíricas mostraram uma grande dispersão devido às diferentes condições em que foram executados os ensaios de arrancamento. Nota-se que a correlação proposta por Ortigão et. al (1997) apud Lima (2007) apresenta um valor bastante elevado. No entanto, com os gráficos propostos por Clouterre (1991) obtém-se valores mais conservadores do que com as outras correlações empíricas.

Tabela 2.5 - Resumo de correlações empíricas (Lima, 2007).

\begin{tabular}{|c|c|c|}
\hline Referência & Correlação & Valor de $\boldsymbol{q}_{\boldsymbol{s}}$ para $\boldsymbol{N}_{\mathbf{S P T}}=\mathbf{1 0}$ \\
\hline Ortigão (1997) & $q_{s}=50+7,5 N_{S P T}$ & $125 \mathrm{kPa}$ \\
\hline Ortigão et. al (1997) & $q_{s}=67+60 \ln N_{S P T}$ & $205 \mathrm{kPa}$ \\
\hline Clouterre (1991) & Figura 2.14 & $50 \mathrm{kPa}$ (argila) \\
& & $80 \mathrm{kPa}$ (areia) \\
\hline Springer (2006) & $q_{s}=45,12 \ln N_{S P T}-14,99$ & $89 \mathrm{kPa}$ \\
\hline
\end{tabular}




\subsection{Mecanismo do Comportamento da Estrutura}

Modelos físicos construídos em escala natural e simulações numéricas permitiram determinar a existência de uma linha de máximas tensões de tração nos grampos (superfície potencial de ruptura) que divide o maciço reforçado em duas zonas (ver Figura 2.16a).

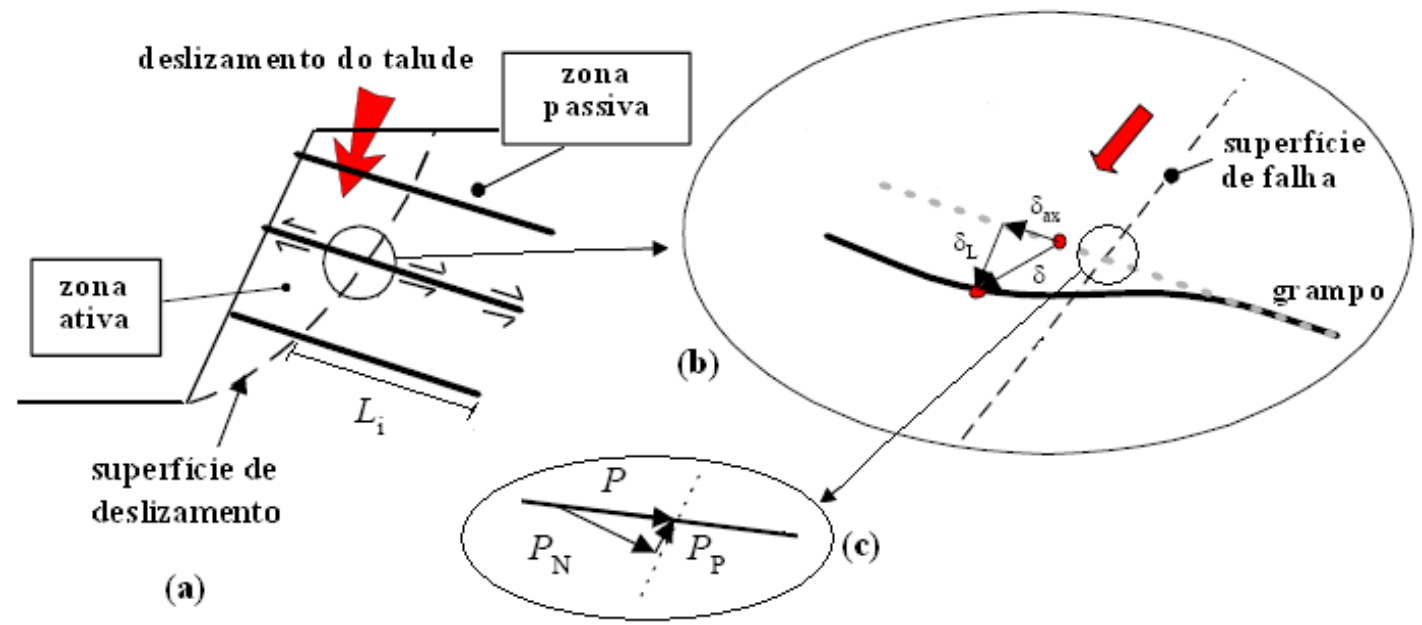

Figura 2.16 - (a) Principio do comportamento do solo grampeado; (b) deformações que o grampo sofre; (c) forças que agem no grampo. (modificado de Rogbeck et al. 2004)

- Zona Ativa, onde as forças de atrito na interface solo-grampo tendem a provocar um arrancamento do reforço, pois estão em direção à face do talude.

- Zona Passiva, onde as forças de atrito resistem ao movimento do reforço, já que sua direção é para o interior do maciço reforçado.

Pequenas deformações na estrutura de solo grampeado provocam o desenvolvimento de forças de atrito na zona passiva e ativa, esforços axiais nos grampos, e deslocamentos verticais e horizontais nos grampos que são os que mobilizam a resistência à flexão e corte. Na Figura 2.16b é mostrada a posição de um grampo deformado e as componentes do deslocamento (axial e perpendicular à posição inicial do grampo). As forças internas que se desenvolvem nos grampos também apresentam duas componentes (perpendicular e paralela à superfície de ruptura). (ver Figura 2.16c) 


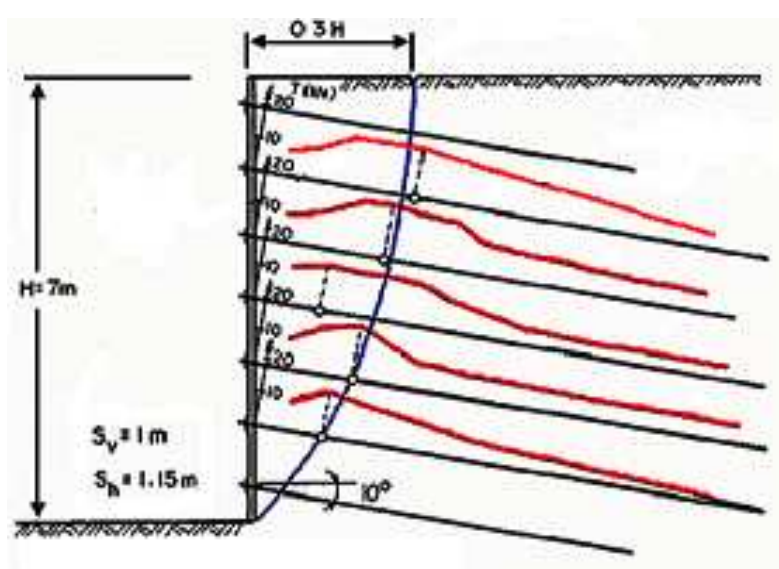

(a)

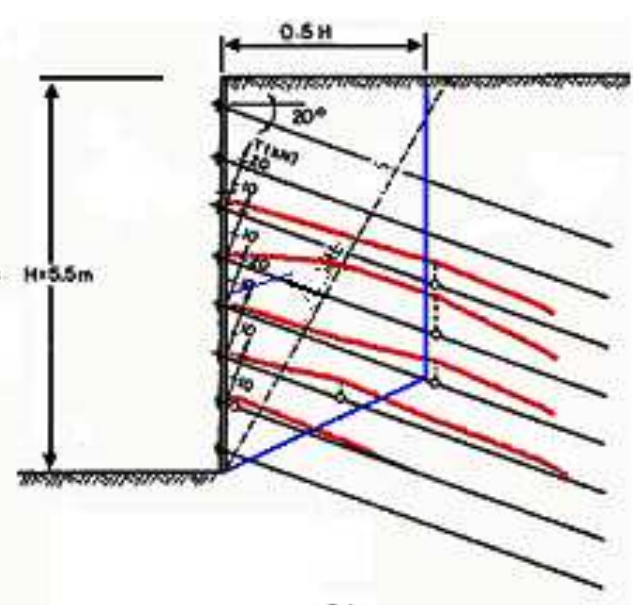

(b)

Figura 2.17 - (a) Talude reforçado com superfície parabólica; (b) superfície de ruptura bi-linear. (Clouterre, 1991)

Clouterre (1991) apresenta as Figura 2.17a e 2.17b onde é mostrado que a superfície potencial de ruptura para taludes verticais não coincide com a linha de ruptura proposta por Coulomb. Pode-se observar também que para o caso de grampos instalados com inclinações entre $10^{\circ}$ e $20^{\circ} \mathrm{com}$ a horizontal, em taludes de areia e areia fina, a superfície potencial de ruptura pode ser do tipo parabólica ou bi-linear, com uma localização de 0,3 a 0,5 vezes a altura do talude, respectivamente.

A forma da superfície de ruptura depende do tipo de solo, ângulo de instalação do grampo, carregamento na estrutura, quantidade de grampos, inclinação do talude e forças de percolação. Segundo Gassler et al. (1983) apud Rogbeck et al. (2004) a superfície de ruptura tende a ser circular no caso dos solos coesivos, e bi-linear nos solos não coesivos.

\subsection{Deslocamentos da Estrutura}

A ocorrência de deslocamentos da face do talude em maciços de solo grampeado é usual durante o processo de escavação como também após a construção; Estes são provocados pela descompressão lateral que sofre o maciço de solo. Os máximos deslocamentos horizontais e verticais ocorrem na 
crista do talude e são geralmente da mesma magnitude.(Clouterre, 1991). (ver Figura 2.18a)

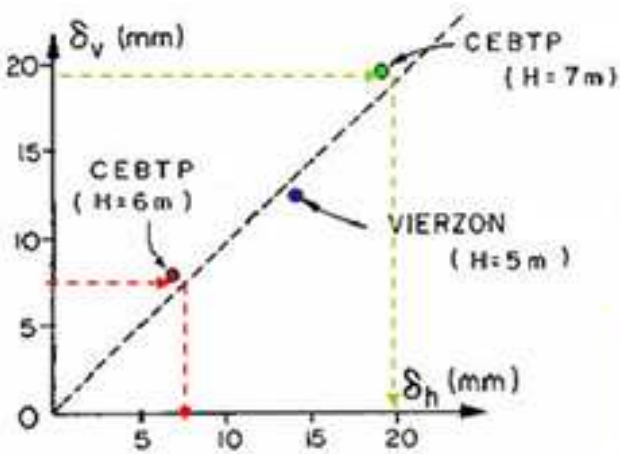

(a)

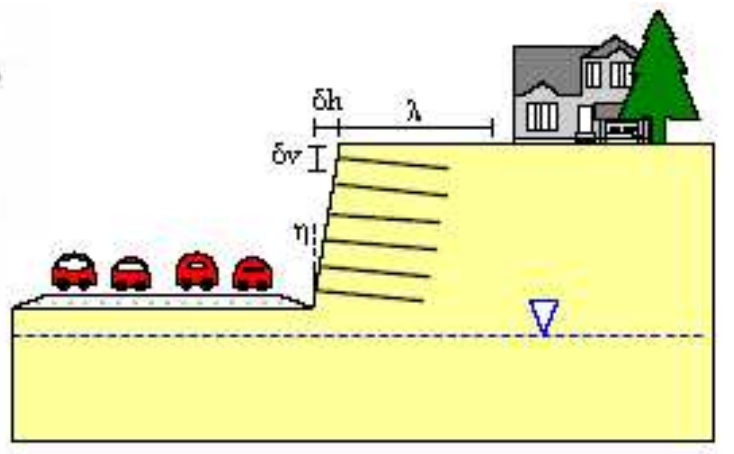

(b)

Figura 2.18 - (a) Variação dos deslocamentos na face de taludes de solo grampeado instrumentados (Clouterre, 1991); (b) Esquema da localização dos máximos deslocamentos. (modificado de Rogbeck et al. 2004)

Tabela 2.6 - Estimação empírica dos deslocamentos (Clouterre, 1991)

\begin{tabular}{|c|c|c|c|}
\hline & Solos Intermediários & Areias & Argilas \\
\hline$\delta_{\mathrm{h}}=\delta_{\mathrm{v}}$ & $\mathrm{H} / 1000$ & $2 \mathrm{H} / 1000$ & $4 \mathrm{H} / 1000$ \\
\hline$\kappa$ & 0,8 & 1,25 & 1,5 \\
\hline
\end{tabular}

Para o cálculo da distancia $\lambda$, Clouterre (1991) apresenta a equação (2.3) baseada em correlações empíricas.

$$
\lambda=H(1-\tan \eta) \kappa
$$

A Figura 2.18b mostra a localização dos máximos deslocamentos horizontais e verticais numa estrutura de solo grampeado, assim como também a distancia ( $\lambda$ ) onde estes são nulos. Clouterre (1991) apresenta correlações empíricas para os valores dos deslocamentos e coeficiente $\kappa$, ambos em função do tipo de solo (ver Tabela 2.6). Onde $H$ é a altura do talude e $\eta$ é a sua inclinação em relação à vertical.

Os deslocamentos da parede de escavação geralmente dependem dos seguintes fatores: altura da escavação, relação $H / L$, espaçamento entre grampos, inclinação dos grampos, e seqüência construtiva. Springer (2006) apresenta valores típicos de máximos deslocamentos horizontais para diversos tipos contenções de solo grampeado registrados na literatura. (ver Tabela 2.7) 
Tabela 2.7 - Deslocamentos horizontais em muros de solo grampeado. (Springer, 2006)

\begin{tabular}{|c|c|c|c|}
\hline Solo & $\begin{array}{c}\text { Tipo de } \\
\text { Grampo }\end{array}$ & $\begin{array}{c}\text { Deslocamentos } \\
\text { Horizontais }\end{array}$ & Referências \\
\hline Areia média & Cravado & $3 \mathrm{H} / 1000$ & Gassler e Gudehus (1981) \\
\hline Areia siltosa & Injetado & $\mathrm{H} / 1000$ & Shen e outros (1981) \\
\hline $\begin{array}{c}\text { Areia fina a areia } \\
\text { Argilosa }\end{array}$ & Cravado & $\mathrm{H} / 1000$ & Cartier e Gigan (1983) \\
\cline { 1 - 2 } $\begin{array}{c}\text { Folhelho alterado } \\
\text { e arenitos }\end{array}$ & Injetado & $0,5 \mathrm{H} / 1000$ & \multirow{2}{*}{ Juran e Elias (1987) } \\
\hline Areia siltosa & Injetado & $0,5 \mathrm{H} / 1000$ & \multirow{2}{*}{ Juran e Elias (1990) } \\
\hline Rochas brandas & $*$ & $\mathrm{H} / 1000$ & \multicolumn{1}{|c}{} \\
\hline Solo Arenoso & $*$ & $2 \mathrm{H} / 1000$ & $4 \mathrm{H} / 1000$ \\
\hline Solo argiloso & $*$ & \multicolumn{2}{|c|}{}
\end{tabular}

\subsection{Mecanismos de ruptura}

Byrne et. al (1998) descrevem vários tipos de potenciais mecanismos de ruptura que podem acontecer numa estrutura de solo grampeado. A Figura 2.19 mostra a ruptura de muro de solo grampeado devido à insuficiente resistência da conexão entre o muro e grampo. Pode-se observar que o deslizamento ocorre na zona ativa do maciço reforçado e que os reforços ficam pendurados na zona passiva.
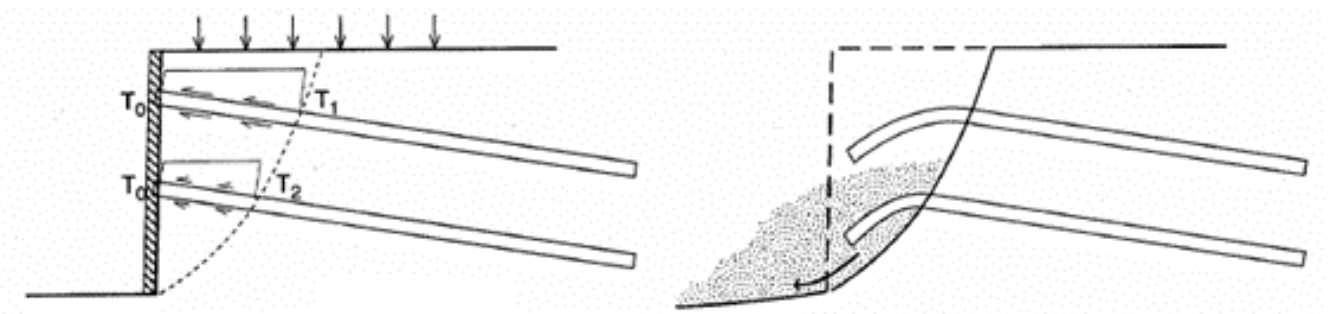

Figura 2.19 - Ruptura na face do talude. (Byrne et. al, 1998) 
Estruturas de solo grampeado com alta resistência no reforço, no entanto, com pouco comprimento de grampo embutido na zona passiva apresentam uma ruptura devido ao arrancamento do grampo. (ver Figura 2.20)

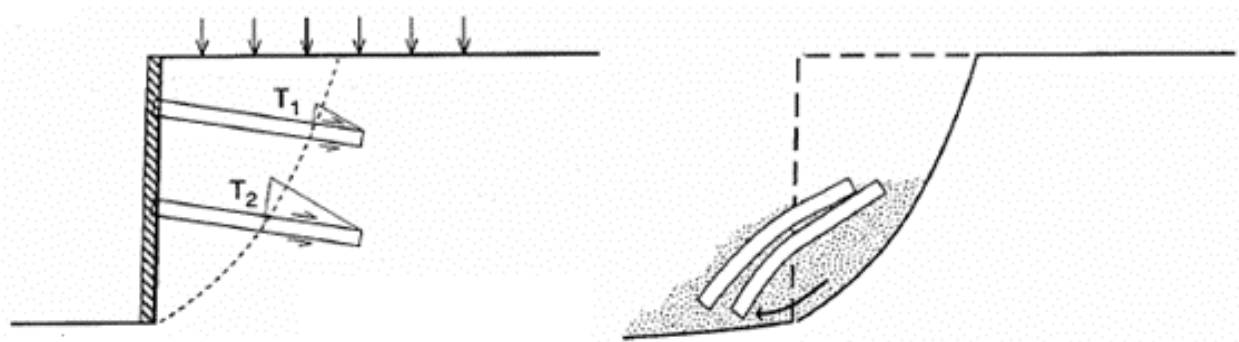

Figura 2.20 - Ruptura por arrancamento do grampo. (Byrne et. al, 1998)

A Figura 2.21 apresenta um tipo de ruptura em que a resistência à tração do reforço foi insuficiente, provocando assim o colapso do talude grampeado.

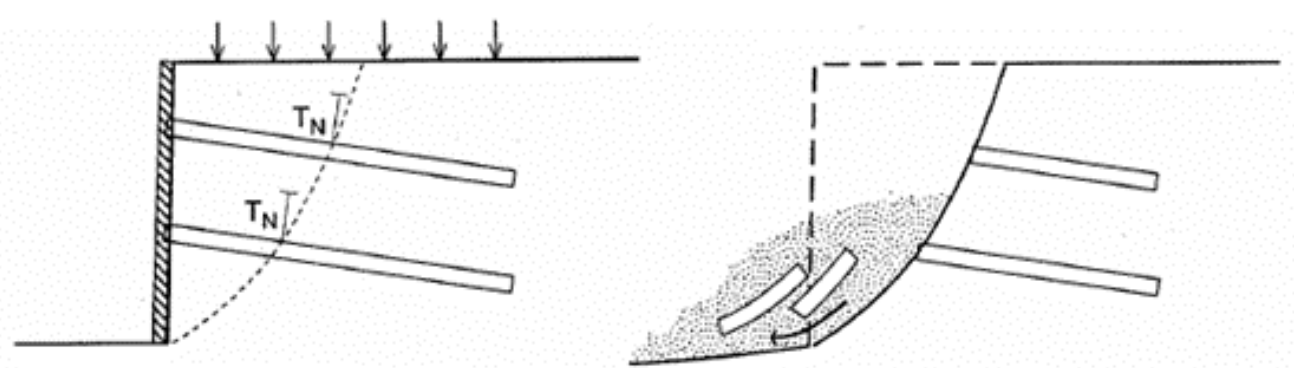

Figura 2.21 - Ruptura por insuficiente resistência a tração do reforço. (Byrne et. al, 1998)

\subsection{Métodos de Equilíbrio Limite}

Existem vários métodos de dimensionamento de taludes de solo grampeado baseados no método de equilíbrio limite (Stocker 1979, Davis 1982, Jewell et al. 1984, Juran et al. 1990, Clouterre 1991, Schlosser 1992, por exemplo). A Figura 2.22 apresenta esquematicamente, o método de cálculo proposto Jeweell (1984) apud Camargo (2005), onde o talude de solo grampeado é dividido em cunhas. A aplicação das equações de equilíbrio da estática permitem encontrar a força requerida nos grampos para garantir a estabilidade da estrutura. 


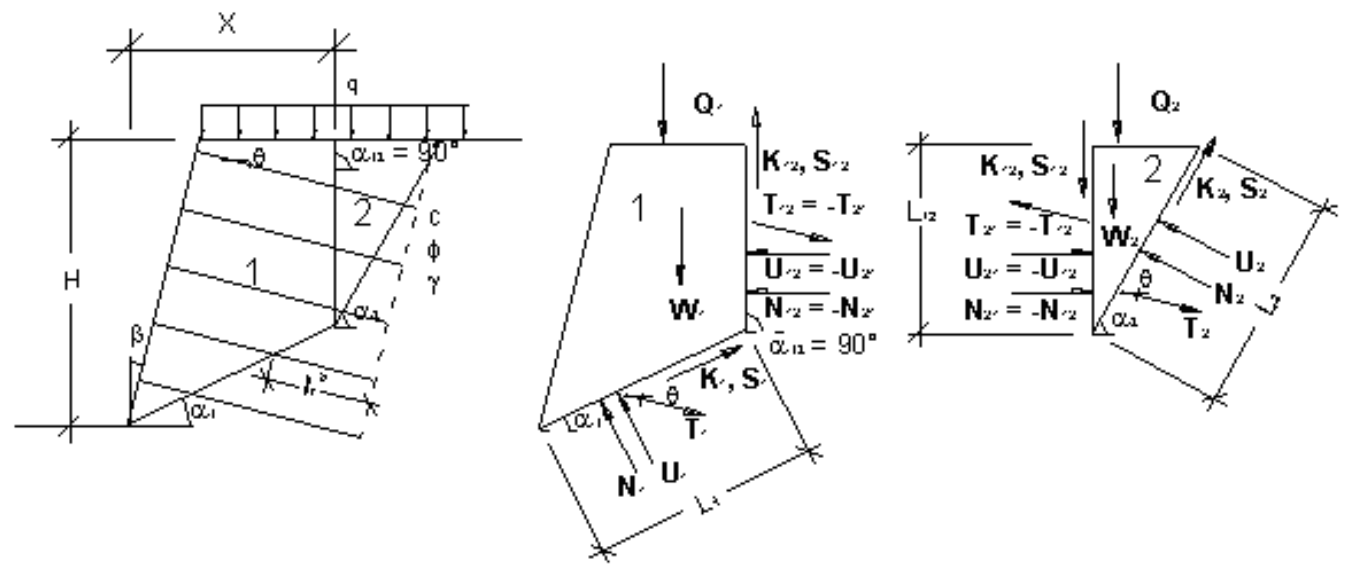

Figura 2.22 - Mecanismo cunha bipartida. (JEWELL, 1984 apud CAMARGO, 2005)

Camargo (2005) apresenta uma comparação dos diversos métodos existentes para o cálculo de estruturas de solo grampeado baseados no equilíbrio limite. A tabela 2.8 apresenta um resumo de diversos métodos de dimensionamento para estruturas de solo grampeado. Segundo este autor, o método Multicritério de Schlosser (1988-1990) é o mais completo.

A estabilidade externa da estrutura de solo grampeado, relacionadas com: deslizamento pela fundação, capacidade de carga do solo de fundação, tombamento e ruptura global deve ser sempre verificada, assim como também uma provável condição de ruptura mista.

É importante ressaltar que todos os métodos de equilíbrio limite só analisam a condição de pré-ruptura sob um comportamento rígido-plástico do material; isto é problemático para os maciços de solo grampeado, que tendem a deformar-se durante e após a construção e que muitas vezes não apresentam uma ruptura física claramente caracterizada. Portanto os métodos de cálculo de estruturas de solo grampeado baseados na teoria de equilíbrio limite apresentam deficiências por não fornecerem informação sobre os deslocamento que ocorrem na estrutura. 
Tabela 2.8 - Características dos métodos de cálculo para estruturas de solo grampeado (adaptado de Abramson et al., 1996 apud Lima, 2006).

\begin{tabular}{|c|c|c|c|c|c|c|c|}
\hline Características & Alemåo & Davis & Multicriténio & Cinemático & Cardiff & Davis Modificado & Escoamento \\
\hline Referência & \begin{tabular}{|c|} 
Stocker et. al (1979) e \\
Gassler e Gudehos (1981)
\end{tabular} & Shen et al. (1981) & Schlosser (1982 e 1983) & Juran et al, (1988 e 1990) & $\begin{array}{c}\text { Bridle (1989), Bridle e } \\
\text { Barr (1990) }\end{array}$ & Elias e Juran (1990) & Anthonie (1990) \\
\hline Análise & $\begin{array}{c}\text { Equilibrio limite (forças) } \\
\text { Estabilidade global }\end{array}$ & \begin{tabular}{|c|} 
Equilibrio limite (forcas) \\
Estabilidade global \\
\end{tabular} & $\begin{array}{c}\text { Equilibrio limite (momentos) } \\
\text { Estabilidade global }\end{array}$ & $\begin{array}{c}\text { Análise de Tensőes internas } \\
\text { Estabilidade local }\end{array}$ & $\begin{array}{l}\text { quilíbrio limite (momentos) } \\
\text { Estabilidade global }\end{array}$ & $\begin{array}{c}\text { Equilibrio limite (forcas) } \\
\text { Estabilidade global }\end{array}$ & \begin{tabular}{|c|} 
Teoria do escoamento \\
Estabilidade global \\
\end{tabular} \\
\hline $\begin{array}{l}\text { Soperficie } \\
\text { de Ruptura }\end{array}$ & Bilinear & Parabólica & \begin{tabular}{|c|} 
Circular ou \\
polinomial \\
\end{tabular} & $\begin{array}{c}\text { Espiral } \\
\text { logaritmica }\end{array}$ & $\begin{array}{c}\text { Espiral } \\
\text { logaritmica }\end{array}$ & Parabólica & \begin{tabular}{|c|} 
Espiral \\
logaritmica \\
\end{tabular} \\
\hline Parâmetros & $c, \phi, q_{s}, \mathrm{e} T_{\max }$ & $c, \phi, q_{s}, \mathrm{e} T_{\max }$ & $c, \phi, q_{s}, T_{\max }$ e $M_{\max }$ & $c, \phi \mathrm{eN}$ & $c, \phi, q_{s}, T_{\max }$ e $M_{\max }$ & $c, \phi, q_{s}, \mathrm{e} T_{\max }$ & \\
\hline $\begin{array}{l}\text { Mecanismo } \\
\text { de Ruptura }\end{array}$ & $\begin{array}{l}\text { Arrancamento dos } \\
\text { grampos }\end{array}$ & Misto & Misto & & Misto & Misto & \\
\hline Nivel freático & Năo & Năo & $\operatorname{Sim}$ & $\operatorname{Sim}$ & Não & Não & \\
\hline $\begin{array}{l}\text { Solo } \\
\text { Estratificado }\end{array}$ & Não & Nẵo & $\operatorname{Sim}$ & $\operatorname{Sim}$ & Não & Näo & Näo \\
\hline $\begin{array}{l}\text { Geometria da } \\
\text { estrutura }\end{array}$ & $\begin{array}{l}\text { Face Vertical } \\
\text { ou inclinada }\end{array}$ & Face Vertical & Qualquer & $\begin{array}{l}\text { Face Vertical } \\
\text { ou inclinada }\end{array}$ & $\begin{array}{l}\text { Face Vertical } \\
\text { ou inclinada }\end{array}$ & $\begin{array}{l}\text { Face Vertical } \\
\text { ou inclinada }\end{array}$ & $\begin{array}{l}\text { Face Vertical } \\
\text { ou inclinada }\end{array}$ \\
\hline
\end{tabular}




\section{Capitulo 3 - MODELAGENS NUMÉRICAS DE ESTRUTURAS DE SOLO GRAMPEADO}

\subsection{Introdução}

A aplicação dos métodos numéricos na previsão do comportamento de escavações é usualmente realizada, pois permite simular cada uma das etapas construtivas. Os métodos numéricos mais empregados para análises tensãodeformação são as diferenças finitas e elementos finitos.

Esta seção apresenta um resumo de alguns dos trabalhos apresentados no meio técnico nacional e internacional que abordam análises numéricas bidimensionais e tridimensionais em estruturas de solo grampeado.

\subsection{Modelagens Bidimensionais}

Segundo Unterreiner et. al (1995) apud Lima (2006), com a hipótese de estado plano de deformação, comumente utilizada em modelagens numéricas bidimensionais de taludes e escavações reforçadas com a técnica de solo grampeado, pode-se obter resultados aceitáveis na previsão das deformações da estrutura.

Dentre os trabalhos apresentados no Brasil ressaltam-se os seguintes:

Estudos paramétricos realizados por Lima (1996) e Ehrlich et al. (1996) apud Lima (2006), demonstram que o aumento da inclinação do grampo com a horizontal provoca uma diminuição da resistência a tensões de tração e um aumento na mobilização da resistência à flexão nos grampos. 
O estudo realizado por Springer (2001) versa sobre uma análise numérica tensão-deformação de uma escavação grampeada efetuada no programa computacional,. FLAC (Fast Langrangian Analysis of Continua) utilizando um modelo elasto-plástico do tipo Mohr-Coulomb para representar o comportamento do solo e um modelo elástico-linear para os grampos e paramento de concreto projetado. A autora mostra que a relação $L / H^{1}$ é inversamente proporcional às deformações horizontais na crista do talude.

Lima et al. (2002) apresentou um estudo sobre a deformabilidade de escavações grampeadas, considerando os seguintes aspectos: resistência no contato solo-grampo definida pela adesão e atrito na interface solo-grampo (o problema tridimensional do contato solo-grampo foi transformado em uma condição bidimensional mediante divisão do módulo de elasticidade do reforço, carga de escoamento e módulo de rigidez para os esforços desenvolvidos na interface solo-grampo entre o espaçamento horizontal entre grampos), e comportamento elásto-plástico do solo. Os resultados mostraram que uma variação da inclinação de $90^{\circ}$ para $80^{\circ}$ no talude escavado, consegue-se uma redução de até $75 \%$ do deslocamento horizontal na crista do talude.

As técnicas de modelagem numérica de escavações de taludes em solo grampeado com os programas computacionais FLAC (método das diferenças finitas) e PLAXIS (método dos elementos finitos), apresentadas por Gerscovich et al. (2005), mostraram várias alternativas para a simulação da interface sologrampo e a influência significativa que apresentam os resultados de deslocamentos horizontais, quando a conexão do grampo com a parede é fixada. Os autores também mencionaram que houve uma concordância razoável nos resultados obtidos com o FLAC e PLAXIS.

Dentre os trabalhos publicados no meio técnico internacional destacam-se os seguintes:

${ }^{1} \mathrm{~L}=$ Comprimento do grampo e $\mathrm{H}=$ Altura da escavação. 
Shen et al. (1981) realizaram comparações entre dados obtidos da instrumentação de uma escavação grampeada e resultados de uma modelagem numérica com elementos finitos que utilizou como lei constitutiva o modelo hiperbólico de Duncan e Chang na representação do comportamento do solo. Os resultados desse trabalho mostraram uma excelente previsão dos deslocamentos horizontais até $2 / 3$ da altura da escavação, no entanto, em maiores profundidades não houve uma boa previsão dos deslocamentos horizontais, pois a rigidez do solo especificada na análise numérica foi menor à existente em campo.

Cheang et al. (2000) estudaram o comportamento de uma escavação grampeada em solo residual e a influência da rigidez à flexão do grampo nos deslocamentos da face de escavação. Nesse trabalho foi demonstrado que são necessários grandes deslocamentos para mobilizar a resistência à flexão do grampo, e que com uma baixa rigidez do paramento de concreto projetado, provoca-se um incremento maior na mobilização da resistência à flexão nos grampos.

O trabalho apresentado por Ann et al. (2004) versa sobre uma retro-análise de um talude grampeado mediante elementos finitos, onde foram utilizados os seguintes modelos constitutivos: elástico-linear e Hardening/Softening Soil (Enrijecimento e amolecimento do solo) para a representação do comportamento do grampo e solo respectivamente. A simulação do contato solo-grampo foi realizada mediante elementos de interface com modelo elástoplástico do tipo Mohr-Coulomb. Resultados desse trabalho não mostraram boa concordância entre as modelagens numéricas e os registros da instrumentação de campo. Os autores concluem que a simulação do grampo com a hipótese de estado plano de deformação não representa adequadamente a transferência de tensões no contato solo-grampo; os mesmos também recomendam a utilização de modelos constitutivos mais complexos para a representação do comportamento da interface solo-grampo. 
Shiu e Chang (2005) apresentaram um estudo sobre o efeito da inclinação dos grampos e disposição dos comprimentos em escavações grampeadas. As modelagens numéricas realizadas pelos autores utilizaram um modelo eslátoplástico e elementos de interface para a representação do comportamento do solo e da interface solo-grampo respectivamente. Na Figura 3.1 pode-se observar os três casos analisados no estudo do efeito da disposição dos comprimentos, onde a somatória do comprimento dos grampos por seção é a mesma para os três casos analisados. Os resultados dos autores demonstraram: (a) O aumento da inclinação do grampo provoca maiores deslocamentos horizontais, pois a capacidade para resistir tensões de tração nos grampos é diminuída; (b) Seções com grampos compridos próximos à crista (caso 3 ) do talude apresentaram menores deslocamentos horizontais, no entanto, escavações com grampos compridos no pé do talude (caso 1) apresentam um fator de segurança maior.

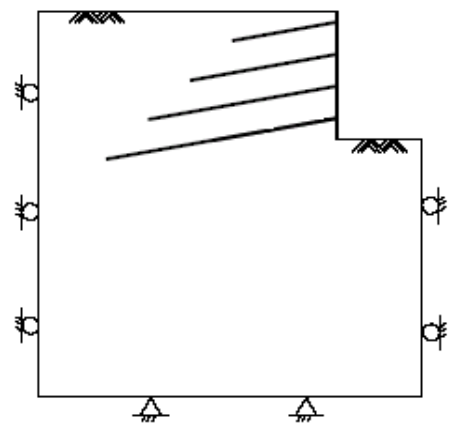

Caso (1)

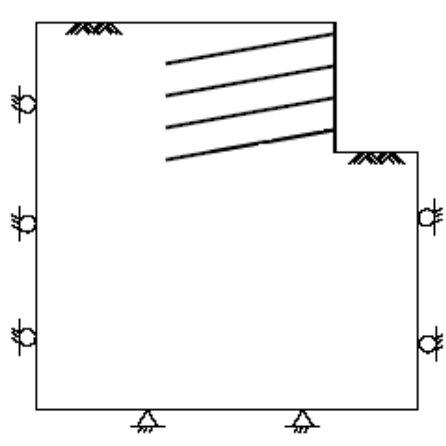

Caso (2)

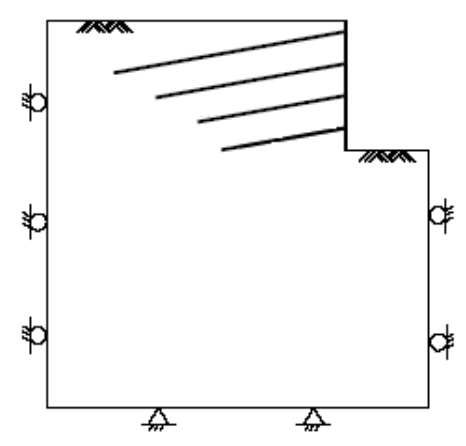

Caso (3)

Figura 3.1 - Disposição do comprimento dos grampos. (Shiu e Chang, 2005)

\subsection{Modelagens Tridimensionais}

A hipótese de estado de deformação plana é geralmente empregada em análises numéricas de taludes reforçados, porém, somente valida quando 0 reforço apresenta uma dimensão considerável na direção perpendicular à seção analisada. Portanto em um talude reforçado com grampos essa hipótese não é realista, pois os grampos apresentam uma semelhança maior com elementos unidimensionais do que bidimensionais. Além disso, modelagens 
bidimensionais não representam adequadamente a transferência de tensões na interface solo-grampo. Considerando o exposto acima, considera-se que é necessária a realização de uma modelagem numérica tridimensional para entender melhor o comportamento de um talude grampeado.

A seguir serão descritos alguns trabalhos nas quais foram realizadas modelagens numéricas tridimensionais de escavações grampeadas.

Possivelmente a primeira modelagem numérica tridimensional seja a apresentada por Cardoso e Carreto (1989), na qual se encontrou uma razoável previsão dos deslocamentos horizontais utilizando uma formulação composta para representar as características de deformabilidade do maciço reforçado (mediante um material equivalente com comportamento elástico-linear e características anisotrópicas) e a variação do módulo de elasticidade com a tensão de confinamento. O comentário apresentado a seguir, realizado por Cardoso e Carreto (1989), versa sobre a importância de considerar-se a variação do módulo de elasticidade segundo o tipo de trajetória de tensão que segue o solo.

"O maciço de solo localizado embaixo do fundo da vala fica fundamentalmente sujeito a uma trajetória de tensão de descarga. Portanto, é conveniente considerar para essa região um módulo de elasticidade maior da ordem de 2,5 vezes superior". (Cardoso e Carreto, 1989, p55, tradução nossa)

Em modelagem numérica tridimensional com elementos finitos apresentada por Ho e Smith (1993) foram realizados estudos sobre o comportamento de uma escavação grampeada e influência do método de construtivo, considerando-se as seguintes condições nas análises: (1) instalação do reforço depois de ter realizada a etapa de escavação, (2) grampo instalado antes de realizada a escavação. O modelo constitutivo aplicado para o solo e a interface sologrampo (representada mediante elementos hexaédricos de catorze nós de pouca espessura) foi um elasto-plástico com o critério de ruptura de Mohr- 
Coulomb. Resultados desse trabalho mostraram as seguintes conclusões: (a) deformações diretamente proporcionais ao valor do $K_{o}$; (b) deformações na segunda condição de análise foram quatro vezes menos do que na primeira (ver Figura 3.2); (c) valor de $K_{o}$ não influência as máximas tensões de tração registradas nos grampos, pois os mesmos são inseridos depois que o maciço de solo entra no estado ativo; (d) a duplicação do espaçamento horizontal entre grampos dobra o valor da máxima tensão de tração nos grampos; (e) existência de uma mobilização maior da resistência à flexão nos grampos localizados próximos ao topo do talude, pois é a região que sofre maiores deformações; (f) a duplicação do espaçamento horizontal entre grampos gera uma mobilização da resistência à flexão seis vezes maior nos grampos.

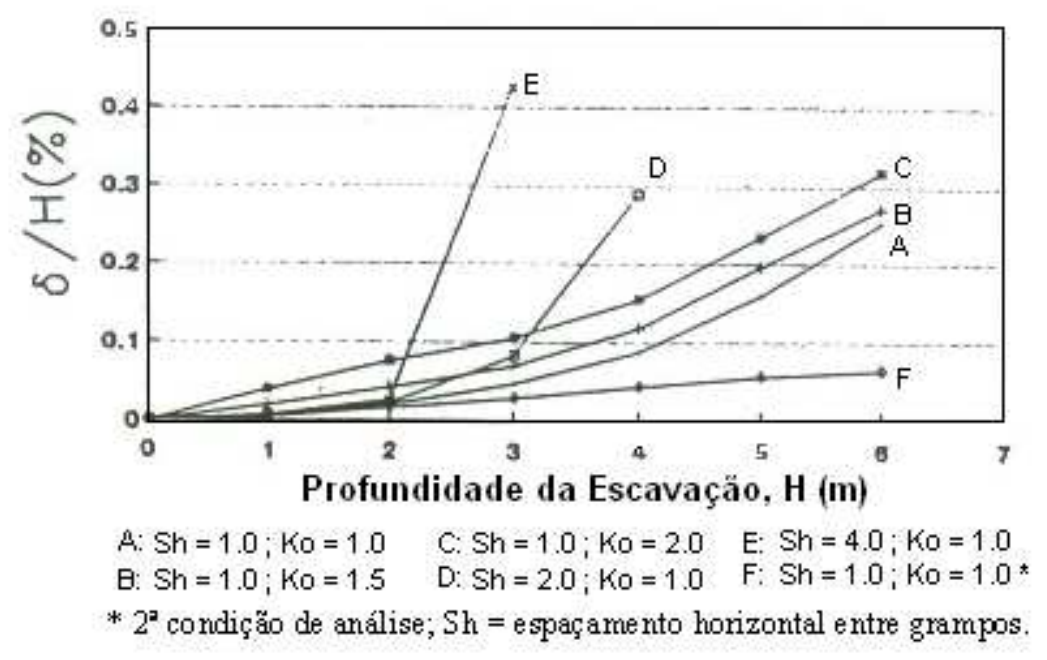

Figura 3.2 - Deformações horizontais da parede escavada em função da profundidade. (Ho e Smith, 1993)

Smith e Su (1997) estudaram o comportamento de uma parede curva de solo grampeado (ver Figura 3.3a) considerando um carregamento situado próximo à crista do talude. A representação do comportamento do solo e da interface solo-grampo foi realizada com a utilização de um modelo elasto-plástico do tipo Mohr-Coulomb. Nos resultados apresentados pelos autores descreve-se o seguinte: (a) maiores deslocamentos horizontais ocorrem a um metro de profundidade; (b) a resistência à flexão e corte nos grampos é somente mobilizada em condições de carregamentos elevados (condição na qual a estrutura encontra-se próxima ao colapso); (c) a existência de uma alta concentração de deformações plásticas nos extremos dos grampos (ver Figura 
3.3b), confirma a existência das zonas passiva e ativa no talude grampeado. A conclusão final do trabalho menciona que a forma e posição da superfície de escorregamento dependem de vários fatores, o mais importante desses é a posição da carga aplicada no topo do talude escavado. As Figuras 3.3(a) e (b) mostram que a condição de contorno na base do modelo encontra-se muito próxima ao fundo da vala, portanto acredita-se que os resultados de Smith e Su (1997) encontram-se influenciados por essa condição de contorno ${ }^{2}$.

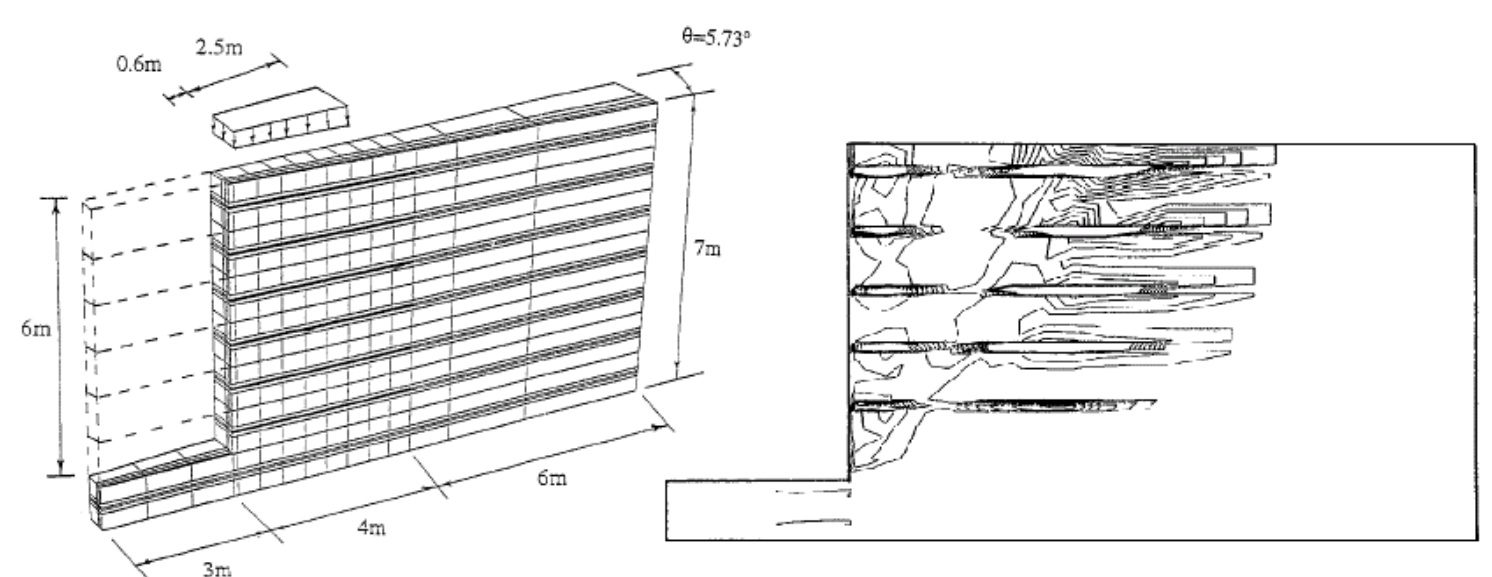

(a)

(b)

Figura 3.3 - (a) Geometria e malha de elementos finitos do modelo; (b) distribuição de deformações plásticas ao redor dos grampos. (Smith e Su 1997)

Briaud e Lim (1997) realizaram uma análise numérica do encontro de uma ponte reforçada com solo grampeado e apoiada sobre estacas. Nesse trabalho foram utilizados elementos tipo viga e placa para representar os grampos e paramento de concreto projetado respectivamente. Também foram utilizados os modelos constitutivos elástico não-linear ${ }^{3}$ (modelo hiperbólico de Duncan e Chang) e elástico linear para o solo e elementos de reforço (grampos e estacas) respectivamente. Os resultados dos deslocamentos horizontais mostraram-se influenciados pelos valores de Ko utilizados, e da rigidez à flexão do paramento de concreto projetado, os autores também notaram que a distribuição do empuxo horizontal do solo na escavação é semelhante à proposta por Terzaghi e Peck (1997).

2 O capitulo IV apresenta um estudo sobre a influência da proximidade das condições de contorno num modelo numérico.

${ }^{3}$ O modelo hiperbólico de Duncan e Chang (1970) é indevidamente chamado de "Modelo Elástico Não Linear", pois este descreve o comportamento de um material elasto-plástico nãolinear. 
No trabalho apresentado por Zhang; Song e Chen (1999) realizou-se uma comparação de resultados encontrados em uma modelagem numérica, com informação registrada por Shen et. al (1981) em um modelo físico de uma escavação grampeada em escala natural. O modelo constitutivo empregado nessa modelagem numérica considerou: um comportamento elástico não-linear no solo, e a interface solo-grampo representada mediante elementos "Doublé Spring"A. Nas conclusões dos autores menciona-se que foi encontrada uma boa concordância nos resultados de deslocamentos horizontais obtidos na modelagem numérica com os registros da instrumentação da escavação grampeada de Shen et. al (1981). Porém, os valores dos recalques na crista do talude obtidos na modelagem numérica foram menores aos registrados na instrumentação; esta diferencia foi atribuída à ocorrência de trincas de tração próximas à crista do talude reforçado com técnica de solo grampeado. Acha-se importante ressaltar que os grampos utilizados na modelagem numérica foram instalados horizontalmente, no entanto, no modelo físico apresentam uma inclinação de 10; isto provavelmente também influenciou os resultados encontrados.

Em trabalho apresentado por Oliveira e Ferreira (2006) compararam-se os fatores de segurança de um talude grampeado, encontrados com os métodos de equilíbrio limite e modelagens numéricas tridimensionais com elementos finitos. Conclusões desse trabalho mostram um valor maior do fator de segurança calculado com o método de equilíbrio limite, pois o fator de segurança calculado em uma modelagem numérica tridimensional considera a contribuição da resistência do solo adjacente ao grampo.

A tabela 3.1 apresenta um resumo das modelagens numéricas descritas acima.

4 Os elementos "Doublé Spring" simulam o comportamento do grampo mediante dois elementos do tipo mola, que consideram uma rigidez axial e tangencial na interface sologrampo. 
Tabela 3.1 - Resumo de modelagens numéricas.

\begin{tabular}{|c|c|c|c|c|c|}
\hline Autor & $\begin{array}{l}\text { Tipo de } \\
\text { Modelo } \\
\end{array}$ & $\begin{array}{l}\text { Método } \\
\text { Numérico }\end{array}$ & $\begin{array}{c}\text { Modelo } \\
\text { Constitutivo } \\
\end{array}$ & $\begin{array}{l}\text { Representação } \\
\text { do Contato }\end{array}$ & Conclusōes Principais \\
\hline Shent et al. (1981) & Bidimensinal & $\begin{array}{c}\text { Elementos } \\
\text { Finitos }\end{array}$ & $\begin{array}{l}\text { Hiperbólico de } \\
\text { Duncan e Chang }\end{array}$ & - & $\begin{array}{l}\text { Valores de deslocamentos horizontais próximos } \\
\text { aos regitrados em campo. }\end{array}$ \\
\hline Unterreiner et al. (1995) & Bidimensinal & $\begin{array}{l}\text { Elementos } \\
\text { Finitos }\end{array}$ & - & - & $\begin{array}{l}\text { Para pequenas deformçỗes é valida a hipotése } \\
\text { de estado plano de deformaçẫo. }\end{array}$ \\
\hline Lima e Erlich (1996) & Bidimensinal & - & - & - & $\begin{array}{l}\text { Aumento da inclinaçẫo provoca maior mobilizaçẫo } \\
\text { da resistência à flexẫo no grampo. }\end{array}$ \\
\hline Springer et al. (2001) & Bidimensinal & $\begin{array}{l}\text { Diferenças } \\
\text { Finitas }\end{array}$ & $\begin{array}{l}\text { Elásto-plástico } \\
\text { Mohr-Coulomb }\end{array}$ & * & $\begin{array}{l}\text { A relação LiH é diretamente proporcional aos } \\
\text { delocamentos da parede escavada. }\end{array}$ \\
\hline Lima et al. (2002) & Bidimensinal & $\begin{array}{l}\text { Diferenças } \\
\text { Finitas }\end{array}$ & $\begin{array}{l}\text { Elásto-plástico } \\
\text { Mohr-Coulomb }\end{array}$ & * & $\begin{array}{l}\text { Reduçẫo de } 75 \% \text { nos delocamentos horizontais } \\
\text { com a diminuiçẫo de } 90 \text { para } 80 \text { da inclinaçẫo do } \\
\text { talude. }\end{array}$ \\
\hline Cheng et al. (2002) & Bidimensinal & $\begin{array}{l}\text { Elementos } \\
\text { Finitos }\end{array}$ & $\begin{array}{l}\text { Elásto-plástico } \\
\text { Mohr-Coulomb }\end{array}$ & * & $\begin{array}{l}\text { Baixa rigidez do paramento gera uma maior mobi- } \\
\text { lizaçẫo da resistência à flexẫo nos grampos. } \\
\text { Somente grandes deformaçốes mobilizam a resis- } \\
\text { tência à flexẫo nos grampos. }\end{array}$ \\
\hline Tan et al. (2004) & Bidimensinal & $\begin{array}{l}\text { Elementos } \\
\text { Finitos }\end{array}$ & Hardening Soil & $\begin{array}{l}\text { Elementos de interface } \\
\text { Interface "Stick-Slip" }\end{array}$ & $\begin{array}{l}\text { O estado palno de deformaçẫo nẫo representa } \\
\text { adequadamento o comportamento do grampo. }\end{array}$ \\
\hline Shiu e Chang (2005) & Bidimensinal & $\begin{array}{l}\text { Elementos } \\
\text { Finitos }\end{array}$ & $\begin{array}{l}\text { Elásto-plástico } \\
\text { Mohr-Coulomb }\end{array}$ & $\begin{array}{l}\text { Elementos de } \\
\text { Interface "Spring-Slider" }\end{array}$ & $\begin{array}{l}\text { Aumento da inclinaçẫo gera maiores deslocamen- } \\
\text { tos horizontais. }\end{array}$ \\
\hline Cardoso e Carreto (1989) & Tridimensional & $\begin{array}{c}\text { Elementos } \\
\text { Finitos }\end{array}$ & $\begin{array}{l}\text { Elástico-linear } \\
\text { Anisotrópico }\end{array}$ & - & $\begin{array}{l}\text { Módulos de deformabilidade para o fundo da vala } \\
\text { sẫo } 2,5 \text { vezessuperiores. }\end{array}$ \\
\hline Ho e Smith (1993) & Tridimensional & $\begin{array}{l}\text { Elementos } \\
\text { Finitos }\end{array}$ & $\begin{array}{l}\text { Elásto-plástico } \\
\text { Mohr-Coulomb }\end{array}$ & $\begin{array}{c}\text { Elementos finitos } \\
\text { Mohr-Coulomb }\end{array}$ & $\begin{array}{l}\text { Instalaçẫo do grampo antes da escavaçẫo reduz } \\
\text { quatro vezes as deformaçỗes obtidas ocorridos. }\end{array}$ \\
\hline Smith e Su (1997) & Tridimensional & $\begin{array}{c}\text { Elementos } \\
\text { Finitos }\end{array}$ & \multirow{3}{*}{$\begin{array}{l}\text { Elásto-plástico } \\
\text { Mohr-Coulomb } \\
\text { Modelo Hiperbólico } \\
\text { de Duncan e Chang } \\
\text { Modelo Hiperbólico } \\
\text { de Duncan e Chang }\end{array}$} & $\begin{array}{l}\text { Elementos finitos } \\
\text { Mohr-Coulomb }\end{array}$ & $\begin{array}{l}\text { Maiores deslocamentos horizontais ocorridos } \\
\text { a um metro de profundidade da crista do talude. }\end{array}$ \\
\hline Briaud e Lim (1997) & Tridimensional & $\begin{array}{c}\text { Elementos } \\
\text { Finitos }\end{array}$ & & - & $\begin{array}{l}\text { Distribuiçẫo da pressẫo lateral encontrada é parecida } \\
\text { à proposta por Terzaghy e Peck. }\end{array}$ \\
\hline Zhang; Song e Chen (1999) & Tridimensional & $\begin{array}{l}\text { Elementos } \\
\text { Finitos }\end{array}$ & & $\begin{array}{l}\text { Elementos de interface } \\
\text { "Stick-Slip" }\end{array}$ & $\begin{array}{l}\text { Modelo contituvo hiperbólico representa bem as } \\
\text { deformaçốes de um escavaçẫo grampeada. }\end{array}$ \\
\hline Oliveira e Ferreira (2006) & Tridimensional & $\begin{array}{l}\text { Elementos } \\
\text { Finitos }\end{array}$ & $\begin{array}{l}\text { Elásto-plástico } \\
\text { Mohr-Coulomb }\end{array}$ & - & $\begin{array}{l}\text { FS em modelagens numéricas tridimensionais sẫo } \\
\text { maiores do que com os métodos de equilibrio limite. }\end{array}$ \\
\hline
\end{tabular}

rmaçẫo nẫo encontrada.

* Simulaçẫo do grampo como tira metálica. 


\section{Capitulo 4 - ANÁLISES EFETUADAS UTILIZANDO MODELOS NUMÉRICOS BASEADOS NA TEORIA DA ELASTICIDADE}

\subsection{Introdução}

A teoria da elasticidade tem sido utilizada em vários problemas da engenharia prática, muito embora o comportamento real dos solos diste bastante do comportamento elástico, principalmente no que diz respeito à reversibilidade das deformações quando as solicitações mudam de sentido. Neste capitulo serão revisados alguns aspetos básicos da teoria da elasticidade, limitações desta, problemas que surgem da aplicação da teoria da elasticidade nas modelagens numéricas, análise da influência de alguns fatores nos resultados das modelagens numéricas, e trajetórias de tensões no maciço ao redor de escavações a céu aberto.

\subsection{Teoria da Elasticidade Linear}

A determinação dos campos de tensões, deformações e deslocamentos em sólidos deformáveis é realizada com a aplicação da teoria da elasticidade, mediante a utilização das principais relações e hipóteses oferecidas pela teoria, que podem ser expressas pelas equações de equilíbrio, compatibilidade e constitutivas. $\mathrm{Na}$ figura 4.1 ilustra-se um sólido deformável submetido a forças de volume em $f_{v}$, a forças de superfície em $\mathrm{f}_{\mathrm{s}}$, e deslocamentos prescritos $\mathrm{S}_{u}$ 


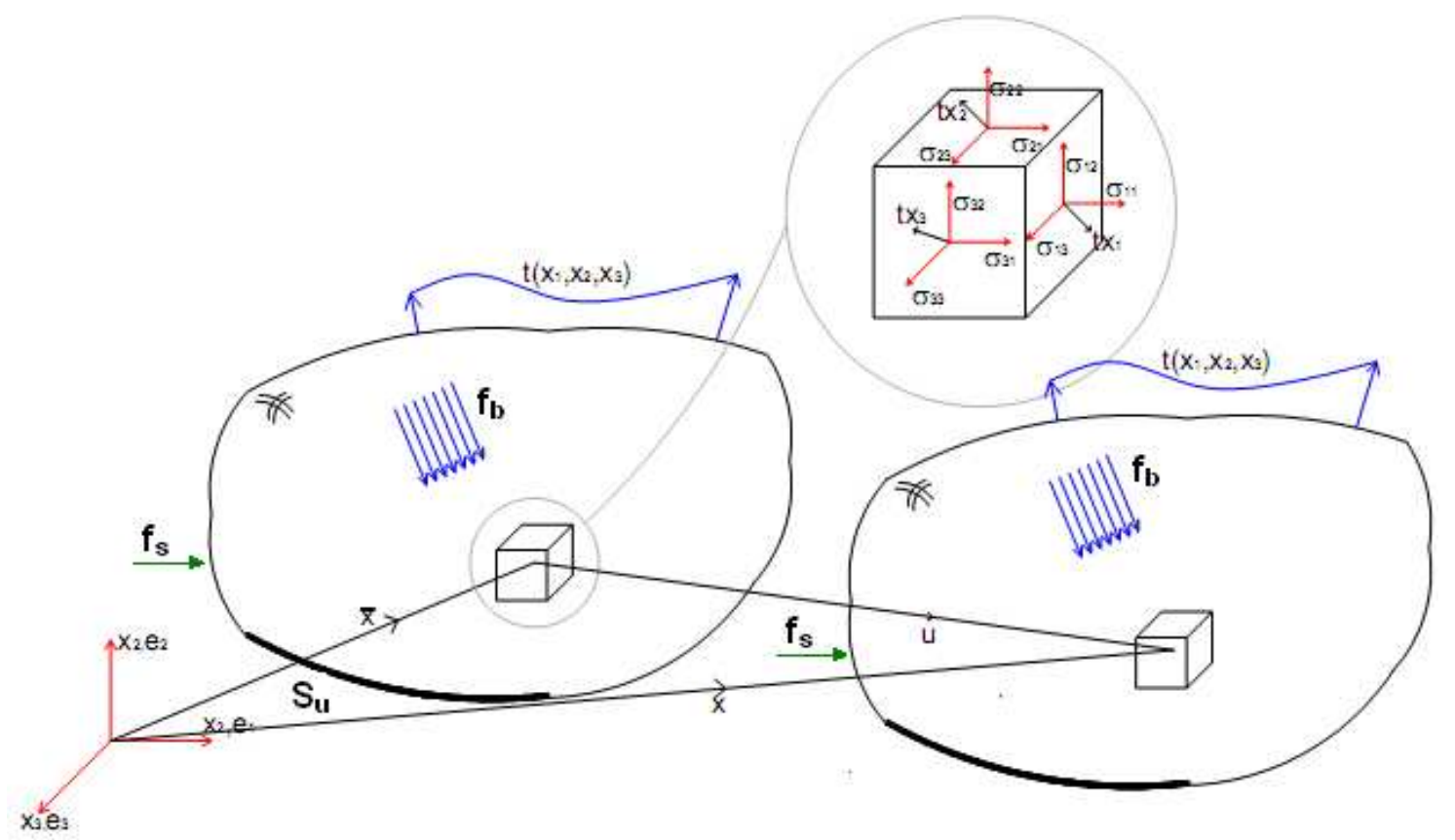

Figura 4.1 - Sólido deformável submetido a forças de volume, forças de superfície e deslocamentos prescritos.

Denomina-se o Tensor das Tensões de Cauchy a grandeza expressa por:

$$
[T]=\left[\begin{array}{lll}
\sigma_{11} & \tau_{12} & \tau_{13} \\
\tau_{21} & \sigma_{22} & \tau_{23} \\
\tau_{31} & \tau_{32} & \sigma_{33}
\end{array}\right] \quad \text { ou } \quad[T]=\left[\begin{array}{ccc}
\sigma_{x} & \tau_{x y} & \tau_{z x} \\
\tau_{x y} & \sigma_{y} & \tau_{y z} \\
\tau_{z x} & \tau_{y z} & \sigma_{z}
\end{array}\right]
$$

Onde $\sigma_{\mathrm{ij}}=\sigma_{\mathrm{ji}}$, os índices referem-se a uma base ortonormal $e=\left(e_{1}, e_{2}, e_{3}\right)$.

Considerando-se os incrementos infinitesimais nas componentes de tensão entre duas faces opostas de um paralelepípedo infinitesimal, a equação de equilíbrio pode ser expressa por:

$$
\sigma_{i j, j}+b_{i}=0
$$

Conhecidas cada uma das componentes de $\sigma_{\mathrm{ij}}$ em um ponto qualquer e aplicando equilíbrio dos momentos em um tetraedro infinitesimal, obtém-se a relação entre as componentes do vetor das forças superficiais $t$, definido por $t=t_{1} e_{1}+t_{2} e_{2}+t_{3} e_{3}$ 
e as componentes $\sigma_{\mathrm{ijj}}$. Esta relação é conhecida como fórmula de Cauchy e é dada por:

$$
t_{i}=\sigma_{i j} n_{j}
$$

A magnitude das componentes de $\sigma_{\mathrm{ij}}$ depende da direção escolhida para as coordenadas dos eixos de referência. Em função disso, ao invés de tensões referidas a um eixo específico de coordenadas cartesianas, é comum utilizar tensões principais $\left(\sigma_{1}, \sigma_{2}\right.$ e $\left.\sigma_{3}\right)$ referidas aos eixos das direções das tensões principais. As direções dos eixos principais são as direções onde não ocorre nenhuma tensão de cisalhamento. As tensões principais são auto-valores do tensor das tensões e podem ser determinadas da seguinte forma:

$$
\operatorname{det}(\sigma-\sigma . I)=0
$$

Onde $I$ é a matriz identidade. A equação fornece três soluções, que são justamente as tensões principais $\sigma_{1}, \sigma_{2}$, e $\sigma_{3}$, sendo:

$$
\sigma_{1} \geq \sigma_{2} \geq \sigma_{3}
$$

Para um determinado elemento submetido a um estado de tensões, as tensões principais atuam nos planos principais e possuem magnitudes independentes do sistema de coordenadas escolhido para descrição do problema. Elas são, portanto, "Invariantes" à escolha do sistema de coordenadas dos eixos. Onde: $I_{1}, I_{2}$ e $I_{3}$ são chamadas de "Invariantes de Tensão", as quais podem ser expressas em função das tensões principais ou das tensões orientadas segundo o sistema cartesiano de coordenadas.

$$
\begin{aligned}
& I_{1}=\sigma_{1}+\sigma_{2}+\sigma_{3}=\sigma_{x}+\sigma_{y}+\sigma_{z} \\
& I_{2}=\sigma_{1} \sigma_{2}+\sigma_{2} \sigma_{3}+\sigma_{3} \sigma_{1}=\sigma_{x} \sigma_{y}+\sigma_{y} \sigma_{z}+\sigma_{z} \sigma_{x}-\tau_{x y}{ }^{2}-\tau_{y z}{ }^{2}-\tau_{z x}{ }^{2} \\
& I_{3}=\sigma_{1} \sigma_{2} \sigma_{3}=\sigma_{x} \sigma_{y} \sigma_{z}-\sigma_{x} \tau_{y z}{ }^{2}-\sigma_{y} \tau_{z x}{ }^{2}-\sigma_{z} \tau_{x y}{ }^{2}-2 \tau_{x y} \tau_{y z} \tau_{z x}
\end{aligned}
$$


A média das tensões normais é chamada de Tensão Octaédrica, e é função da primeira invariante de tensão.

$$
\sigma_{o c t}=\frac{I_{1}}{3}
$$

O Tensor de Tensões Desviadoras está definido como segue:

$$
[S]=\left[\begin{array}{ccc}
\sigma_{x}-\sigma_{o c t} & \tau_{x y} & \tau_{x z} \\
\tau_{x y} & \sigma_{y}-\sigma_{o c t} & \tau_{y z} \\
\tau_{x z} & \tau_{y z} & \sigma_{z}-\sigma_{o c t}
\end{array}\right]
$$

E Também se pode expressar mediante as Invariantes de Tensões Desviadoras $\left(J_{1}\right.$, $\left.J_{2} \mathrm{e} J_{3}\right)$.

$$
\begin{aligned}
& J_{1}=\left(\sigma_{1}-\sigma_{o c t}\right)+\left(\sigma_{2}-\sigma_{o c t}\right)+\left(\sigma_{3}-\sigma_{o c t}\right) \\
& J_{2}=-\frac{1}{6}\left[\left(\sigma_{1}-\sigma_{2}\right)^{2}+\left(\sigma_{2}-\sigma_{3}\right)^{2}+\left(\sigma_{3}-\sigma_{1}\right)^{2}\right] \\
& J_{3}=\frac{1}{27}\left(2 \sigma_{1}-\sigma_{2}-\sigma_{3}\right)\left(2 \sigma_{2}-\sigma_{1}-\sigma_{3}\right)\left(2 \sigma_{3}-\sigma_{1}-\sigma_{2}\right)
\end{aligned}
$$

Por sua vez, as equações de compatibilidade resultam de hipóteses sobre a alteração da geometria de um modelo deformável. Uma das grandezas fundamentais neste estudo é o vetor deslocamento $u$, para um ponto genérico $x$, dado por:

$$
u=u_{1} e_{1}+u_{2} e_{2}+u_{3} e_{3}
$$

Considerando a hipótese de pequenos deslocamentos e analisando a geometria de um elemento infinitesimal antes e depois da deformação, tem-se: 


$$
\varepsilon_{i j}=\frac{1}{2}\left(u_{i, j}+u_{j, i}\right)
$$

Onde $\varepsilon_{i j}=\varepsilon_{j i}$; do mesmo modo como a tensão em ponto $x$ foi representada mediante tensor das tensões, a deformação também pode ser expressa por um Tensor de Deformações.

$$
[D]=\left[\begin{array}{lll}
\varepsilon_{11} & \varepsilon_{12} & \varepsilon_{13} \\
\varepsilon_{21} & \varepsilon_{22} & \varepsilon_{23} \\
\varepsilon_{31} & \varepsilon_{32} & \varepsilon_{33}
\end{array}\right] \quad \text { ou } \quad[D]=\left[\begin{array}{ccc}
\varepsilon_{x} & \gamma_{x y} & \gamma_{x z} \\
\gamma_{x y} & \varepsilon_{y} & \gamma_{y z} \\
\gamma_{x z} & \gamma_{y z} & \varepsilon_{z}
\end{array}\right]
$$

Agora, considera-se o parâmetro do material por meio das equações constitutivas. Estas equações relacionam tensões com deformações, tendo como base observações experimentais. Para materiais elásticos lineares, estas equações são expressas por:

$$
\begin{array}{lll}
\varepsilon_{x}=\frac{1}{E}\left(\sigma_{x}-v \sigma_{y}-v \sigma_{z}\right) & (4.17) & \gamma_{x y}=\frac{\tau_{x y}}{2 G} \\
\varepsilon_{y}=\frac{1}{E}\left(v \sigma_{x}-\sigma_{y}-v \sigma_{z}\right) & (4.18) & \gamma_{y z}=\frac{\tau_{y z}}{2 G} \\
\varepsilon_{z}=\frac{1}{E}\left(v \sigma_{x}-v \sigma_{y}-\sigma_{z}\right) & (4.19) & \gamma_{z x}=\frac{\tau_{z x}}{2 G}
\end{array}
$$

As componentes $\varepsilon_{x}, \varepsilon_{y}$ e $\varepsilon_{z}$ representam as deformações provocadas por tensões normais, e $\gamma_{x y}, \gamma_{y z}$ e $\gamma_{z x}$ as deformações por tensão cisalhante.

Pequenas deformações volumétricas num elemento de volume $V$, são definidas como segue:

$$
\varepsilon_{V}=\frac{\Delta V}{V}=\varepsilon_{x}+\varepsilon_{y}+\varepsilon_{z}
$$

Quando expressadas em forma matricial, obtém-se a matriz [C], que relaciona os incrementos de tensões totais com os incrementos de deformações. 


$$
\begin{gathered}
\Delta \sigma=[C] \Delta \varepsilon \\
\left\{\begin{array}{c}
\Delta \sigma_{X} \\
\Delta \sigma_{Y} \\
\Delta \sigma_{Z} \\
\Delta \tau_{X Y} \\
\Delta \tau_{Y Z} \\
\Delta \tau_{Z X}
\end{array}\right\}=\frac{E}{(1+v)(1-2 v)}\left[\begin{array}{cccccc}
1-v & v & v & 0 & 0 & 0 \\
v & 1-v & v & 0 & 0 & 0 \\
v & v & 1-v & 0 & 0 & 0 \\
0 & 0 & 0 & 1-2 v & 0 & 0 \\
0 & 0 & 0 & 0 & 1-2 v & 0 \\
0 & 0 & 0 & 0 & 0 & 1-2 v
\end{array}\right]\left\{\begin{array}{c}
\Delta \varepsilon_{X} \\
\Delta \varepsilon_{Y} \\
\Delta \varepsilon_{Z} \\
\Delta \gamma_{X Y} \\
\Delta \gamma_{Y Z} \\
\Delta \gamma_{Z X}
\end{array}\right\}
\end{gathered}
$$

É conhecido que o comportamento do solo pode ser razoavelmente representado aplicando a teoria da elasticidade para baixos níveis de deformação, onde o estado de tensão no solo não chega a atingir nenhum tipo de condição de ruptura.

No Apêndice A demonstrou-se que em um modelo tridimensional de uma escavação, a tensão perpendicular à fatia analisada apresenta uma diminuição, registrando-se uma tendência de contração. Nesse estudo também se apresentam os tensores de tensão para três elementos situados ao redor da escavação, nas etapas inicial ${ }^{5}$ e final da escavação.

\subsection{Limitações da Teoria de Elasticidade}

Quando é utilizada a teoria da elasticidade se deve ter presente que esta apresenta algumas limitações como: comportamento reversível das deformações, ausência de mudanças de volume devido a tensões de cisalhamento, e variação da rigidez do maciço de solo devido ao tipo de trajetória de tensão.

Lade (2005) explica de maneira simples algumas das limitações da teoria da elasticidade para representar o comportamento do solo.

\footnotetext{
${ }^{5}$ Naquele estudo considerou-se como etapa inicial uma situação,na qual não foi iniciado o processo de escavação.
} 


$$
\left\{\begin{array}{c}
\Delta \varepsilon_{X} \\
\Delta \varepsilon_{Y} \\
\Delta \varepsilon_{Z} \\
\Delta \gamma_{X Y} \\
\Delta \gamma_{Y Z} \\
\Delta \gamma_{Z X}
\end{array}\right\}=\left[\begin{array}{ccc:ccc}
1 / E & -v / E & -v / E & 0 & 0 & 0 \\
-v / E & 1 / E & -v / E & 0 & 0 & 0 \\
-v / E & -v / E & 1 / E & 0 & 0 & 0 \\
\hdashline 0 & 0 & 0 & 1 / 2 G & 0 & 0 \\
0 & 0 & 0 & 0 & 1 / 2 G & 0 \\
0 & 0 & 0 & 0 & 0 & 1 / 2 G
\end{array}\right]\left\{\begin{array}{l}
\Delta \sigma_{X} \\
\Delta \sigma_{Y} \\
\Delta \sigma_{Z} \\
\Delta \tau_{X Y} \\
\Delta \tau_{Y Z} \\
\Delta \tau_{Z X}
\end{array}\right\}
$$

A matriz que relaciona as deformações com as tensões apresenta duas submatrizes nulas (1 e 2), a sub-matriz nula (1) mostra que não existe relação entre as tensões normais e de cisalhamento, no entanto, ensaios de cisalhamento simples realizados em areias densas mostram que solos submetidos a tensões normais e de cisalhamento sofrem um incremento de volume (dilatação) devido a um acréscimo da tensão de cisalhamento (ver Figura 4.2a). Sendo assim, o incremento de deformação normal é produto do incremento da tensão de cisalhamento.
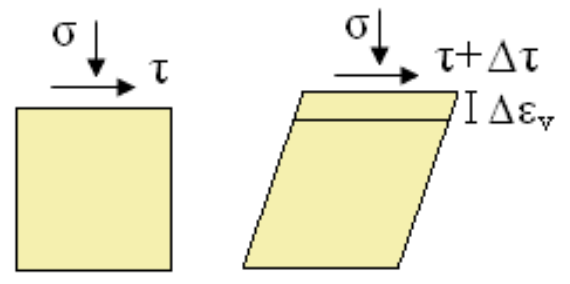

(a)
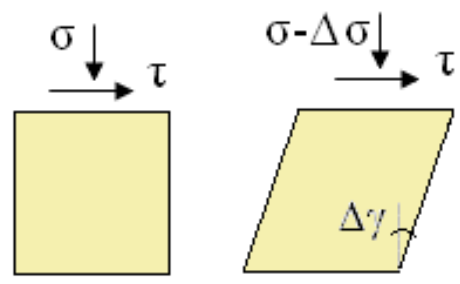

(b)

Figura 4.2 - Limitações teoria da elasticidade (a) Incremento de $\tau$ provoca $\Delta \varepsilon_{v}$; (b) Incremento da $\Delta \gamma$ provoca decréscimo de $\sigma$.

A sub-matriz nula (2) indica que não há relação entre a variação das deformações por cisalhamento com as tensões normais, porém, o comportamento real do solo mostra que um incremento da deformação por cisalhamento gera um decréscimo da tensão normal. (ver Figura 4.2b) 


\subsection{Programas Computacionais Utilizados}

\subsubsection{ADINA}

O ADINA (Automatic Dynamic Incremental Nonlinear Analysis) é um programa comercializado pela empresa ADINA R \& D, Inc. (http:/www.adina.com), fundada pelo Prof. Dr. K.J. Bathe e outros associados. O ADINA é um sistema integrado utilizado para análise de estruturas e escoamento de fluidos. Todos os módulos de solução ${ }^{6}$ utilizam o mesmo pré e pós-processador (ADINA-IN e ADINA-PLOT), acoplados ao ADINA-AUI (Adina User Interface).

O programa computacional permite realizar análises tensão-deformação com o método dos elementos finitos em sólidos (2D e 3D), e em estruturas submetidas a solicitações estáticas e dinâmicas. As análises podem ser lineares ou não-lineares incluindo efeitos de não linearidade do material, grandes deformações e problemas de contato em sólidos.

\subsubsection{SIGMA/W}

O SIGMA/W é um software de elementos finitos que pode ser usado para realizar análises de tensão-deformação de estruturas geotécnicas como fundações, aterros, escavações e túneis. O SIGMAW permite utilizar simples e complexos modelos constitutivos (elástico-linear e elasto-plástico não linear). Também oferece a possibilidade de realizar análises tensão-deformação com ou sem a mudança da pressão neutra que surge da alteração no estado tensões do solo.

\subsection{Tipos de Elementos Finitos Utilizados nas Modelagens Numéricas}

A representação do maciço de solo nas modelagens numéricas bidimensionais foi realizada mediante elementos isoparamétricos triangulares e quadrangulares de

\footnotetext{
${ }^{6}$ ADINA, ADINA-F (fluid) e ADINA-T (Thermal).
} 
sete e nove nós nos programas computacionais SIGMA/W e ADINA respectivamente. No caso das modelagens tridimensionais utilizaram-se elementos sólidos isoparamétricos de vinte nós

Os grampos foram representados com elementos do tipo barra, com a particularidade de que no programa computacional ADINA pode-se fazer uso da função “Rebar Element", função esta que permite utilizar o elemento barra em qualquer tipo de configuração de malha, pois nas interseções da malha com 0 elemento barra os nós são gerados automaticamente. A figura 4.3 ilustra como a função "Rebar Element" cria automaticamente equações de restrição que compatibilizam os deslocamentos nas interseções com os.elementos sólidos. $O$ paramento de concreto projetado foi representado com elementos do tipo viga e casca para modelagens bidimensionais e tridimensionais respectivamente.

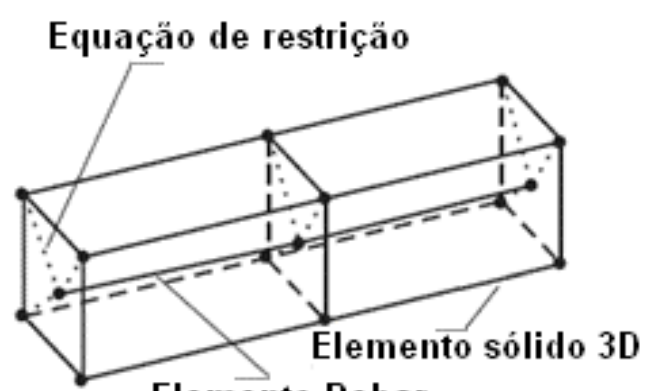

Elemento Rebar

Figura 4.3 - Elemento rebar em elementos sólidos.

\subsection{Problemas em Modelagens Numéricas que Utilizam a Teoria da}

\section{Elasticidade}

Nesta seção descrevem-se dois tipos de problemas comuns em modelagens numéricas de escavações. No primeiro demonstra-se a impossibilidade de se encontrar resultados corretos em análises numéricas de escavações a céu aberto com a utilização de um único módulo de elasticidade para todo o maciço de solo ${ }^{7}$ ao redor da escavação. O outro problema apresenta o erro que pode-se cometer ao

\footnotetext{
${ }^{7}$ Menciona-se maciço de solo, mas acredita-se que o problema também pode ocorrer em maciços de rocha.
} 
realizar análises numéricas de escavações com malhas de elementos finitos grosseiras.

Para explicar o primeiro problema realizou-se a análise numérica de uma escavação ${ }^{8}$ em etapas. Resultados dessa modelagem mostraram que o perfil de deslocamentos verticais apresentam valores contrários aos esperados (ver Figura 4.4), pois sabe-se que em qualquer tipo de escavação a céu aberto, a superfície $A B$ apresentaria um perfil de recalque.

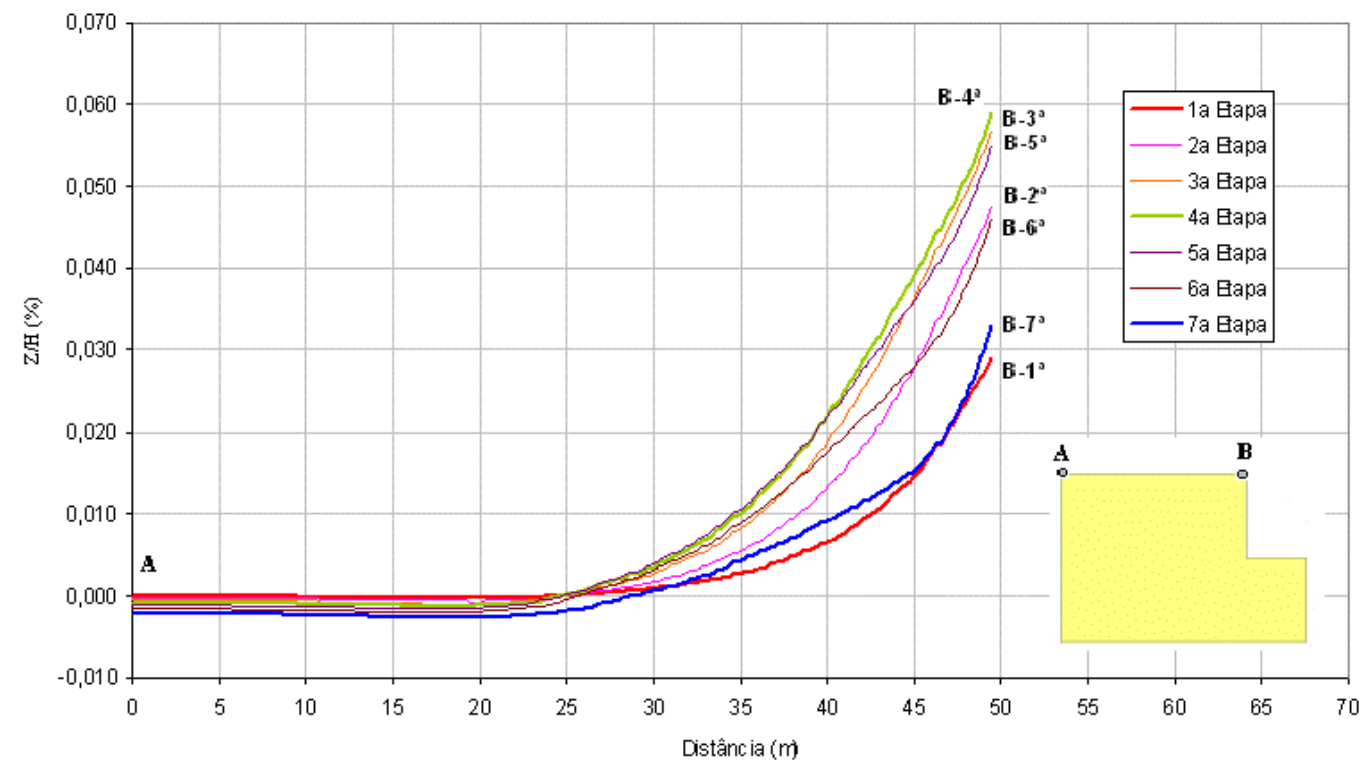

Figura 4.4 - Deslocamentos verticais da superfície AB.

O segundo problema descreve um erro identificado em um exemplo de modelagem numérica de uma escavação realizada somente numa etapa, encontrado no manual do usuário do programa computacional SIGMA/W ${ }^{9}$. Na figura 4.5 apresentam-se dois perfis de deslocamento vertical da superfície $A B$, de uma escavação com os mesmos parâmetros geométricos e mecânicos, mas com uma densidade diferente de malha de elementos finitos em cada modelo ${ }^{10}$. A curva vermelha apresenta os resultados do exemplo descrito no manual do SIGMA/W, na qual pode-se observar que a superfície $A B$ mostra um perfil de recalques. Porém, quando realizado um refinamento de malha no mesmo modelo numérico, a superfície $A B$ apresenta um

\footnotetext{
${ }^{8} \mathrm{~A}$ escavação analisada apresentou os seguintes parâmetros físicos, geométricos e mecânicos: $\gamma=$ $18,5 \mathrm{kN} / \mathrm{m} 3 ; \mathrm{Ko}=0,5 ; \mathrm{H}=10,5 ; \mathrm{E}=40 \mathrm{MPa} ; \mathrm{v}=0.25$.

${ }^{9}$ Nessa modelagem numérica foram empregados os seguintes parâmetros: $\gamma=20 \mathrm{kN} / \mathrm{m}^{3} ; \mathrm{Ko}=0,9 ; \mathrm{H}$ $=16 \mathrm{~m} ; \mathrm{E}=10 \mathrm{MPa} ; \mathrm{v}=0.45$

${ }^{10}$ Malhas de elementos finitos de $4 \mathrm{~m} \times 4 \mathrm{~m}$ e $1 \mathrm{~m} \times 1 \mathrm{~m}$.
} 
levantamento do ponto B. Portanto, acredita-se que uma densidade grosseira de malha de elementos finitos em modelos numéricos de escavações induz interpretações erradas dos resultados.

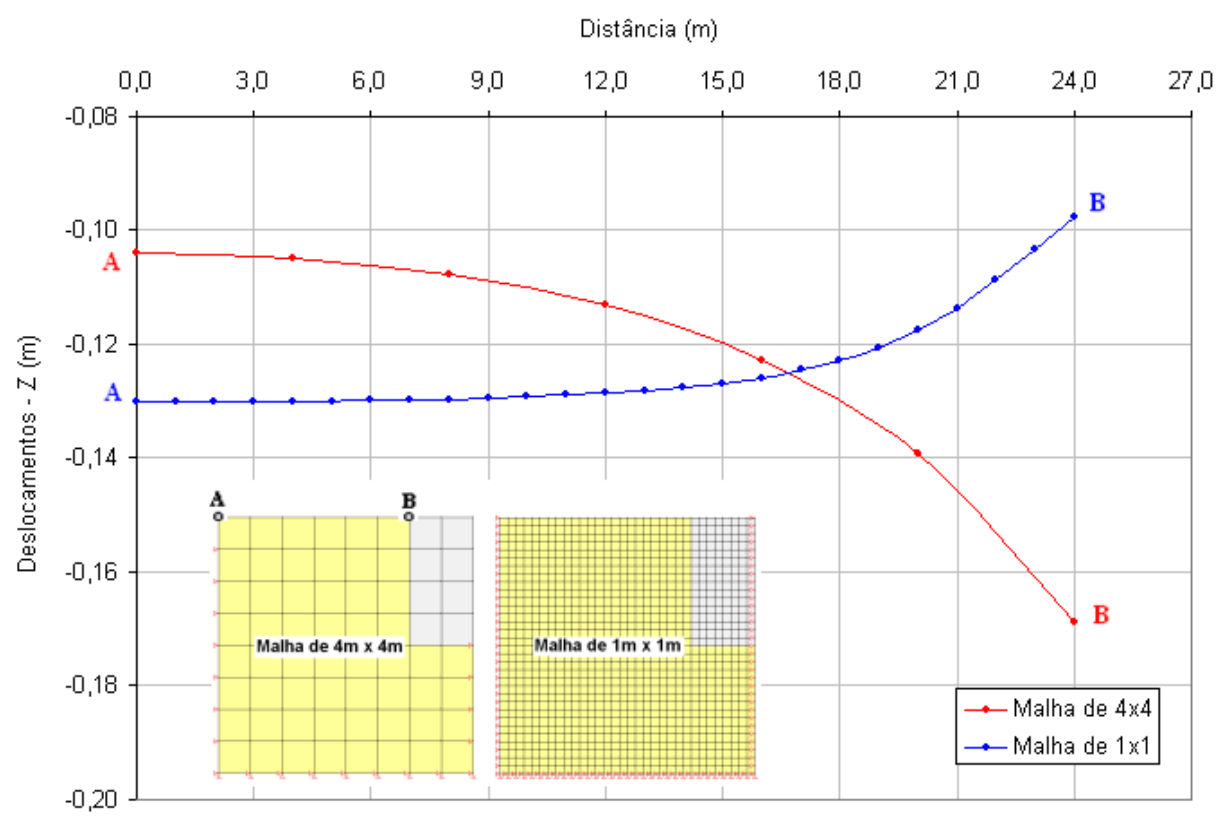

(a)

Figura 4.5 - (a) Recalques e Deslocamentos verticais na superfície AB; (b) Deslocamentos da parede escavada (superfície BC).

De acordo com os resultados apresentados acima, tem-se que modelagens numéricas de escavações a céu aberto não podem ser simuladas com um único módulo de elasticidade, pois deve ser considerado o fato de que durante o processo da escavação, as regiões do maciço de solo ao redor da escavação sofrem diversos tipos de trajetórias de tensão.

\subsection{Influência do $\mathrm{K}_{\mathrm{o}}$ nos Máximos Deslocamentos}

É bastante conhecido que o valor de $\mathrm{K}_{\mathrm{o}}$ influencia os resultados de deslocamentos horizontais em modelagens numéricas. Trabalhos de análises numéricas de escavações a céu aberto como o elaborado por DiBiagio apud Morgenstern e Eisenstein (1970), verificaram a existência de uma relação diretamente proporcional entre o valor de $\mathrm{K}_{\circ}$ e o máximo deslocamento horizontal. Estudo semelhante de modelagens numéricas de taludes escavados foi apresentado por Dunlop e Duncan (1970), no qual se demonstrou que com um valor de $K_{0}=1,25$ o talude analisado 
exibia uma condição próxima à ruptura ${ }^{11}$, no entanto, com $\mathrm{K}_{0}=0,75$ o talude apresentou deformações permissíveis. No caso de escavações grampeadas, 0 trabalho realizado por Briaud et. al (1997) apresenta um estudo sobre a influencia deste parâmetro. Contudo, com o objetivo de conhecer a ordem de grandeza de estes deslocamentos realizou-se o estudo apresentado a seguir.

O estudo consiste na realização de varias modelagens numéricas de uma escavação ${ }^{12}$, variando em cada uma delas o valor de $\mathrm{K}_{\mathrm{o}}$ e mantendo constantes as propriedades físicas do material e a geometria do modelo (ver Figura 4.6a). Para o comportamento do solo considerou-se um modelo elástico-linear com os seguintes parâmetros: $\mathrm{E}=45 \mathrm{MPa}$ e $v=0.25$.

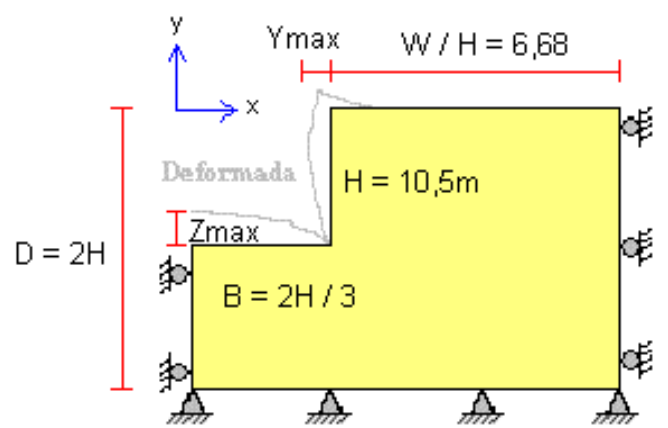

(a)

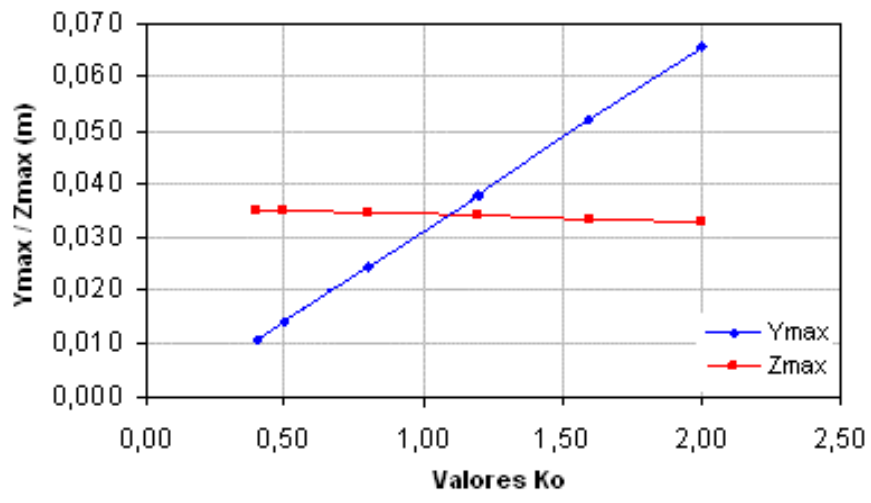

(b)

Figura 4.6 - (a) geometria e nomenclatura utilizada nas modelagens numéricas; (b) Influência do $\mathrm{K}_{\circ}$ nos máximos deslocamentos horizontais e verticais.

Os resultados estão resumidos e apresentados na figura $4.6 \mathrm{~b}$, nota-se que os máximos deslocamentos horizontais com os valores de $\mathrm{K}_{\mathrm{o}}$ apresentam uma relação linear. No entanto, os máximos deslocamentos verticais não se mostraram influenciados pelo valor do $\mathrm{K}_{\mathrm{o}}$.

\footnotetext{
${ }^{11}$ Menciona-se o termo ruptura, pois os resultados mostraram a existência de regiões de plastificação no talude.

${ }_{12}$ É importante ressaltar que as modelagens numéricas consideraram que a escavação total do maciço foi realizada em uma única fase.
} 


\subsection{Influência da Proximidade das Condições de Contorno nos Máximos Deslocamentos Horizontais e Verticais}

Além da influencia do parâmetro $\mathrm{K}_{\mathrm{o}}$ demonstrada no item anterior, existe também uma influencia da geometria do modelo nos resultados de modelagens numéricas. Para avaliar essa questão foi realizado um estudo sobre a in fluência dos parâmetros geométricos $\mathrm{W} / \mathrm{H}, \mathrm{B}$ e $\mathrm{D}^{13}$; mantendo-se constantes a altura de escavação $(H=10,5 \mathrm{~m})$ e as propriedades físicas $\left(\gamma=18,5 \mathrm{kN} / \mathrm{m}^{3}\right.$ e $\left.\mathrm{K}_{\mathrm{o}}=0.5\right)$ e mecânicas (modelo elástico-linear com $E=45 \mathrm{MPa}$ e $v=0.25$ ) do maciço de solo; considerou-se também neste estudo que o processo de escavação foi realizado somente numa etapa.

Resultados das análises paramétricas efetuadas para determinar a influência da largura da vala $(B)$, considerando-se constantes a relação $H / D=0,5$ e a distância $W$ $=70 \mathrm{~m}$, encontram-se apresentados na figura 4.7, na qual pode-se observar que existe muito pouca influência deste parâmetro geométrico no máximo deslocamento horizontal; não obstante, o máximo deslocamento vertical somente atingiu um valor constante, quando B é aproximadamente igual a $\mathrm{H}$.

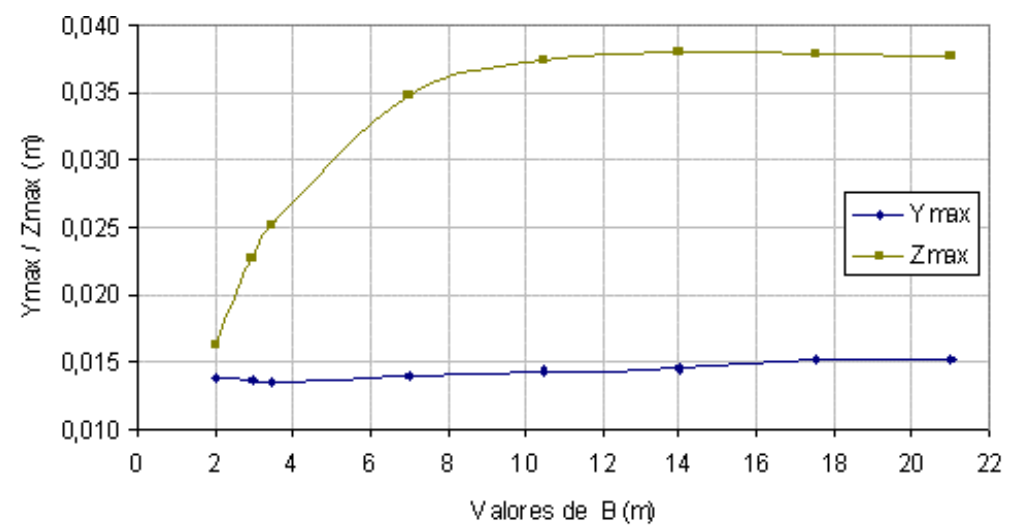

Figura 4.7 - Influencia da largura da vala (B) nos máximos deslocamentos verticais e horizontais, mantendo-se constantes $\mathrm{H} / \mathrm{D}=0,5$ e $\mathrm{W}=70 \mathrm{~m}$.

A influencia da proximidade da condição do contorno do lado esquerdo (W) foi estudada empregando a relação $W / H$ e utilizando como constantes o valor de $H / D=$ 0,5 e $B=2 H / 3$. Nos resultados apresentados na figura 4.8 , mostra-se que a relação

\footnotetext{
${ }^{13}$ Para o estudo da influência dos parâmetros geométricos nas modelagens numéricas, utilizou-se também a nomenclatura definida na figura 4.6a.
} 
W/H não influencia o máximo deslocamento vertical, no entanto, somente a partir de um valor de quatro na relação $\mathrm{W} / \mathrm{H}$ mantiveram-se aproximadamente constantes os valores do máximo deslocamento horizontal.

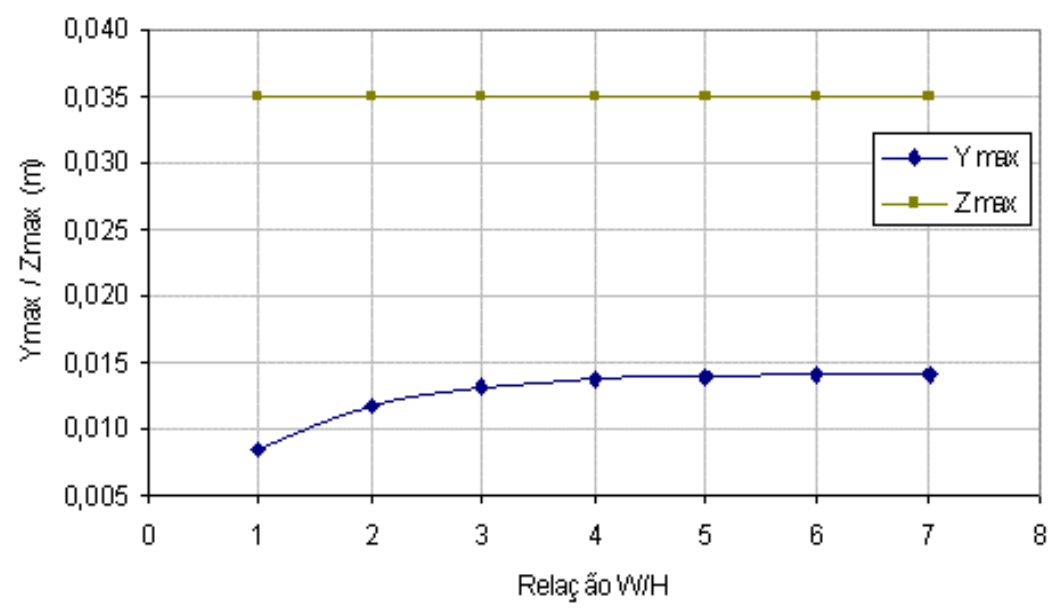

Figura 4.8 - Influencia da relação W/H nos máximos deslocamentos verticais e horizontais mantendo-se constantes $\mathrm{H} / \mathrm{D}=0,5$ e $\mathrm{B}=2 \mathrm{H} / 3$.

O parâmetro geométrico que apresentou maior influencia nos máximos deslocamentos verticais foi a relação $H / D$, pois, enquanto o valor da relação $H / D$ era incrementado, o valor máximo deslocamento vertical apresentava uma diminuição (ver Figura 4.9). Nessa mesma Figura pode-se notar que para valores de 0,5 a 0,75 da relação $H / D$, os valores de deslocamento horizontal atingem um máximo.

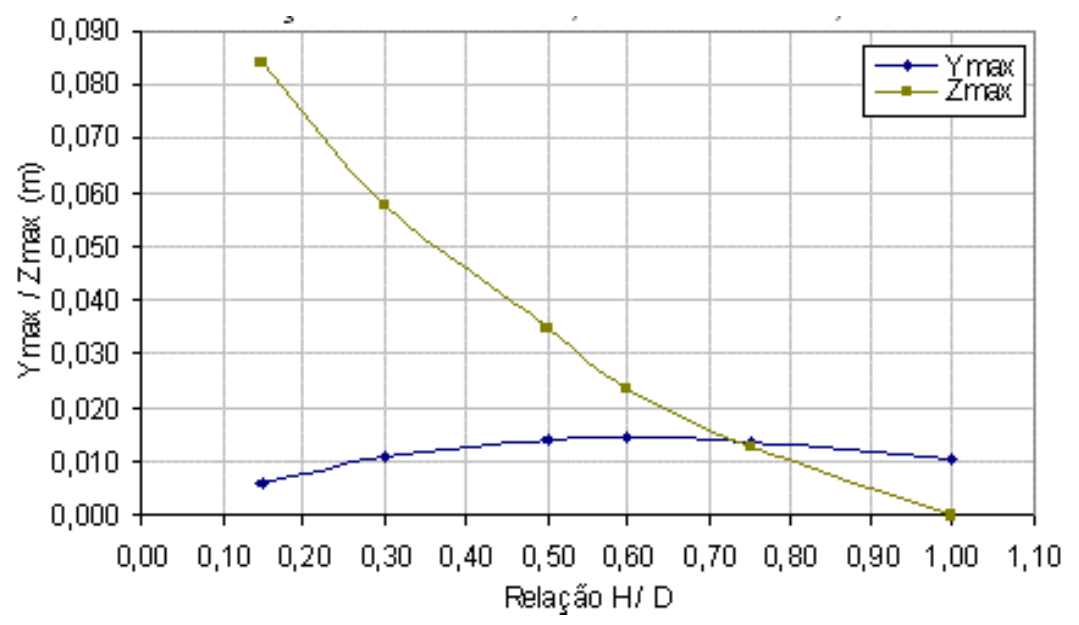

Figura 4.9 - Influencia da relação H/D nos deslocamentos verticais e horizontais, mantendo-se constantes $B=2 \mathrm{H} / 3$ e $W=70 \mathrm{~m}$. 
Estudos realizados por DiBiago (1966) apud Morgenstern e Eisenstein (1970), confirmam a influencia da relação $H / D$ nos deslocamentos verticais, e o efeito pouco significativo da largura da vala nos deslocamentos horizontais da face escavada.

Dunlop e Duncan (1970) também mostraram que as condições de contorno do modelo devem estar suficientemente afastadas da parede de escavação, para não influenciar os resultados das modelagens numéricas. Porém, os autores recomendam que a distância entre a parede de escavação e a condição do lado direito, seja de no mínimo $\mathrm{W}=3 \mathrm{D}$, e a distância entre a condição de contorno do lado esquerdo e a parede de escavação fosse igual a $B=3(D-H)$.

Após algumas análises numéricas utilizando um modelo elástico linear para representar o comportamento do maciço de solo, Briaud e Lim (1997) propuseram uma geometria que não influencie os resultados de modelagens numéricas, recomendando assim $W=4 D$ e $B=4(D-H)$.

O valor de $W \geq 4 D$ também foi confirmado por Lima (2002), utilizando um modelo constitutivo do tipo elasto-plástico com critério de ruptura de Mohr-Coulomb para simular o comportamento do maciço escavado.

\subsection{Influência do Número de Etapas de Escavação}

Um outro fator que poderia afetar os resultados de modelagens numéricas é o número de etapas de escavação. Existem vários trabalhos referentes a este tema, como por exemplo, o apresentado por Christian e Wong (1973), onde foram realizadas simulações numéricas de uma escavação em um meio elástico com o método dos elementos finitos. O produto final dessas simulações mostrou que os deslocamentos verticais e horizontais apresentam uma dependência do número de etapas de escavação. A figura 4.10 apresenta os deslocamentos verticais dos pontos B e C da modelagem numérica realizada por Christian e Wong (1973), na qual se pode observar que a influência do número de etapas de escavação no ponto $B$ é nula. No entanto, o ponto $C$ sofre recalques quando o maciço é escavado em uma ou duas etapas, mas a partir da utilização de três etapas de escavação, ocorre 
um levantamento do ponto C. Os autores atribuem esses resultados a dois fatores: (1) concentração de tensões no pé do talude escavado quando realizado o processo de escavação em um material elástico linear; (2). inadequação dos elementos para representar esses gradientes elevados de tensões, o que seria contornado com a utilização de elementos de ordem superior.

Os deslocamentos horizontais e verticais da parede da escavação mostrados na figura 4.11, também apresentaram uma dependência do número de etapas de escavação. Christian e Wong (1973) recomendam reduzir o número de etapas de escavação para minimizar o erro. Logicamente, este tipo de solução não seria recomendável nos casos onde é necessário um conhecimento do comportamento do maciço durante o processo de escavação, como é caso das escavações reforçadas com a técnica de solo grampeado.

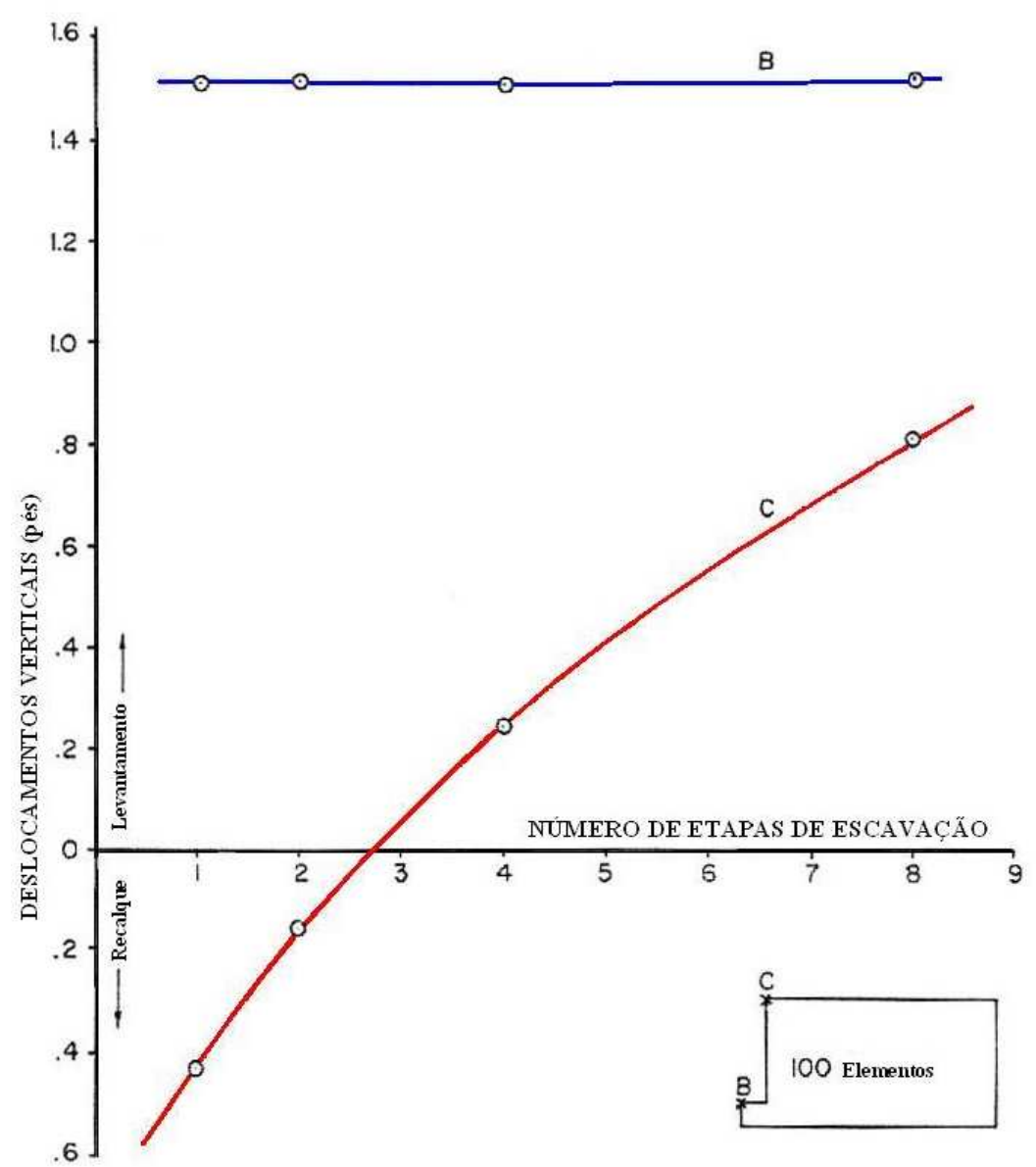

Figura 4.10 - Efeito do número de etapas de escavação nos deslocamentos dos pontos B e C (Christian e Wong, 1973) 
Os resultados obtidos por Christian e Wong (1973) descritos acima, não se coadunam com o trabalho desenvolvido por Ishihara (1971), que versa sobre a demonstração teórica da existência de uma solução única nos processos de escavação.

Acredita-se que seja importante comentar que os erros das modelagens numéricas de Christian e Wong (1973) não foram registrados em nenhuma das análises numéricas realizadas neste trabalho, pois todos os resultados de deslocamentos horizontais e verticais mostraram independência do número de etapas de escavação. Isto foi atribuído à utilização de elementos finitos de ordem superior.

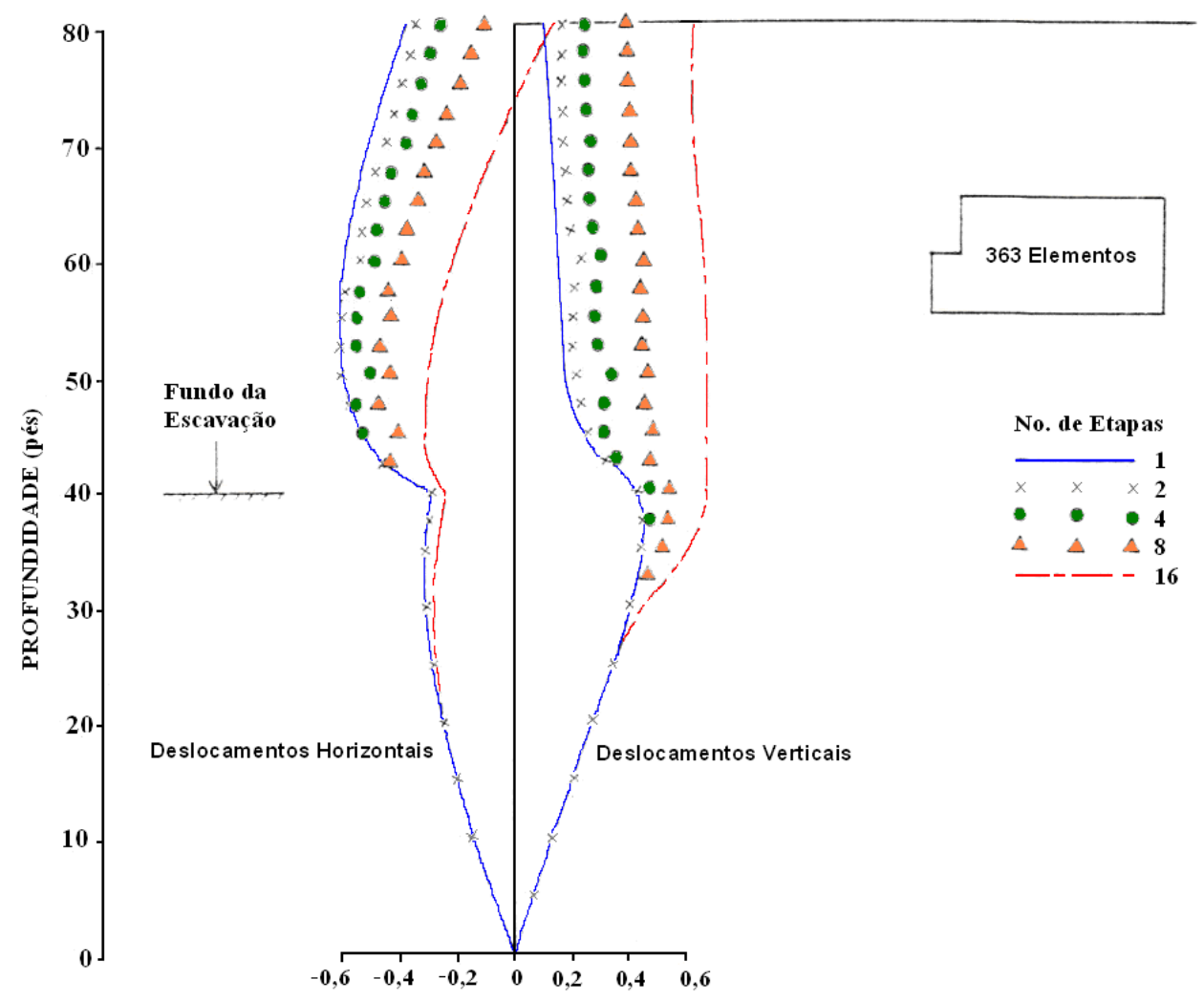

Figura 4.11 - Efeito do número de etapas dos deslocamentos da face escavada (Christian e Wong, 1973)

É importante mencionar que na análise numérica de uma escavação com sistema misto de contenção (grampos e tirantes) apresentada no trabalho de Lima (2002), demonstrou-se que quando utilizado um modelo constitutivo elasto-plástico para representar o comportamento do solo, existe uma influencia do número de etapas de escavação nos resultados. 


\subsection{Módulos de Elasticidade para Diferentes Trajetórias de Tensão}

O módulo de elasticidade depende de vários fatores, dos quais, um dos mais importantes é tipo de trajetória de tensão na qual é submetido o solo. Nesta seção descrevem-se alguns valores de módulos de elasticidade para diferentes trajetórias de tensão, encontrados no material bibliográfico.

Lambe e Whitman (1979) apresentaram resultados de ensaios triaxias em amostras de solo para diferentes trajetórias de tensão (ver Figura 4.12), onde podem ser calculados valores de módulos de elasticidade.

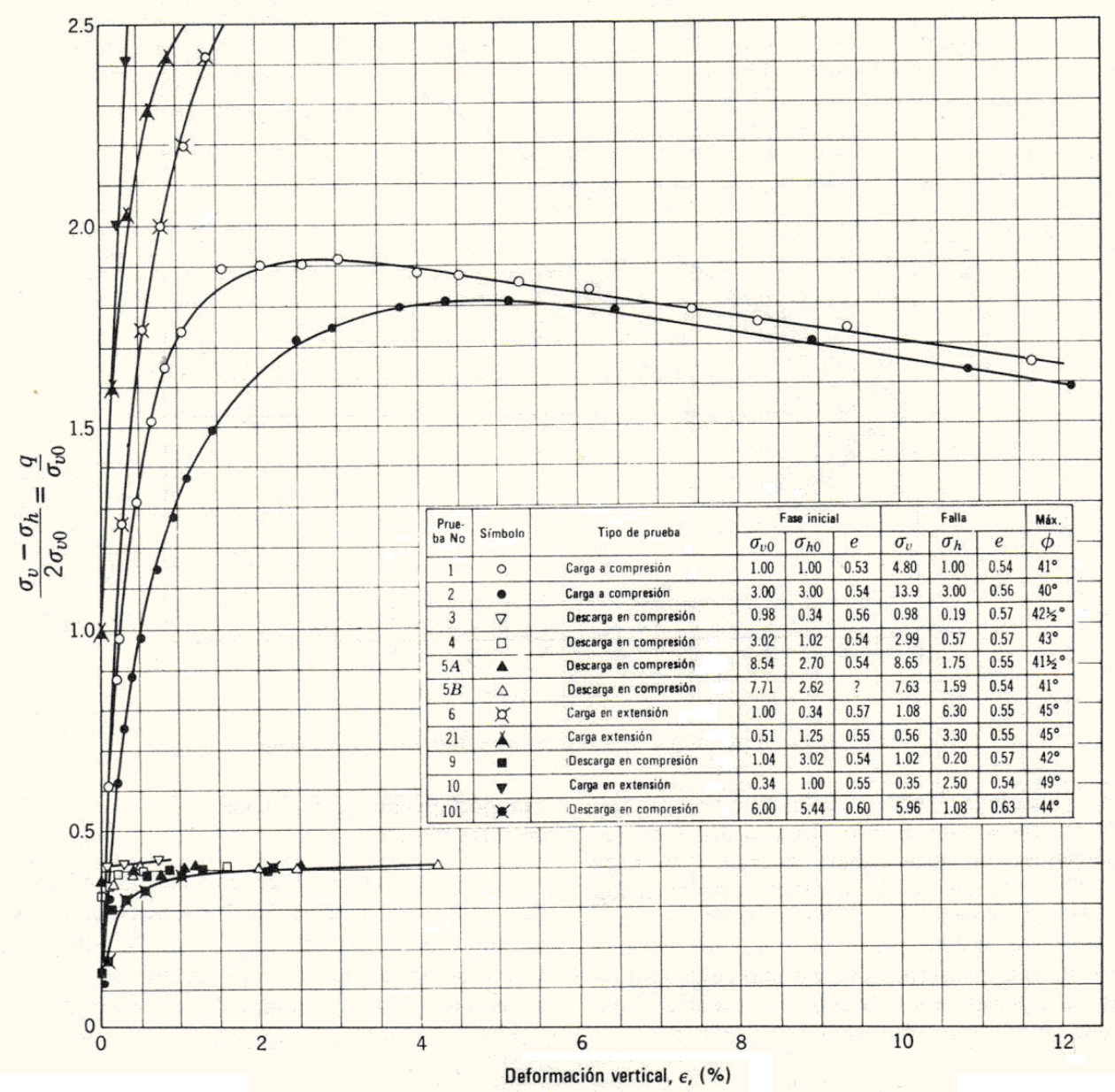

Figura 4.12 - Curvas tensão-deformação para diferentes trajetórias de tensão (Lambe e Whitman, 1979).

Os resultados dos ensaios de Lambe e Whitman (1979) estão apresentados na tabela 4.1, na qual pode-se observar diversos módulos de elasticidade secante para $50 \%$ da máxima tensão desviadora. Nota-se que o valor $E_{50}$ para um ensaio de 
extensão carregamento $(E C)$ é três ou quatro vezes maior do que o módulo de elasticidade para um ensaio com uma trajetória de compressão descarregamento (CD), e este último também é três a quatro vezes maior do que o módulo encontrado num ensaio de compressão carregamento (CC).

Tabela 4.1 - Módulos de elasticidade para diferentes trajetórias de tensão.

\begin{tabular}{|c|c|c|c|c|c|c|c|c|c|c|c|}
\hline \multirow{2}{*}{$\begin{array}{c}\text { Prova } \\
\mathrm{N}^{\circ}\end{array}$} & \multirow{2}{*}{ Simbolo } & \multirow{2}{*}{ Trajetoria de Tensäo } & \multicolumn{3}{|c|}{ Fase Inicial } & \multicolumn{4}{|c|}{ Falha } & \multirow{2}{*}{$\begin{array}{c}\text { Máximo } \\
\left.\phi C^{0}\right)\end{array}$} & \multirow{2}{*}{$\begin{array}{l}E_{\text {sec }-50 \%} \\
\mathrm{Kg} / \mathrm{cm}^{2}\end{array}$} \\
\hline & & & $\sigma_{\mathrm{vo}}$ & $\sigma_{\text {ho }}$ & e & $\sigma_{u}$ & $\sigma_{\mathrm{h}}$ & e & $50 \%\left(\sigma_{\mathrm{vo}}-\sigma_{\mathrm{ho}}\right)$ & & \\
\hline 1 & 0 & Compressão carregamento & 1,00 & 1,00 & 0,53 & 4,80 & 1,00 & 0,54 & 1,90 & 41,0 & 950 \\
\hline 2 & $\bullet$ & Compressã̃o carregamento & 3,00 & 3,00 & 0,54 & 13,90 & 3,00 & 0,56 & 5,45 & 40,0 & 1363 \\
\hline 3 & $\nabla$ & Compressẫo descarregamento & 0,98 & 0,34 & 0,56 & 0,98 & 0,19 & 0,57 & 0,40 & 42,5 & 3950 \\
\hline 9 & a & Compressão descarregamento & 1,04 & 3,02 & 0,54 & 1,02 & 0,20 & 0,57 & 0,41 & 42,0 & 4100 \\
\hline 10 & $\nabla$ & Extensã̃o carregamento & 0,34 & 1,00 & 0,55 & 0,35 & 2,50 & 0,54 & 1,08 & 49,0 & 10750 \\
\hline 21 & A & Extensẫo carregamento & 0,51 & 1,25 & 0,55 & 0,56 & 3,30 & 0,55 & 1,37 & 45,0 & 13700 \\
\hline
\end{tabular}

Estudos realizados por Resendiz e Zonana (1969), baseados em ensaios de laboratório, recomendaram que o módulo de elasticidade do solo submetido a uma trajetória de extensão é três vezes superior ao módulo de elasticidade em uma trajetória de compressão.

No trabalho apresentado por Lima (2002) são aplicados dois fatores de correção, ao módulo de elasticidade utilizado na modelagem numérica de uma escavação em solo residual jovem, obtido mediante um ensaio de compressão carregamento. $O$ primeiro fator $\left(\mathrm{FC}_{1}\right)$ esta relacionado com as diferenças entre campo e laboratório (amolgamento, historia de tensões, etc) e $0 \mathrm{FC}_{2}$ relativo a trajetória de tensões empregada no ensaio. Os valores utilizados para $\mathrm{FC}_{1}$ foram resultados de observações realizadas por Sandroni (1985 e 1991) e Sieira (1998) apud Lima (2002), valores de $\mathrm{FC}_{2}$ foram estudados por Pontes e Filho (2002), Carpio (1990) e Sayão et. al (1999) apud Lima (2002). Os fatores $F_{1}$ e $F_{2}$ utilizaram-se para valores de módulos de elasticidade correspondentes a $50 \%$ tensão desviadora.

Nas figuras 4.13a e 4.13b, apresentam-se respectivamente os resultados de ensaios de laboratório de uma argila siltosa rija e uma areia densa, realizados por Medeiros e Eisenstain (1983). Estas Figuras permitem comparar os valores de módulos de elasticidade tangente para diversos valores de deformação e em diferentes tipos de 
trajetória de tensão ${ }^{14}$. Nota-se que o módulo de elasticidade tangente varia principalmente em função de dois fatores: (1) tipo de trajetória de tensão a que o solo foi submetido, (2) valor da deformação no solo.

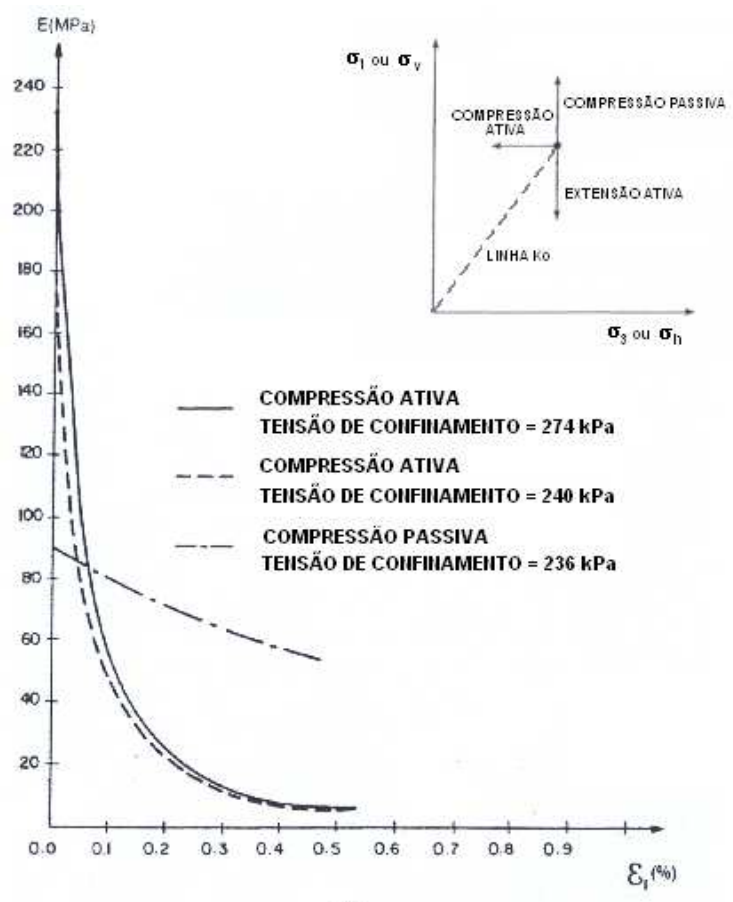

(a)

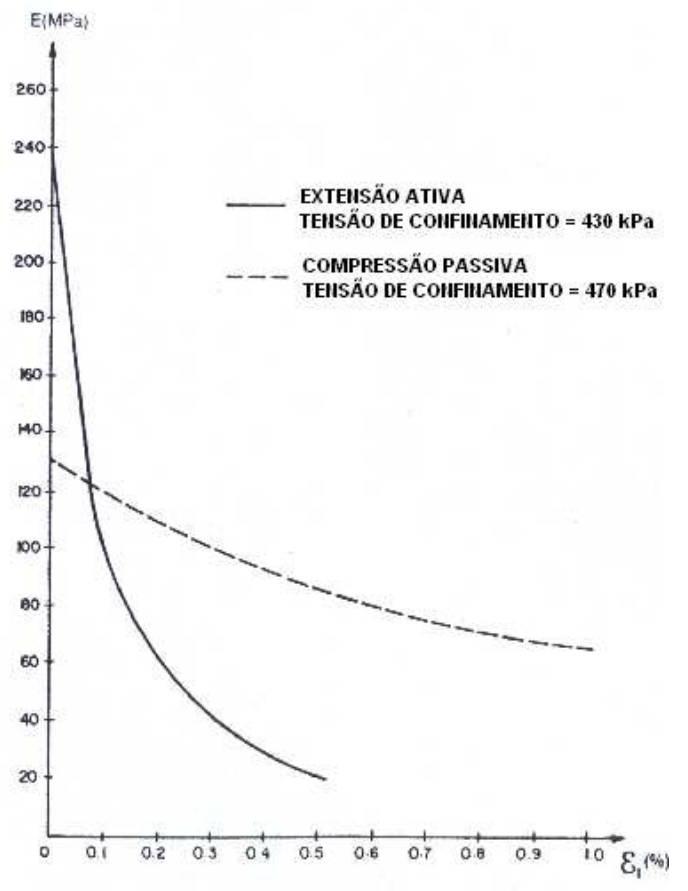

(b)

Figura 4.13 - Comparações do módulo de elasticidade tangente para: (a) ensaios de compressão ativa e passiva, em uma argila siltosa rija; (b) ensaios de extensão ativa e compressão passiva, em uma areia densa (Medeiros e Eisenstein, 1983).

De acordo com o descrito no item 3.2, Cardoso e Carreto (1985) na modelagem numérica de uma escavação grampeada utilizaram um módulo de elasticidade 2,5 vezes superior, região de solo que fica embaixo do fundo da vala.

Acredita-se importante ressaltar que de acordo com 0 descrito acima, as modelagens numéricas de escavações grampeadas apresentadas no próximo capitulo consideraram que o módulo de elasticidade em compressão por descarregamento é três vezes maior que o módulo de elasticidade encontrado em um ensaio com trajetória de compressão por carregamento, e que o módulo de elasticidade em um ensaio com trajetória de tensão do tipo extensão por descarregamento é nove vezes maior do que o módulo de elasticidade em compressão por descarregamento.

${ }^{14}$ Considerou-se: compressão passiva = compressão por carregamento; compressão ativa = compressão por descarregamento; extensão ativa = extensão por descarregamento. 


\subsection{Trajetórias de Tensões no Maciço ao Redor da Escavação}

Uma escavação resulta em um processo de descarregamento onde o maciço de solo situado à direita da escavação sofre um desconfinamento lateral, e o solo embaixo do fundo da vala apresenta uma extensão. Quando utilizada a teoria da elasticidade em modelagens numéricas de escavações a céu a aberto, é necessário conhecer a distribuição das trajetórias de tensão em cada região do maciço.

Considerando-se o exposto acima, realizaram-se varias iterações para determinar o tipo de trajetória de tensão que segue cada elemento em uma modelagem numérica de uma escavação de $6 \mathrm{~m}$ de altura na etapa final e $3 \mathrm{~m}$ na etapa intermediária. As propriedades físicas e mecânicas empregadas no modelo estão apresentadas na tabela 4.2.

Tabela 4.2 - Parâmetros utilizados nas iterações das etapas final e intermediária.

\begin{tabular}{|l|c|}
\hline \multicolumn{1}{|c|}{ Parâmetros } & Valores \\
\hline Peso unitário do solo & $\gamma=18 \mathrm{kN} / \mathrm{m}^{3}$ \\
Coeficiente de empuxo em repouso & $\mathrm{Ko}_{0}=0,43$ \\
Modulo de elasticidade em compressẫo carregamento & $\mathrm{E}_{\mathrm{CC}}=10 \mathrm{MPa}$ \\
Modulo de elasticidade em compressẫo descarregamento & $\mathrm{E}_{\mathrm{CD}}=30 \mathrm{MPa}$ \\
Modulo de elasticidade em extensẫo descarregamento & $\mathrm{E}_{\mathrm{ED}}=90 \mathrm{MPa}$ \\
Coeficiente de Poison & 0,3 \\
\hline
\end{tabular}

$\mathrm{Na}$ etapa final da escavação foram feitas sete iterações, as quais permitiram estabelecer uma distribuição típica das trajetórias de tensão no maciço de solo ao redor da escavação (ver Figura 4.14) ${ }^{15}$. Nota-se que os elementos que ficam detrás da parede de escavação apresentaram uma trajetória de compressão descarregamento, enquanto que os elementos embaixo do fundo da escavação mostraram uma trajetória de extensão descarregamento. Identificou-se também que elementos próximos ao pé do talude escavado indicam uma região de concentração de tensões com trajetórias do tipo compressão carregamento.Acreditou-se que a condição de contorno da borda inferior do modelo influenciou o tipo de trajetória de tensão encontrada nos elementos próximos a essa região (ver Figuras $4.14 \mathrm{~b}$ a

\footnotetext{
${ }^{15}$ Ressalta-se que na $1 \stackrel{a}{a}$ iteração das escavações da etapa final e intermediária foi utilizado um único módulo de elasticidade (10 MPa) para todo o maciço de solo. Nas seguintes iterações foi atribuído o módulo de elasticidade correspondente a cada elemento em função da trajetória de tensão que apresentava o mesmo.
} 
$4.14 \mathrm{~g}$ ), pois as trajetórias obtidas foram do tipo extensão carregamento, quando na realidade esses elementos deveriam apresentar uma trajetória do tipo compressão descarregamento ${ }^{16}$.

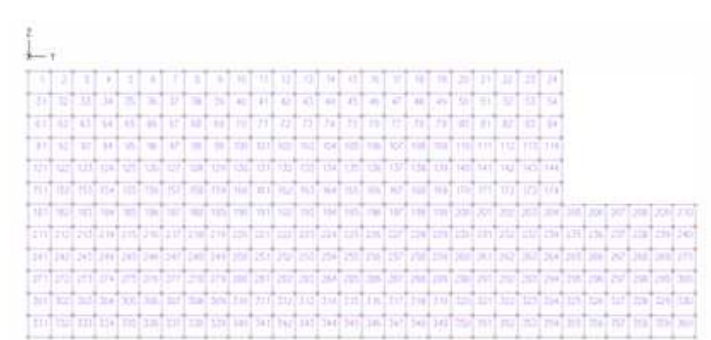

(a)

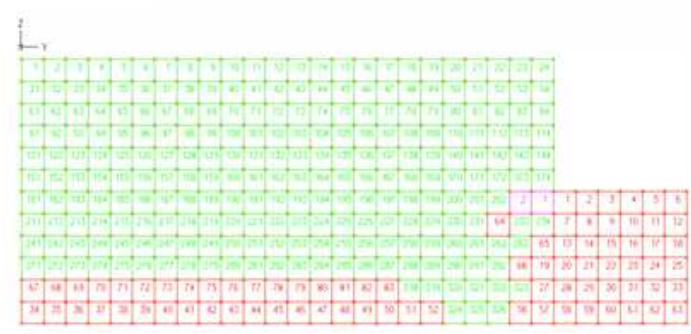

(c)

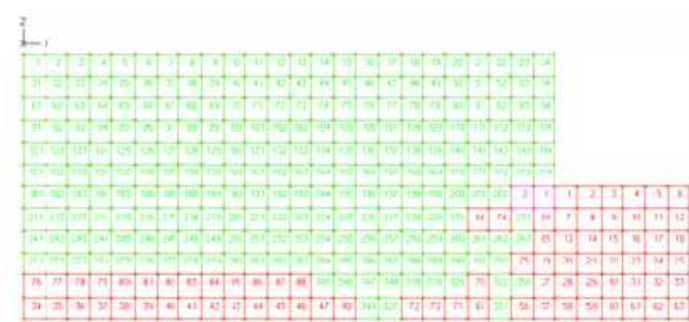

(e)

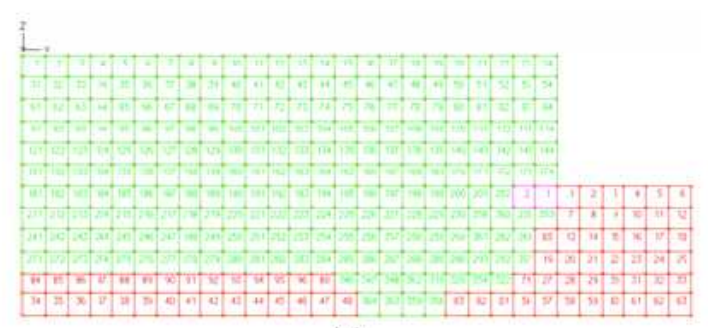

(g)

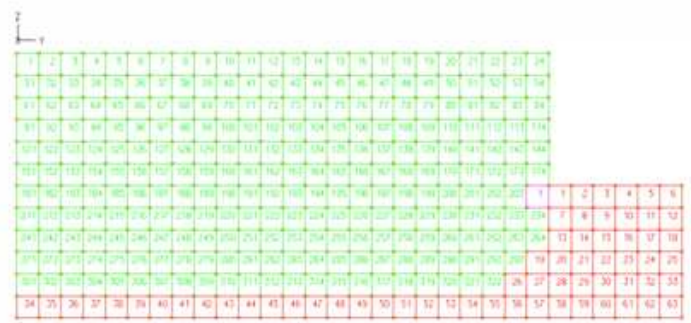

(b)

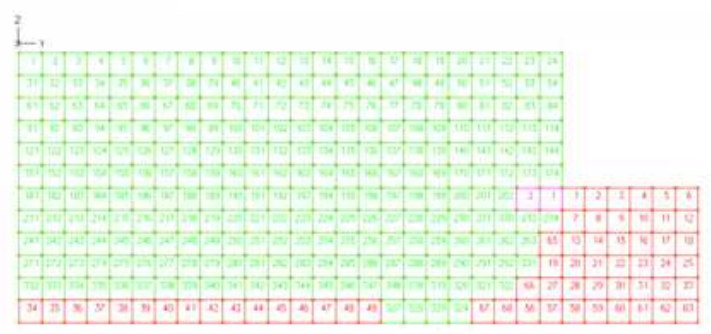

(d)

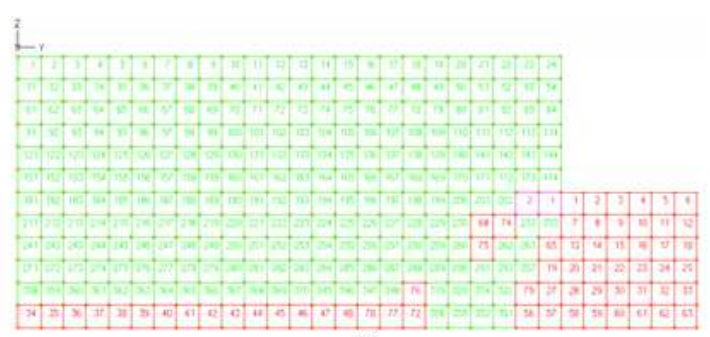

(f)

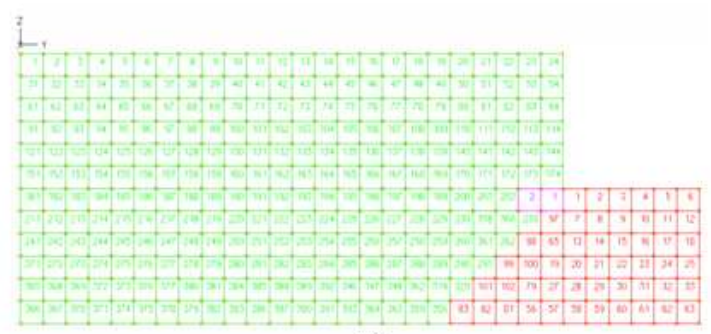

(h)

Figura 4.14 - Tipos de trajetórias de tensão no maciço na etapa final da escavação: (a) 1a iteração; (b) $2^{\underline{a}}$ iteração; (c) $3^{\underline{a}}$ iteração; (d) $4^{\underline{a}}$ iteração; (e) $5^{\underline{a}}$ iteração; (f) $6^{\underline{a}}$ iteração; (g) $7^{\underline{a}}$ iteração; (h) proposta de distribuição típica.

Nas figuras 4.15 e 4.16 estão mostrados os resultados de deslocamentos horizontais e verticais de cada uma das sete iterações e da distribuição típica proposta. Nessas

\footnotetext{
${ }^{16}$ Para um melhor entendimento recomenda-se observar a diferença entre a distribuição dos tipos de trajetória de tensão para cada região nas seis últimas iterações com a proposta de distribuição típica (ver Figuras 4.14b a 4.14h), pois nesta última os elementos situados na esquina inferior esquerda do modelo, com trajetórias de extensão carregamento nas seis últimas iterações, foram substituídos por elementos com trajetórias de tensão do tipo compressão carregamento.
} 
Figuras podem-se observar dois aspectos importantes: (1) diferenças entre os resultados, da modelagem numérica que utilizou um único módulo de elasticidade para todo o maciço (1 $1^{\text {a }}$ Iteração), com as que consideraram a variação do comportamento do maciço de solo ao redor da escavação segundo o tipo de trajetória de tensão no solo ( $2^{\underline{a}}$ a $7^{\mathfrak{a}}$ iteração); (2) resultados da distribuição típica das trajetórias de tensão no maciço de solo exibiram valores muito próximos aos encontrados nas seis últimas iterações.

Deslocamento Horizontal (m)

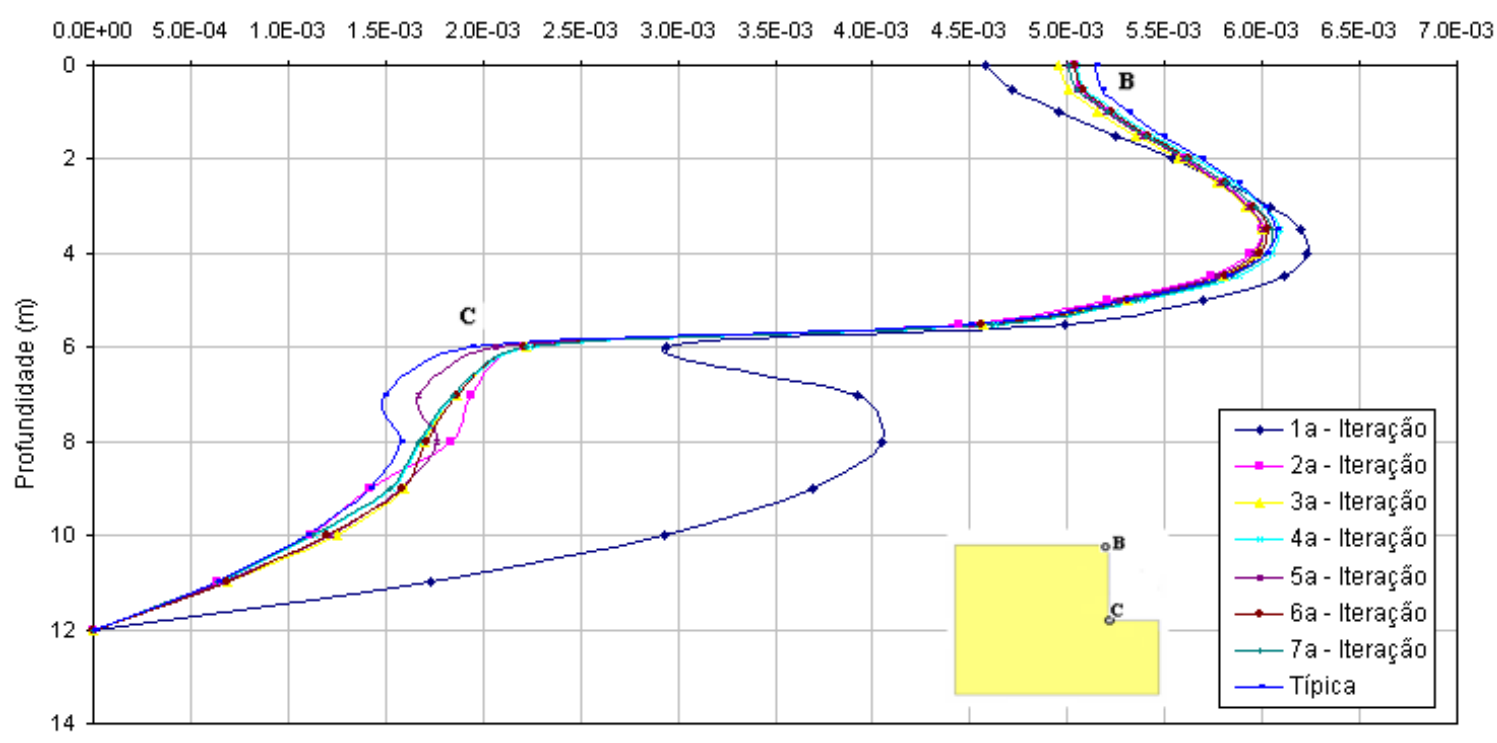

Figura 4.15 - Deslocamentos horizontais na etapa final da escavação das sete iterações e da distribuição típica na superfície BC.

No caso da escavação intermediária realizou-se quatro iterações, que ajudaram a determinar a distribuição típica das trajetórias de tensão no maciço de solo ao redor da escavação, e encontram-se apresentadas na figura 4.17. Os resultados de deslocamento horizontal e vertical das quatro iterações e da distribuição típica para a condição de uma escavação intermediária mostraram-se muito parecidos aos encontrados na etapa final da escavação (ver Figuras 4.18 e 4.19). Porém, o deslocamento vertical do ponto $B$ na figura 4.19 mostrou um levantamento da ordem de $0,0083 \%$ da altura de escavação que foi considerado como desprezível. 


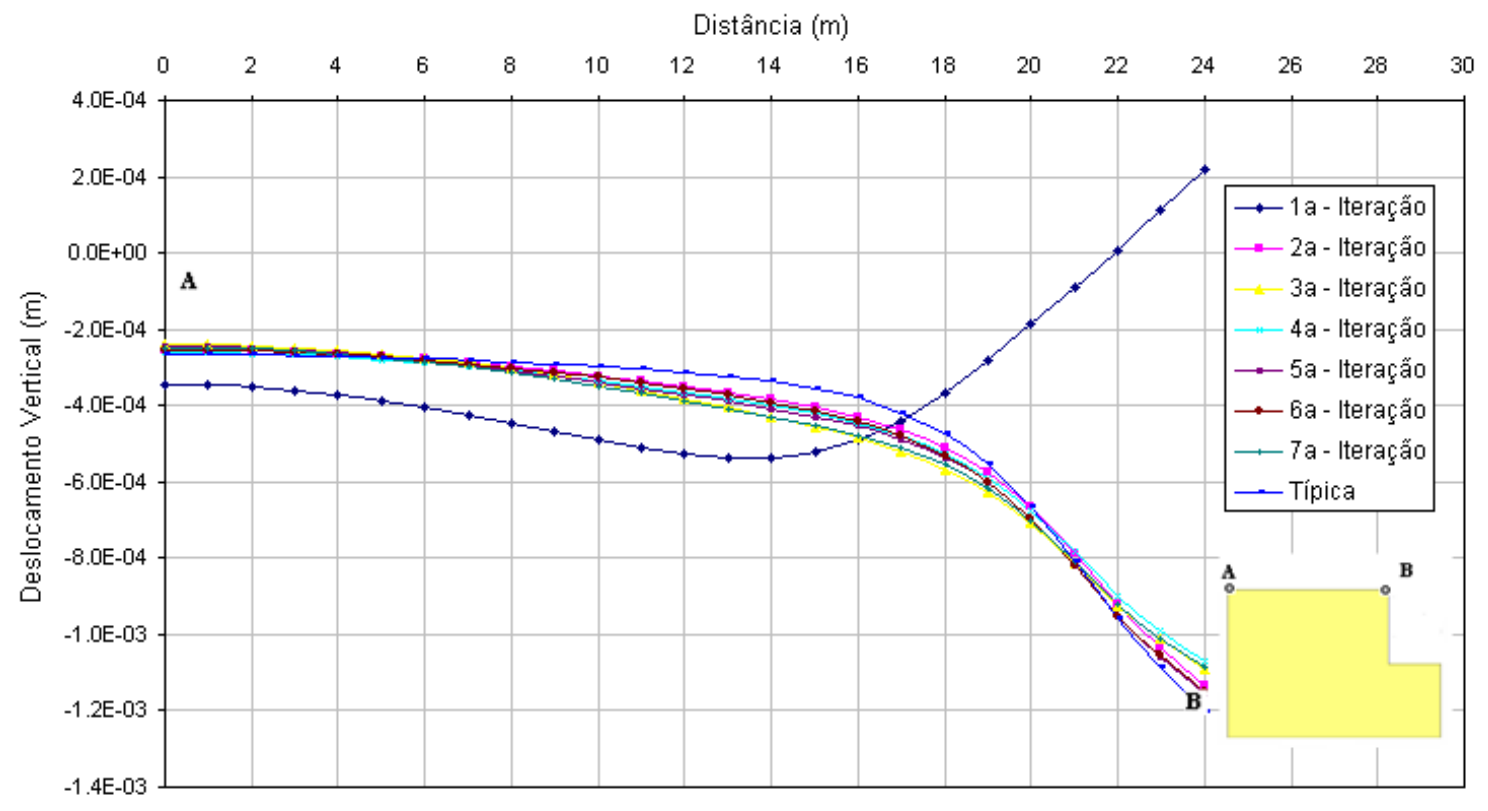

Figura 4.16 - Deslocamentos verticais na etapa final da escavação das sete iterações e da distribuição típica na superfície AB.

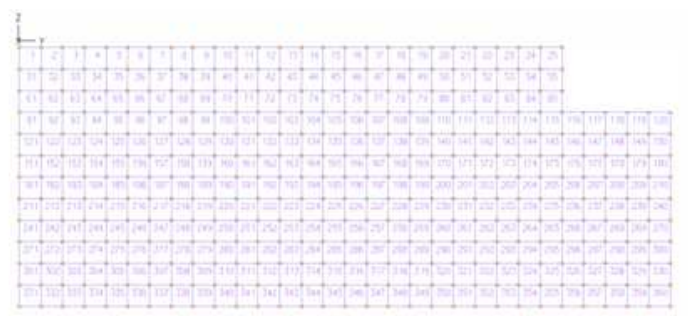

(a)

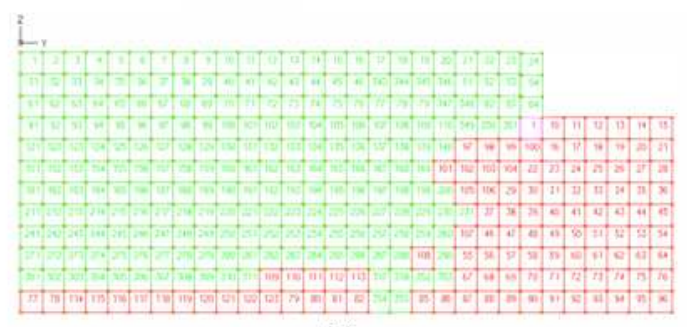

(c)

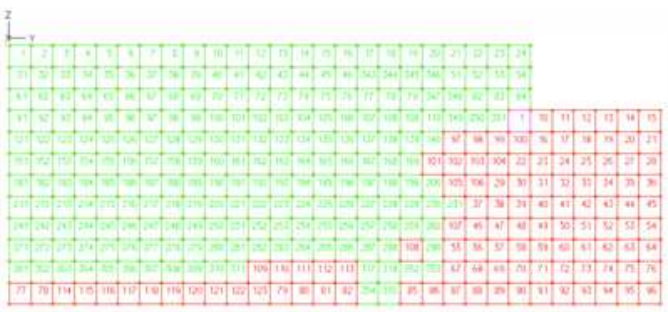

(b)

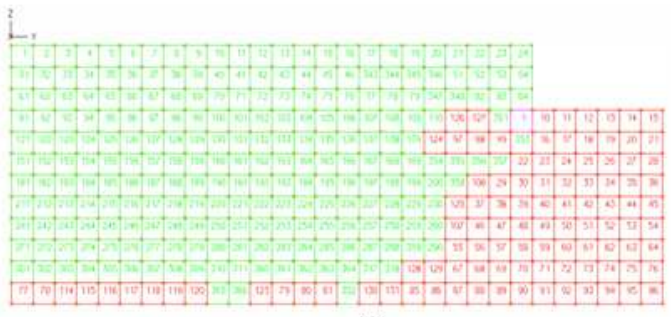

(d)

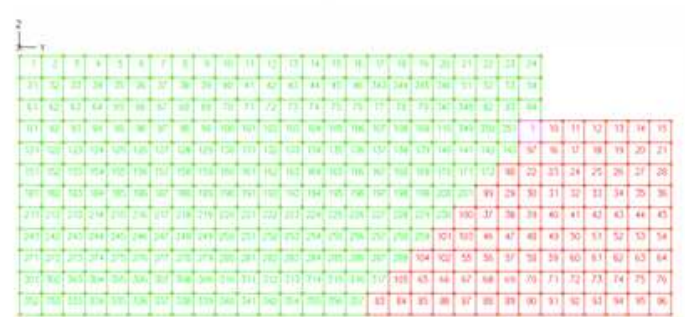

(e)

Figura 4.17 - Tipos de trajetórias tensão no maciço em uma etapa intermediária da escavação: (a) $1^{\text {a }}$

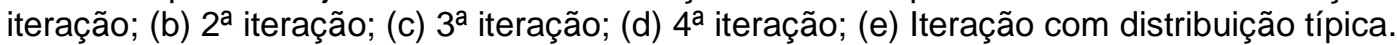


Deslocamento Horizontal (m)

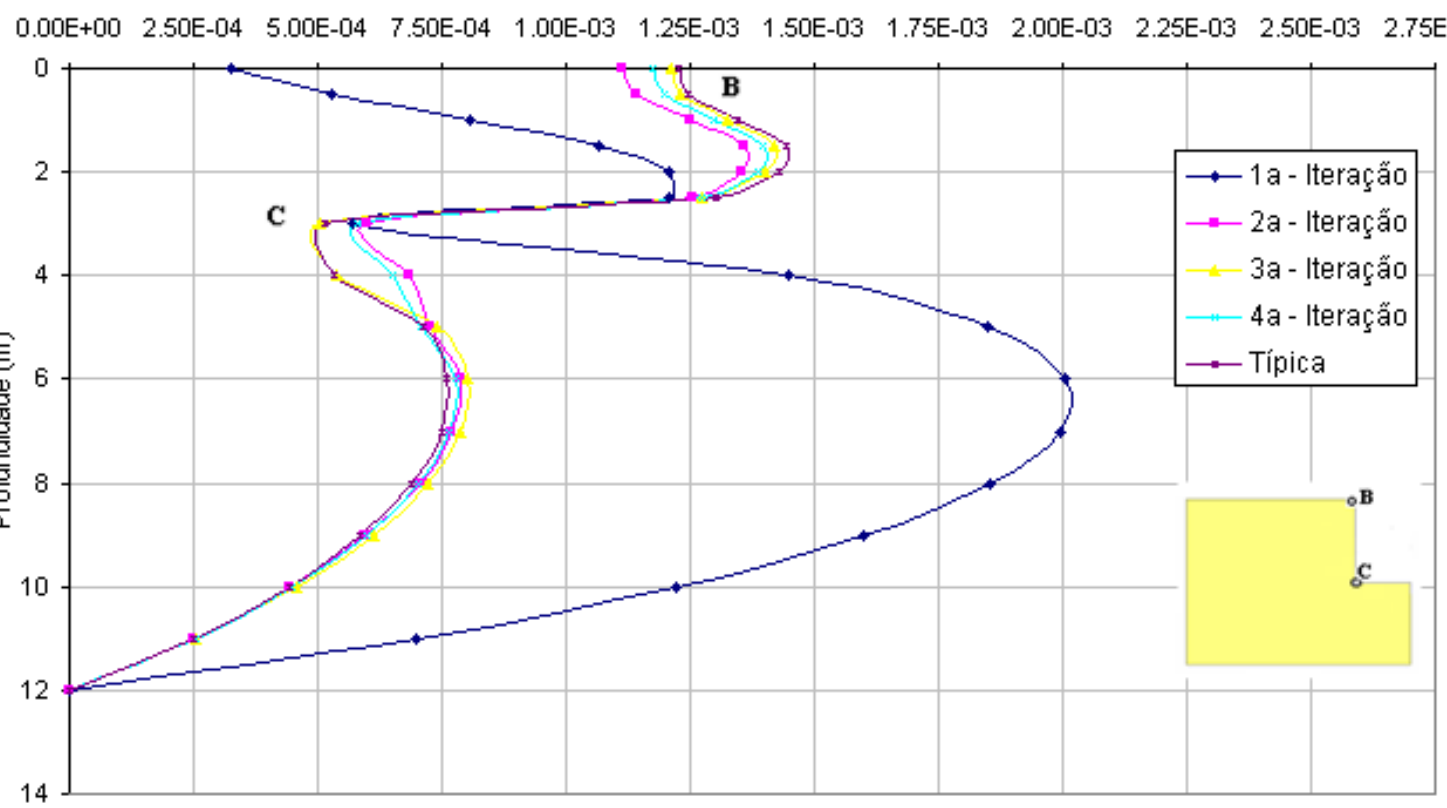

Figura 4.18 - Deslocamentos horizontais em uma etapa intermediária da escavação das sete iterações e da distribuição típica na superfície BC.

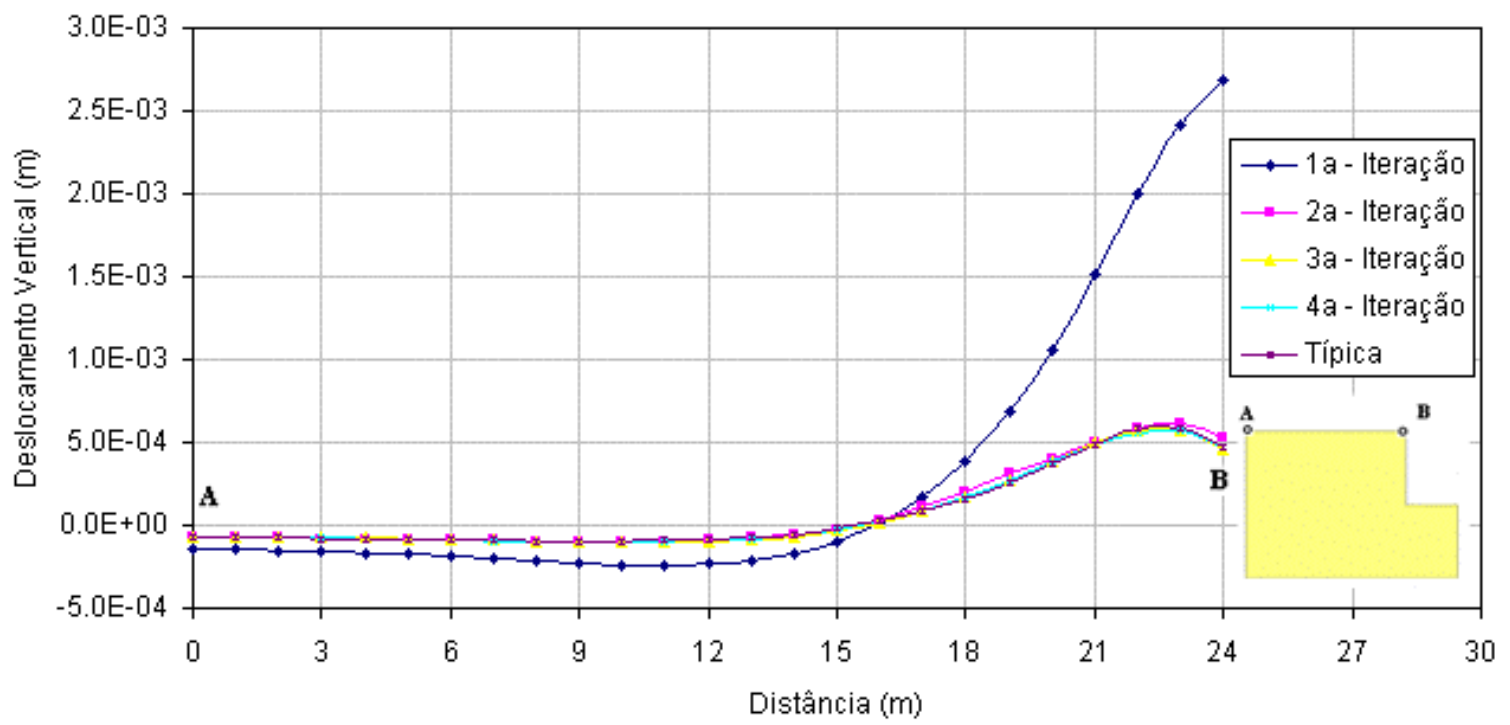

Figura 4.19 - Deslocamentos verticais em uma etapa intermediária da escavação das sete iterações e da distribuição típica na superfície AB.

Considerando os resultados apresentados acima, realizou-se uma proposta da distribuição típica das trajetórias de tensão, na qual pode-se observar que foram desprezadas as regiões com trajetórias de tensão do tipo compressão carregamento. Além disso, as distribuições típicas apresentadas consideraram que a região com trajetórias do tipo extensão carregamento situadas embaixo do fundo da 
vala se estendem com um ângulo de $45^{\circ}$ no interior do maciço em compressão descarregamento (ver Figura 4.20).

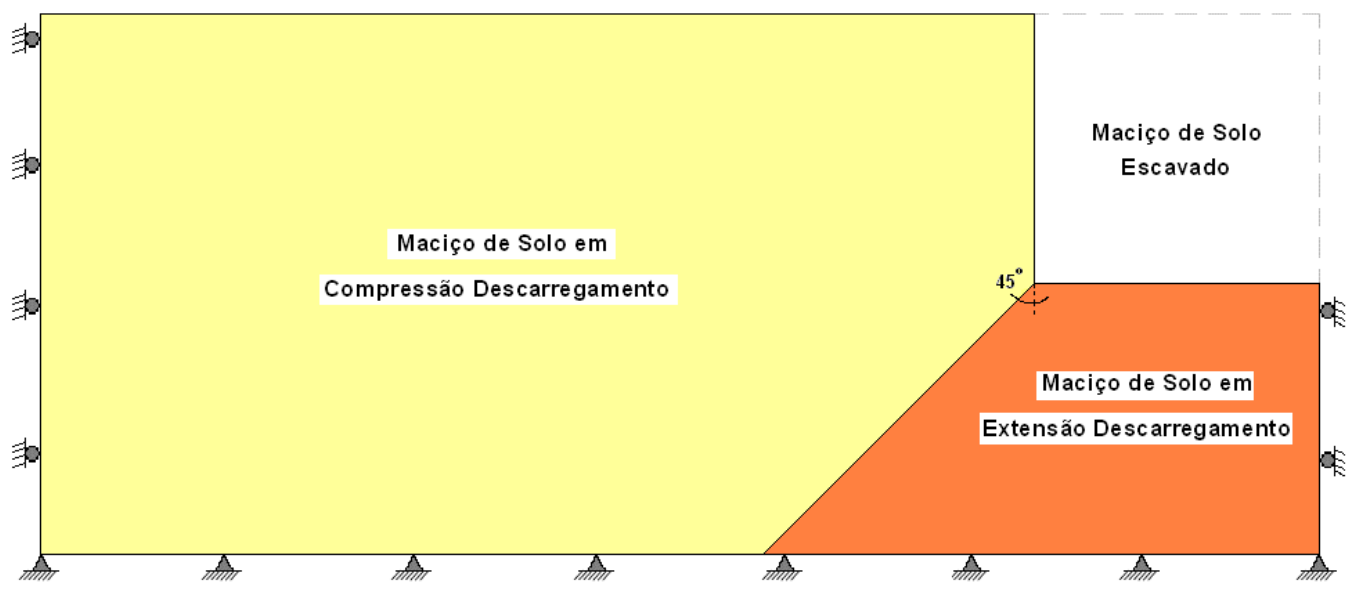

Figura 4.20 - Distribuição típica de trajetórias de tensão no maciço de solo ao redor da escavação.

Análises realizadas mediante elementos finitos por Eisenstein e Medeiros (1983), revelaram a existência de três diferentes regiões de trajetórias de tensão ao redor do maciço escavado (ver Figura 21), em resposta às alterações de tensões que sofre o mesmo, durante o processo próprio de escavação. O maciço de solo localizado detrás da parede de escavação (região A) não exibe mudanças significativas na tensão vertical, porém a tensão horizontal é reduzida devido ao desconfinamento lateral provocado (trajetória de tensão do tipo compressão por descarregamento). A região $B$, situada debaixo do fundo da escavação apresenta pequenas mudanças na tensão horizontal, no entanto, a tensão vertical sofre um alívio (trajetória de tensão do tipo extensão por descarregamento). Nas primeiras etapas da escavação a região $C$ sofre uma redução proporcional das tensões horizontal e vertical, seguido por uma alteração da tensão horizontal nas etapas seguintes da escavação; os autores observaram que a região $\mathrm{C}$ apresentou uma diminuição proporcional das tensões vertical e horizontal (segue a linha Ko) até um valor de $20 \%$ da tensão vertical, para depois continuar com uma trajetória de tensão do tipo compressão por descarregamento. 


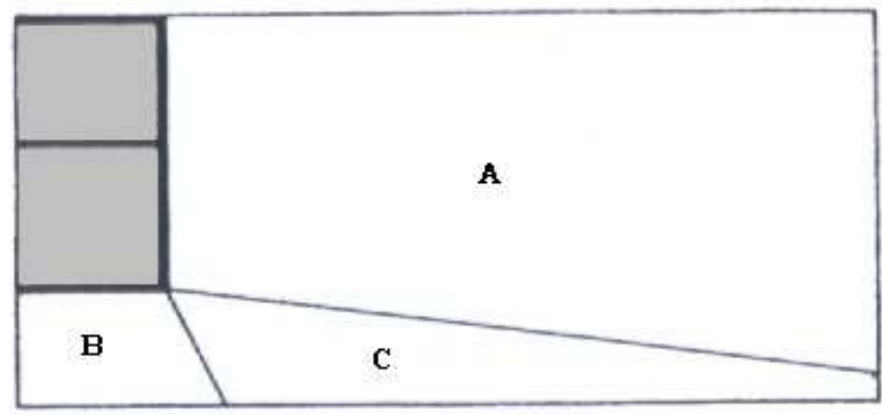

A

$\mathbf{B}$

C

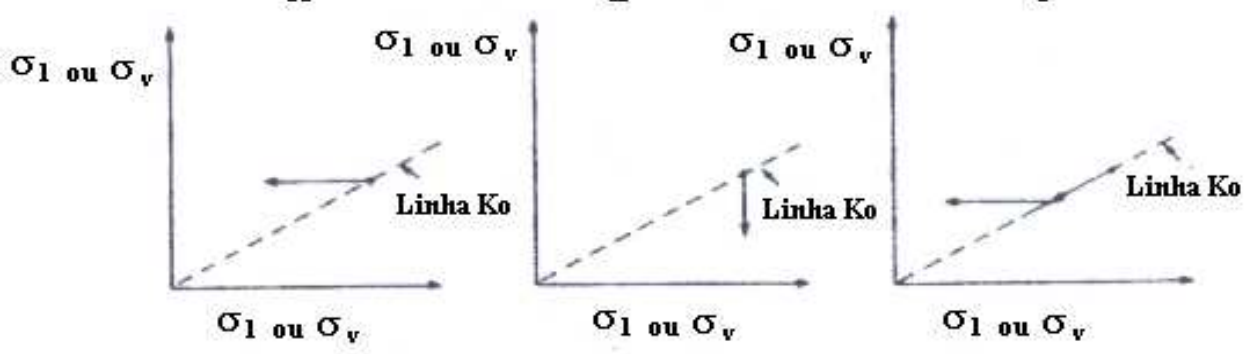

Figura 4.21 - Regiões de trajetórias de tensão ao redor da escavação (Eisenstein e Medeiros, 1983).

De acordo com os resultados obtidos nas análises numéricas das escavações na etapa final e intermediaria, a distribuição típica de trajetórias de tensão para o maciço ao redor da escavação é similar à apresentada por Eisenstein e Medeiros (1983).

\subsection{Influência da Variação do Coeficiente de Poisson}

Modelagens numéricas de escavações realizadas com a teoria da elasticidade seriam mais realistas se considerassem a influência da variação dos parâmetros $v$ e E. Para tal objetivo foram realizados dois estudos: no primeiro realizaram-se varias análises numéricas mantendo o mesmo módulo de elasticidade, mas com diferentes valores de $v$ em cada análise numérica; para o segundo estudo utilizaram-se diferentes valores de $\mathrm{E}$ e $v$ nas regiões de solo próximas à escavação, que seguem trajetórias de tensão do tipo compressão por descarregamento e extensão por descarregamento.

A geometria do modelo numérico utilizado está apresentada na figura 4.22. Nesta se pode observar que a largura da vala é de $10,5 \mathrm{~m}$, e a condição de contorno lateral da esquerda com a face escavada é de $42 \mathrm{~m}$. 


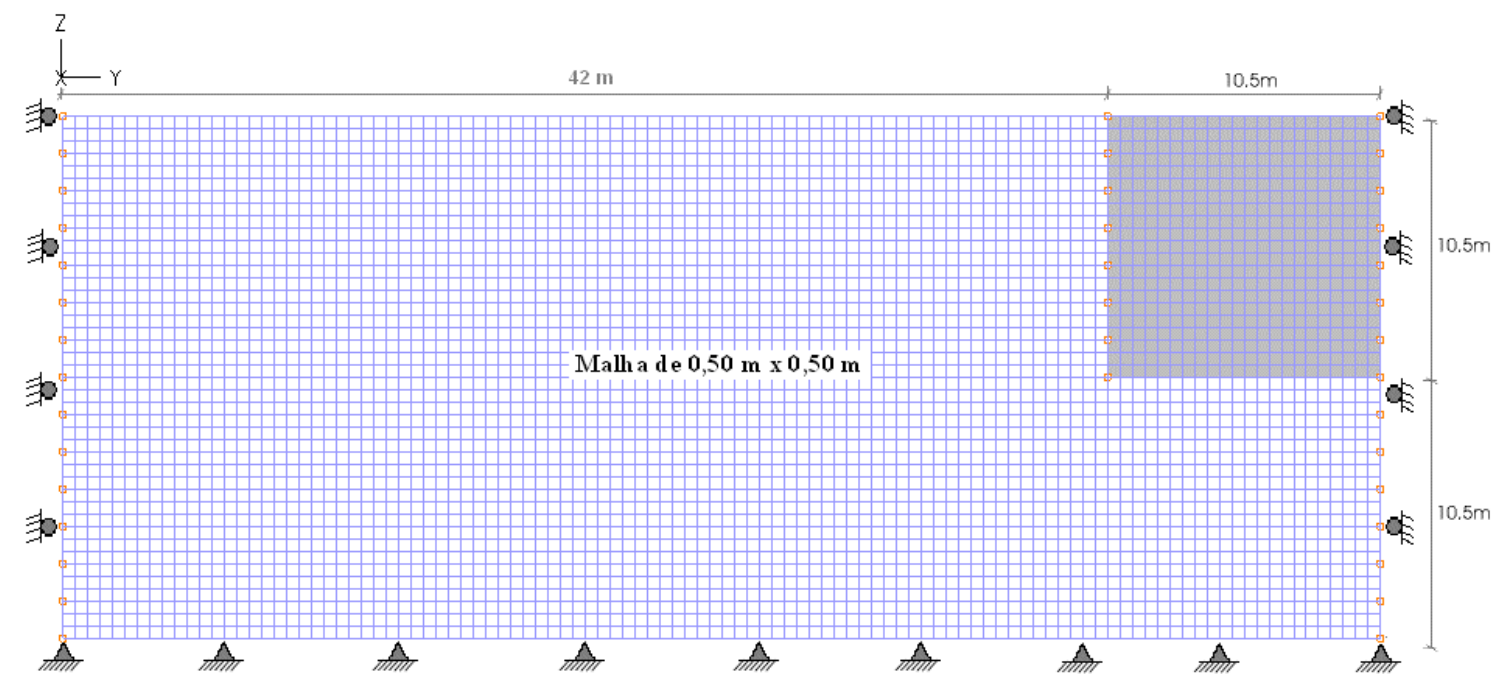

Figura 4.22 - Geometria e malha de elementos finitos utilizada.

Para o primeiro estudo utilizaram-se valores de $v$ variando entre 0.15 a 0.45 (correspondentes a diversos tipos de solo), apresentados por Bowles (1974). O módulo de elasticidade empregado no modelo foi de $45 \mathrm{MPa}$. Os resultados da influência de $v$ nos recalques superficiais podem ser observados na figura 4.23. Nota-se que para valores de Coeficiente de Poisson de até 0,30 , o ponto $B$ sofreu um levantamento. Porém, valores de Coeficiente de Poisson entre 0,35 a 0,45 apresentam valores de recalques, chegando a um valor máximo de $0,073 \%$ da altura de escavação com $v=0,45$, localizado a uma distância de sete metros do ponto $B$.

Os valores de deslocamentos horizontais apresentados na figura 4.24 monstraram que existe uma relação diretamente proporcional entre o valor de $v$ utilizado e valor do deslocamento horizontal obtido na análise numérica. Nessa Figura pode-se notar que com $v=0,45$, também obtiveram-se os máximos valores de deslocamento horizontal, no qual o ponto B atingiu um valor de $0,14 \%$ da altura de escavação. No entanto o máximo valor de deslocamento se encontra a uma profundidade de cinco metros, com um valor da ordem de $0,18 \%$ da altura escavada. 


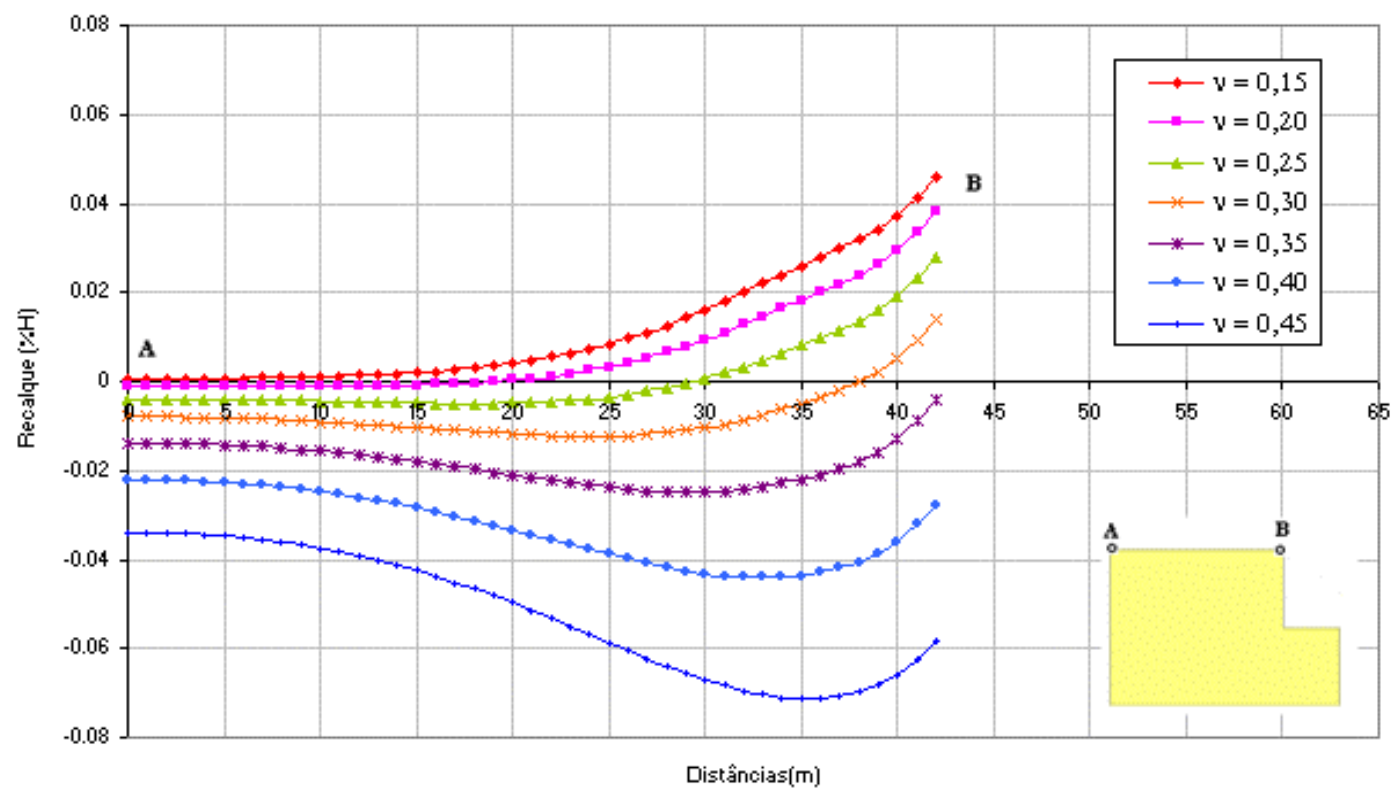

Figura 4.23 - Influência de $v$ nos deslocamentos verticais da superfície AB.

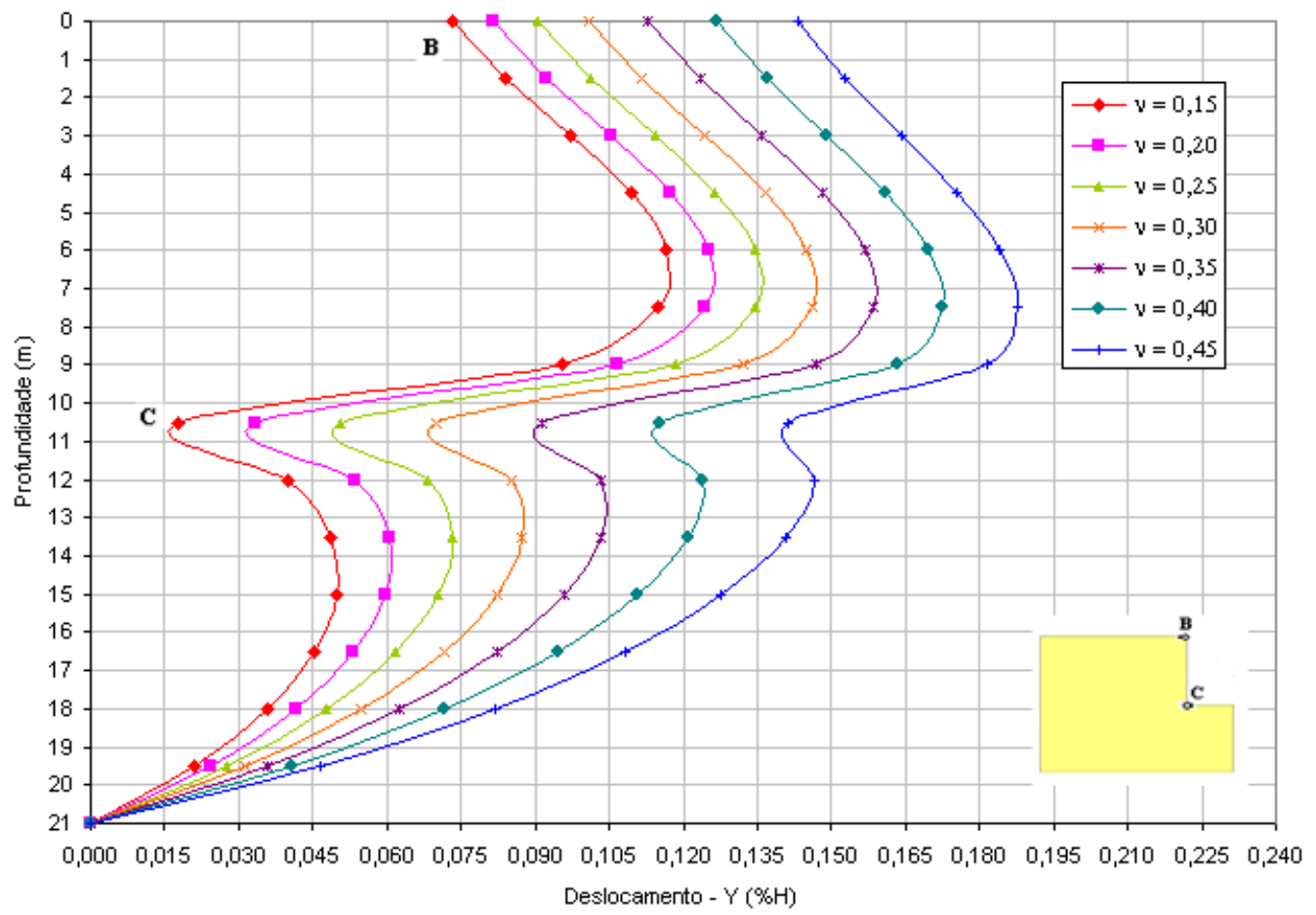

Figura 4.24 - Influência de $v$ nos deslocamentos horizontais da superfície BC.

Segundo os resultados das análises anteriores, pode-se concluir que tanto os recalques superficiais como os deslocamentos horizontais aumentam com 0 incremento do valor do coeficiente de Poisson.

No segundo estudo foi realizada uma comparação dos resultados obtidos em duas simulações numéricas, que se diferenciam principalmente por uma delas considerar 
a variação do $\mathrm{E}$ e $v$ em função do tipo de trajetória de tensão no maciço de solo, enquanto que a outra somente leva em consideração a variação do $E$ (ver Tabela 4.3).

Tabela 4.3 - Parâmetros utilizados nas modelagens numéricas.

\begin{tabular}{|l|l|c|c|}
\hline $\begin{array}{l}\text { Característica do } \\
\text { Modelo }\end{array}$ & $\begin{array}{c}\text { Trajetória no } \\
\text { Maciço de Solo }\end{array}$ & $\begin{array}{c}\text { Módulo de } \\
\text { Elasticidade }\end{array}$ & $\begin{array}{c}\text { Coeficiente } \\
\text { de Poisson }\end{array}$ \\
\hline $\begin{array}{l}\text { Mantendo-se } \\
\text { constante o v e }\end{array}$ & $\begin{array}{l}\text { Compressão } \\
\text { descarregamento }\end{array}$ & $30 \mathrm{MPa}$ & 0,30 \\
\cline { 2 - 4 } $\begin{array}{l}\text { variando o E em } \\
\text { cada trajetória }\end{array}$ & $\begin{array}{l}\text { Extensão } \\
\text { descarregamento }\end{array}$ & $90-\mathrm{MPa}$ & 0,30 \\
\hline $\begin{array}{l}\text { Variando-se o v } \\
\text { e E em cada } \\
\text { trajetória de } \\
\text { tensão }\end{array}$ & $\begin{array}{l}\text { Compressão } \\
\text { descarregamento }\end{array}$ & $30 \mathrm{MPa}$ & 0,45 \\
\cline { 2 - 4 } & $\begin{array}{l}\text { Extensão } \\
\text { descarregamento }\end{array}$ & $90 \mathrm{MPa}$ & 0,35 \\
\hline
\end{tabular}

A geometria do modelo numérico e o tipo de trajetória de tensão no maciço de solo ao redor da escavação, estão apresentadas na figura 4.25.

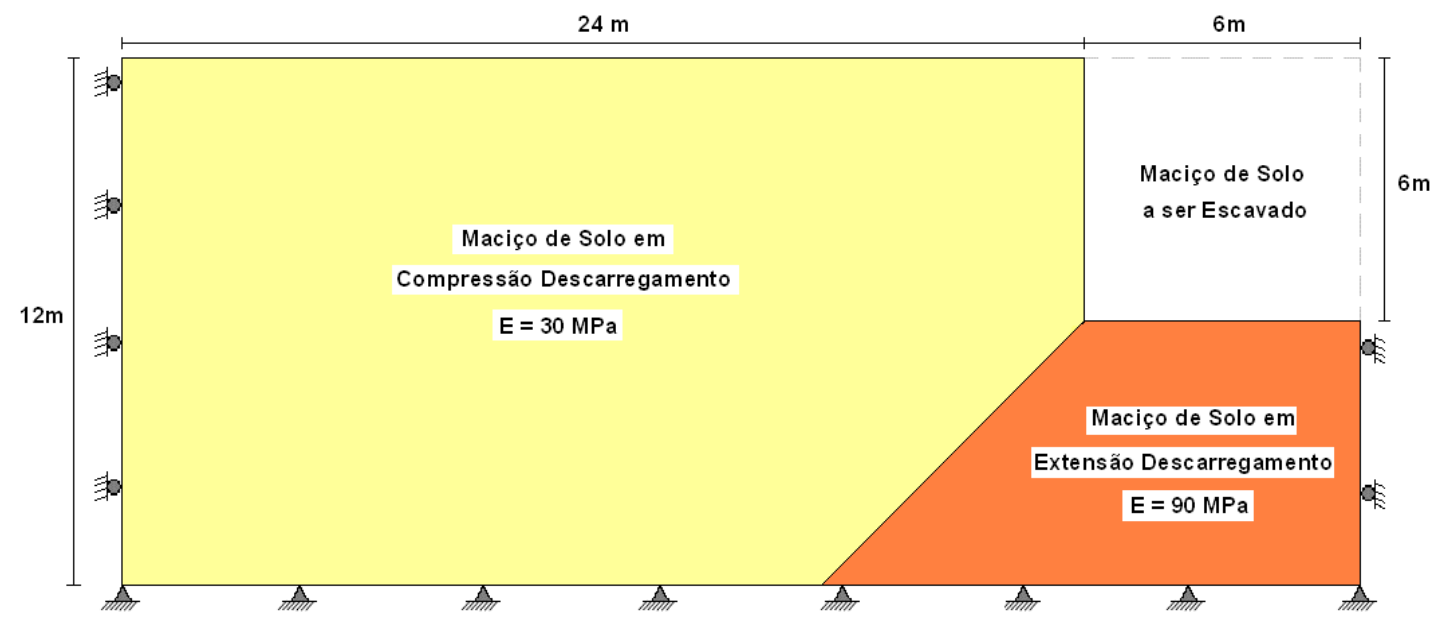

Figura 4.25 - Geometria e características do maciço de solo ao redor da escavação.

Nas figuras 4.26 e 4.27 pode-se observar a comparação realizada entre as duas modelagens numéricas. Nota-se que os deslocamentos horizontais não apresentam nenhum tipo de influência pela variação do v com a trajetória de tensão no maciço de solo. No entanto, os recalques mostraram uma influência considerável, pois na modelagem numérica que levou em conta a variação do $v$ com o tipo de trajetória de tensão se obteve maiores recalques do que a que manteve constante o valor de $v$. Os valores do recalque nos pontos A e B aumentaram aproximadamente em 3,5 e 2,35 vezes, respectivamente. 


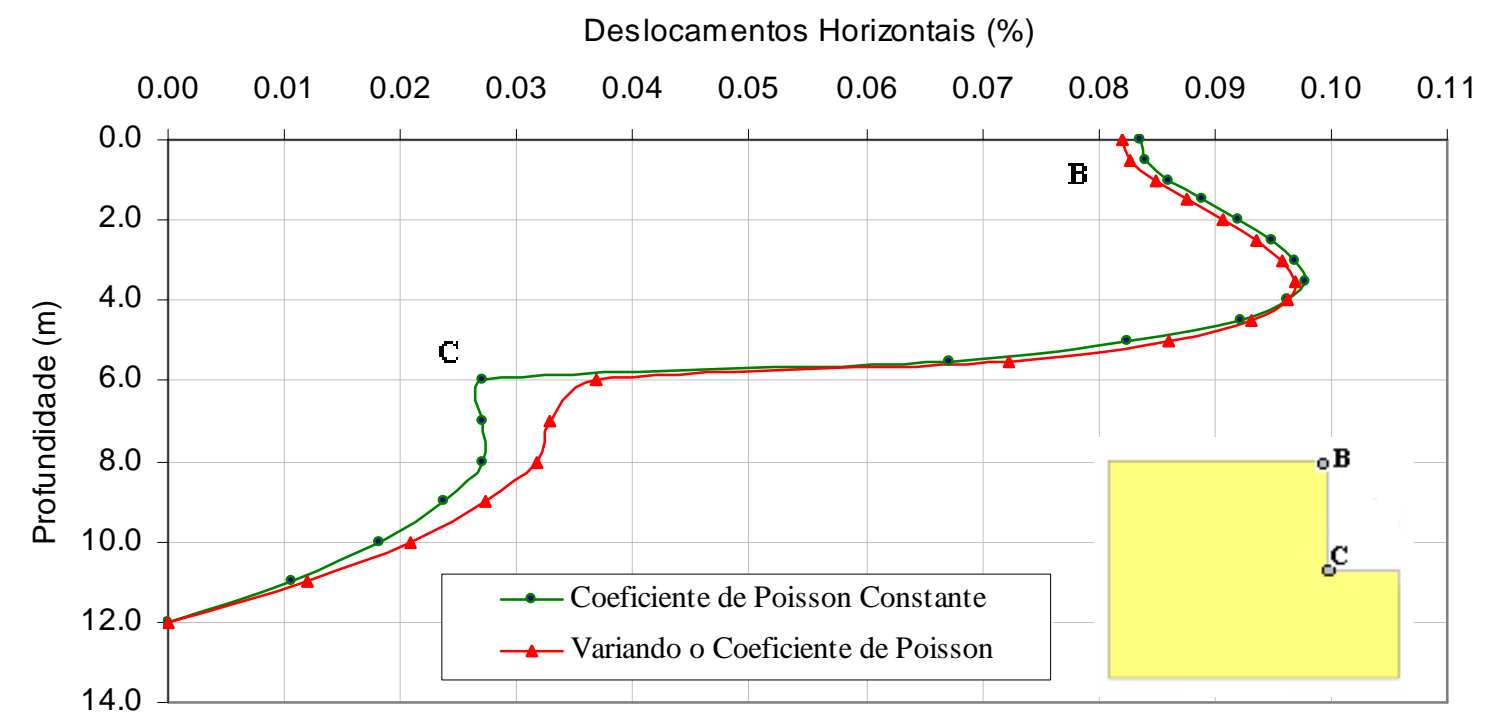

Figura 4.26 - Comparação dos resultados de deslocamentos horizontais na face BC.

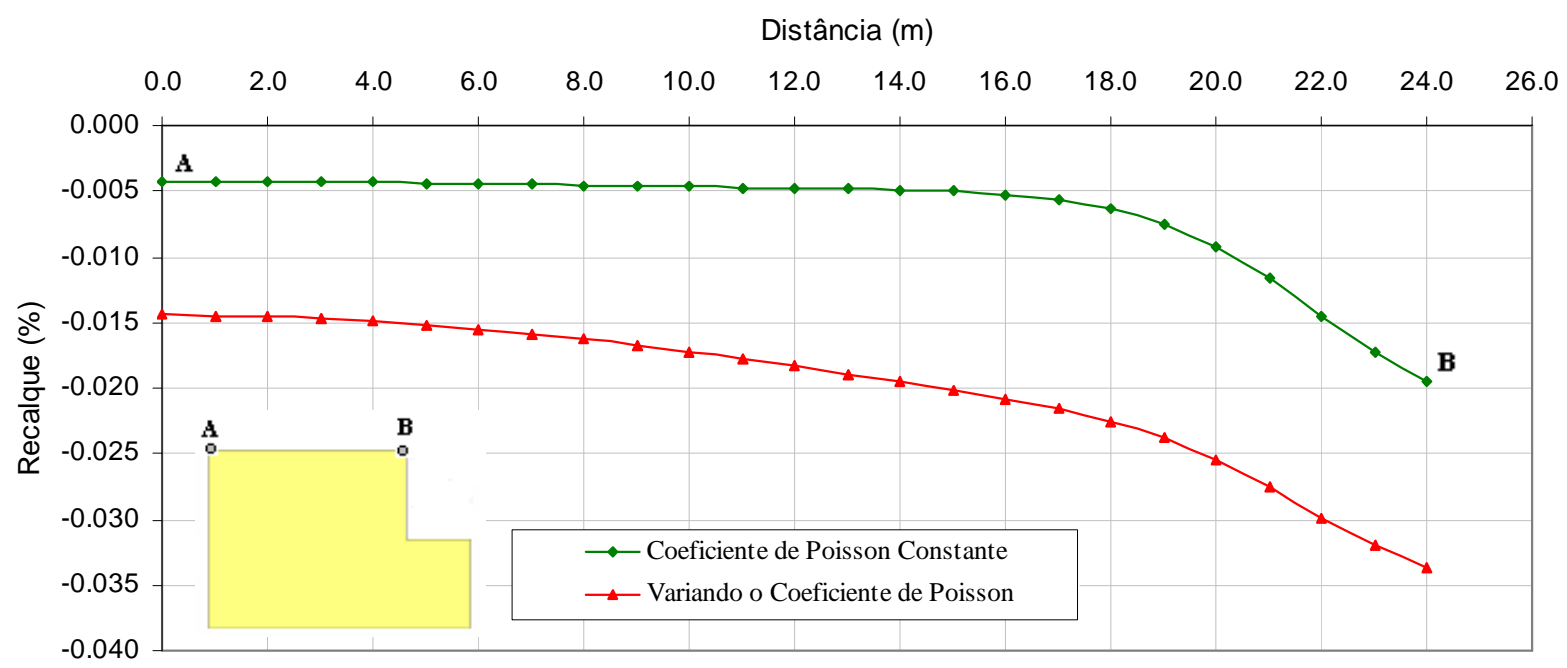

Figura 4.27 - Comparação dos resultados de recalques na superfície AB.

De acordo com os resultados apresentados, acredita-se que existe uma forte influência do valor do Coeficiente de Poisson utilizado nas modelagens numéricas. Portanto, recomenda-se realizar um estudo aprofundado sobre a variação do Coeficiente de Poisson com o tipo de trajetória de tensão que sofre o solo, e a influência dessa variação nos resultados de modelagens numéricas de escavações a céu aberto.

\section{Capitulo 5 - ESTUDO DE CASOS}




\subsection{Introdução}

Neste capitulo são apresentados dois casos de estudo. O primeiro caso contempla uma comparação entre resultados de análises numéricas bidimensionais e tridimensionais de uma escavação grampeada, para a qual foi utilizado um modelo constitutivo elástico-linear para simular o comportamento do maciço. O segundo caso trata sobre uma comparação de resultados obtidos em uma modelagem tridimensional da escavação grampeada, utilizando a teoria da elasticidade, com registros de campo obtidos mediante instrumentação e análises numéricas tridimensionais que utilizaram o modelo hiperbólico como lei constitutiva para solo.

Os casos estudo analisados foram realizados com ajuda do programa computacional de elementos finitos ADINA.

\subsection{Caso Hipotético - Escavação Grampeada de Lima et. al (2002)}

Um dos exemplos de modelagem numérica bastante conhecido na bibliografia técnica é o caso analisado por Springer (2001), Lima et. al. (2002) e Gerscovich et. al (2005). Este exemplo também foi utilizado para comparar os resultados de modelagens bidimensionais e tridimensionais, que consideraram a aplicação da teoria da elasticidade para representar o comportamento do solo ${ }^{17}$ (considerando a variação do módulo de elasticidade em função do tipo de trajetória de tensão no solo), com os resultados obtidos por Lima et. al $(2002)^{18}$ em uma análise numérica bidimensional, que utilizou um modelo elasto-plástico com critério de ruptura de Mohr-Coulomb para simular o comportamento do maciço.

\footnotetext{
${ }^{17}$ É importante ressaltar que as modelagens numéricas feitas por Springer et. al (2001), Lima et. al (2002) e Gerscovich et. al (2005) consideraram um modelo constitutivo elasto-plástico com critério de ruptura do tipo Mohr-Coulomb.

${ }^{18}$ No capitulo 3 do presente trabalho apresentou-se um resumo do trabalho por Lima et. al (2002).
} 
A escavação grampeada apresenta uma altura de $10,5 \mathrm{~m}$, realizada em sete etapas de escavação (cada etapa com 1,5m de altura), sendo que em cada uma destas foram colocados grampos e paramentos de concreto projetado. Os grampos apresentam um comprimento de $6 \mathrm{~m}$, e são compostos por uma barra de aço de $25 \mathrm{~mm}$ de diâmetro e calda de cimento injetada em furos de $75 \mathrm{~mm}$ de diâmetro. Todos os grampos foram instalados com espaçamento horizontal e vertical igual a $1,5 \mathrm{~m}$, e com inclinação de $10^{\circ} \mathrm{com}$ a horizontal. O paramento de concreto projetado apresenta uma espessura de $100 \mathrm{~mm}$. A tabela 5.1 mostra os parâmetros utilizados para cada material empregado na modelagem numérica. Segundo Lima et. al (2002), o fator de segurança obtido para a configuração do sistema de reforço da escavação é igual a 1,05.

Tabela 5.1 - Parâmetros utilizados na modelagem numérica.

\begin{tabular}{|c|c|c|}
\hline Material & Parâmetro & Magnitude \\
\hline Solo & $\begin{array}{l}\text { Peso específico natural } \\
\text { Coeficiente de empuxo em repouso } \\
\text { Modulo de elasticidade em compressẫo descarregamento } \\
\text { Modulo de elasticidade em extensẫo descarregamento } \\
\text { Coeficiente de Poisson }\end{array}$ & $\begin{array}{l}y=18,50 \mathrm{kN} / \mathrm{m}^{3} \\
\mathrm{~K}_{0}=0,5 \\
\mathrm{E}_{\mathrm{CD}}=45 \mathrm{MPa} \\
\mathrm{E}_{\mathrm{ED}}=135 \mathrm{MPa} \\
v=0.25\end{array}$ \\
\hline Grampos & $\begin{array}{l}\text { Tensão de escoamento } \\
\text { Modulo de elasticidade } \\
\text { Diàmetro da barra } \\
\text { Espaçamento vertical } \\
\text { Espaçamento horizontal } \\
\text { Comprimento }\end{array}$ & $\begin{array}{l}\sigma_{\mathrm{y}}=500 \mathrm{MPa} \\
\mathrm{E}=205 \mathrm{GPa} \\
\mathrm{d}=25 \mathrm{~mm} \\
\mathrm{~S}_{\mathrm{v}}=1,5 \mathrm{~m} \\
\mathrm{~S}_{\mathrm{h}}=1,5 \mathrm{~m} \\
\mathrm{~L}=6,0 \mathrm{~m}\end{array}$ \\
\hline $\begin{array}{c}\text { Parede de concreto } \\
\text { projetado }\end{array}$ & Modulo de elasticidade & $\mathrm{E}=24 \mathrm{GPa}$ \\
\hline
\end{tabular}

As modelagens numéricas bidimensional e tridimensional mantiveram a geometria do modelo original, a figura 5.1 ilustra a geometria do modelo e as condições de contorno empregadas nas modelagens numéricas. No caso do modelo tridimensional se utilizou como espessura da fatia da parede de solo grampeado a metade do espaçamento horizontal entre grampos 


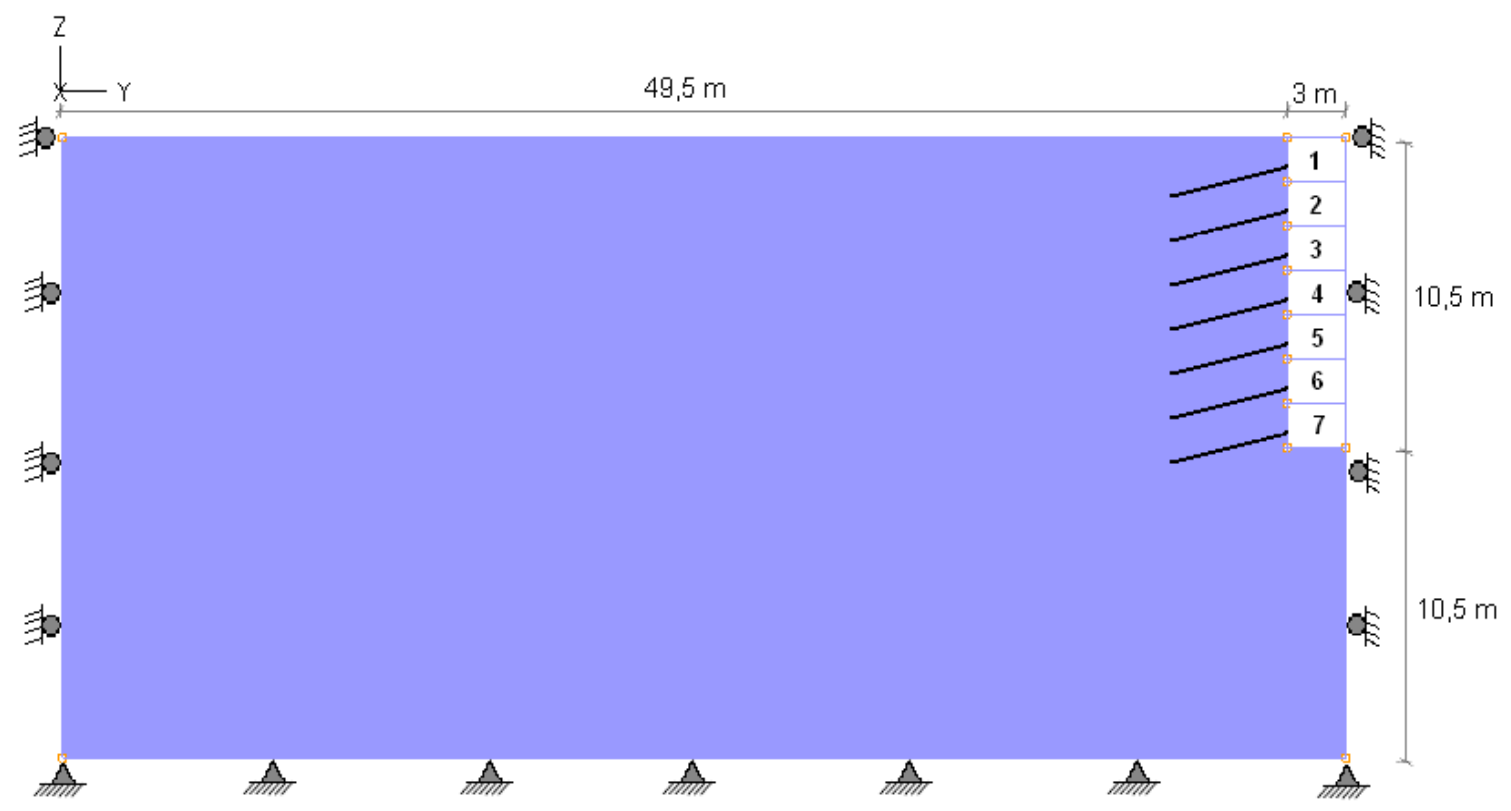

Figura 5.1 - Geometria do modelo e condições de contorno utilizadas na modelagem numérica tridimensional.

As tensões iniciais no maciço de solo foram geradas antes mesmo de iniciar o processo de escavação no maciço, admitindo-se que o contorno inferior esteja impedido de se movimentar em qualquer direção, e os contornos laterais impedidos de se movimentar nas direções $Y$ e $X$, mas permitindo a movimentação na direção $Z$. O campo de tensões iniciais foi imposto mediante a utilização do coeficiente de empuxo em repouso. Na figura 5.2 ilustram-se os campos de tensões iniciais no maciço de solo nas direções $Z, Y$ e $X$. 


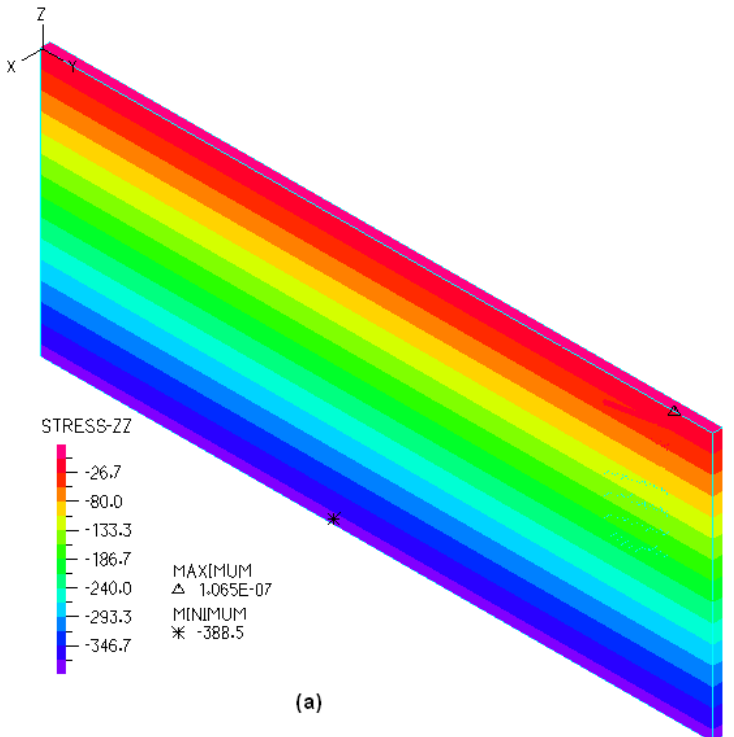

(a)
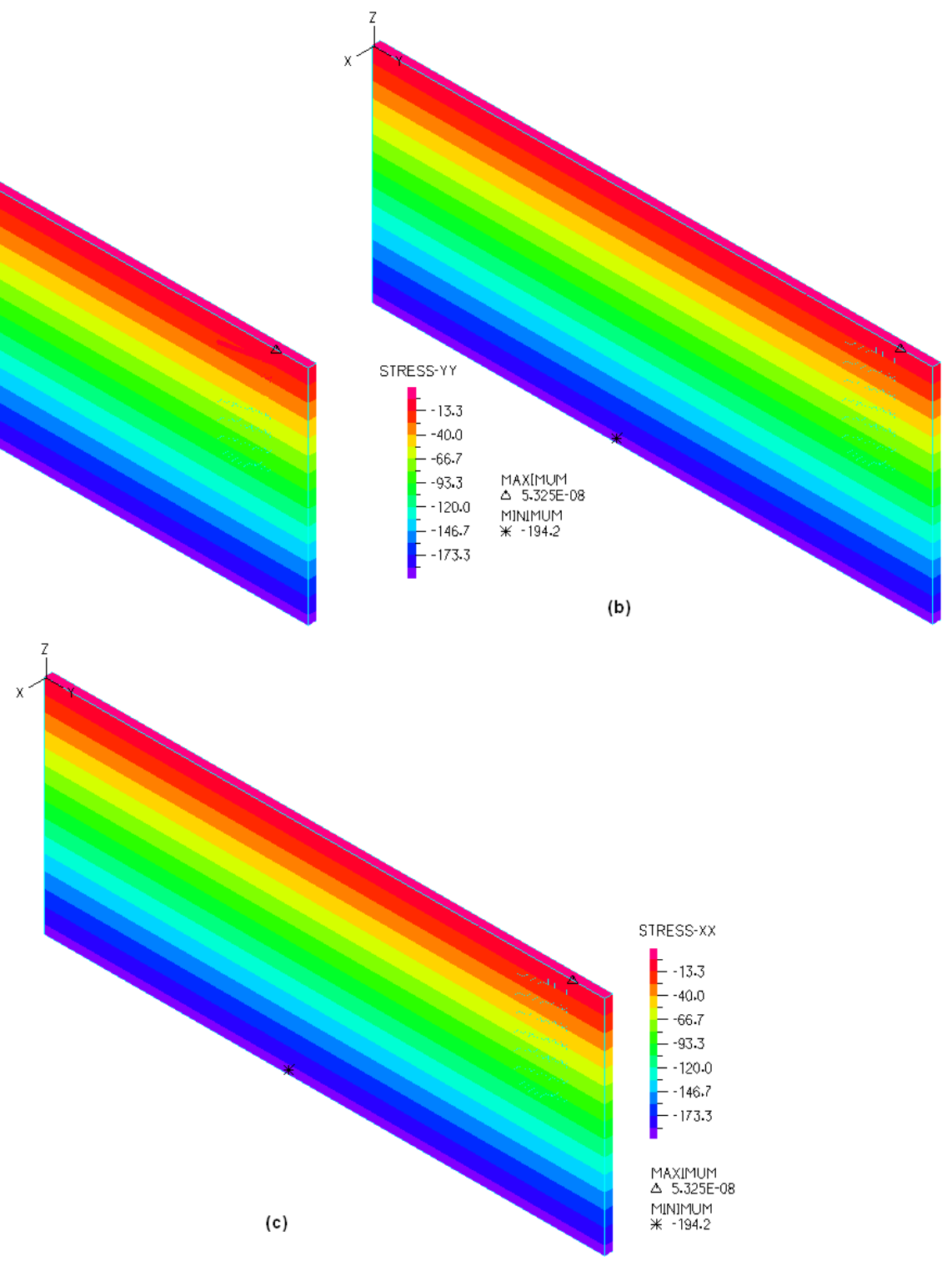

Figura 5.2 -Campos de tensões inicias do modelo tridimensional: (a) direção z; (b) direção y; (c) direção $x$.

$\mathrm{Na}$ realização do processamento computacional o comportamento do solo foi simulado através de varias etapas, com o módulo de elasticidade mudando sucessivamente em cada etapa. Para cada etapa do processamento o maciço de solo ao redor da escavação foi subdividido em diversas regiões, nas quais os parâmetros elásticos foram modificados em função da trajetória tensão em cada etapa da escavação (ver Figura 5.3). 


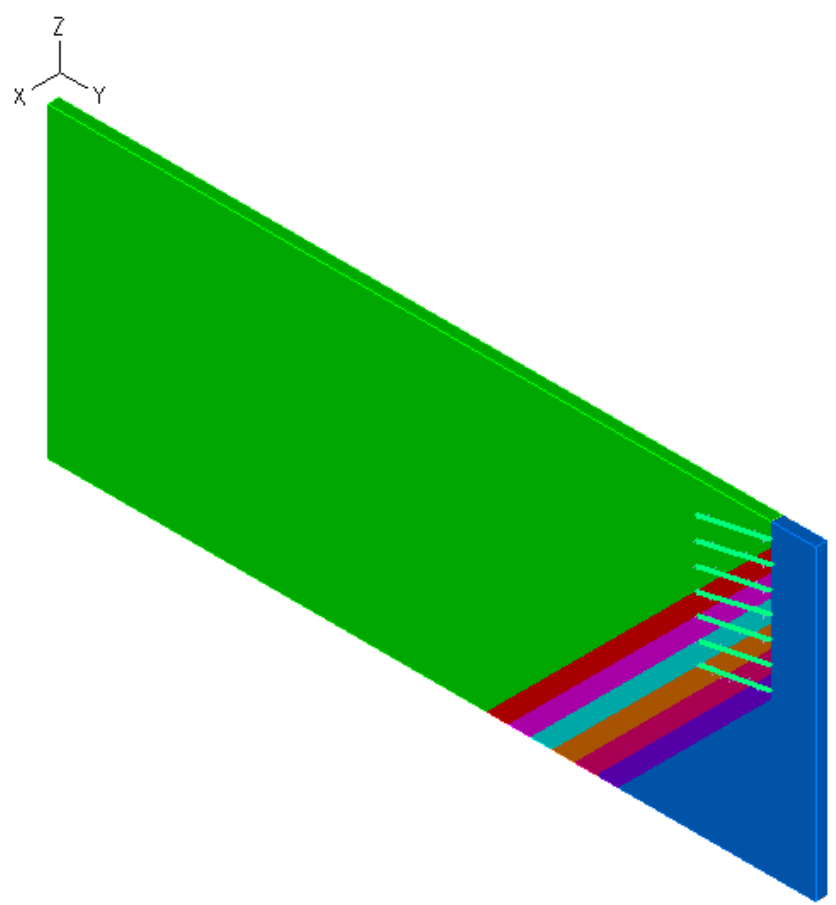

Figura 5.3 -Divisão do modelo tridimensional em regiões para modificação dos parâmetros elásticos durante o processamento computacional.

Os resultados obtidos com a análise numérica tridimensional permitem conhecer a configuração da estrutura depois de sofrer a deformação. A Figura 5.4 ilustra a deformada da estrutura na etapa final da escavação. Nesta Figura é possível observar as deformações da parede de escavação e do fundo da vala deformados e aumentados em 1000 vezes seu valor.

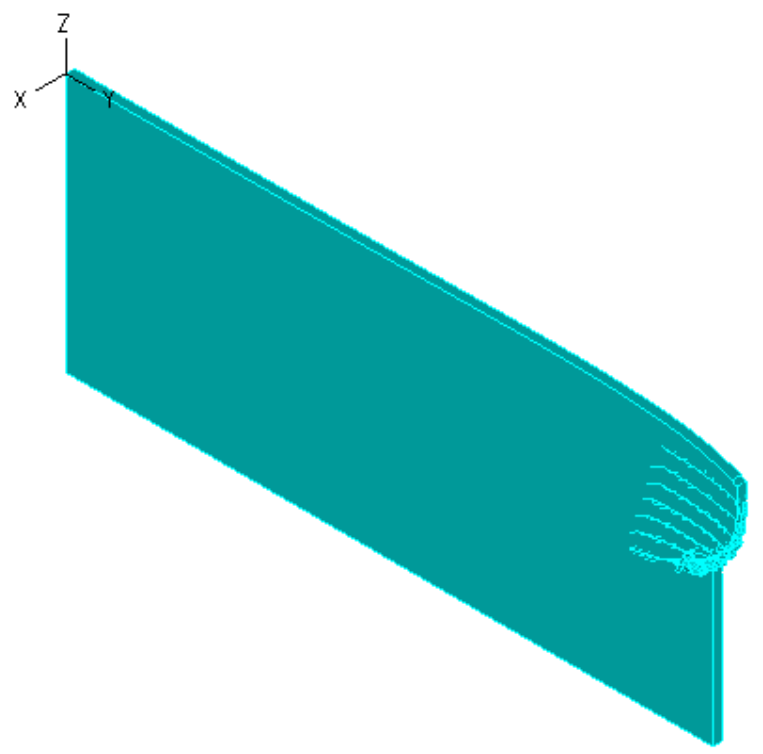

Figura 5.4 - Aspecto do modelo tridimensional deformada na última etapa de escavação. 
O campo de deslocamentos horizontais no maciço de solo na última etapa de escavação, provocada pelo desconfinamento lateral no processo da escavação (ver Figura 5.5). Nota-se que os maiores deslocamentos ocorrem no topo do talude escavado. Na mesma Figura pode-se observar, também, que os deslocamentos horizontais diminuem com a profundidade. Nota-se que o campo de deslocamentos horizontais apresentam cunhas de deslizamento, semelhantes à cunha do empuxo ativo de Rankine.

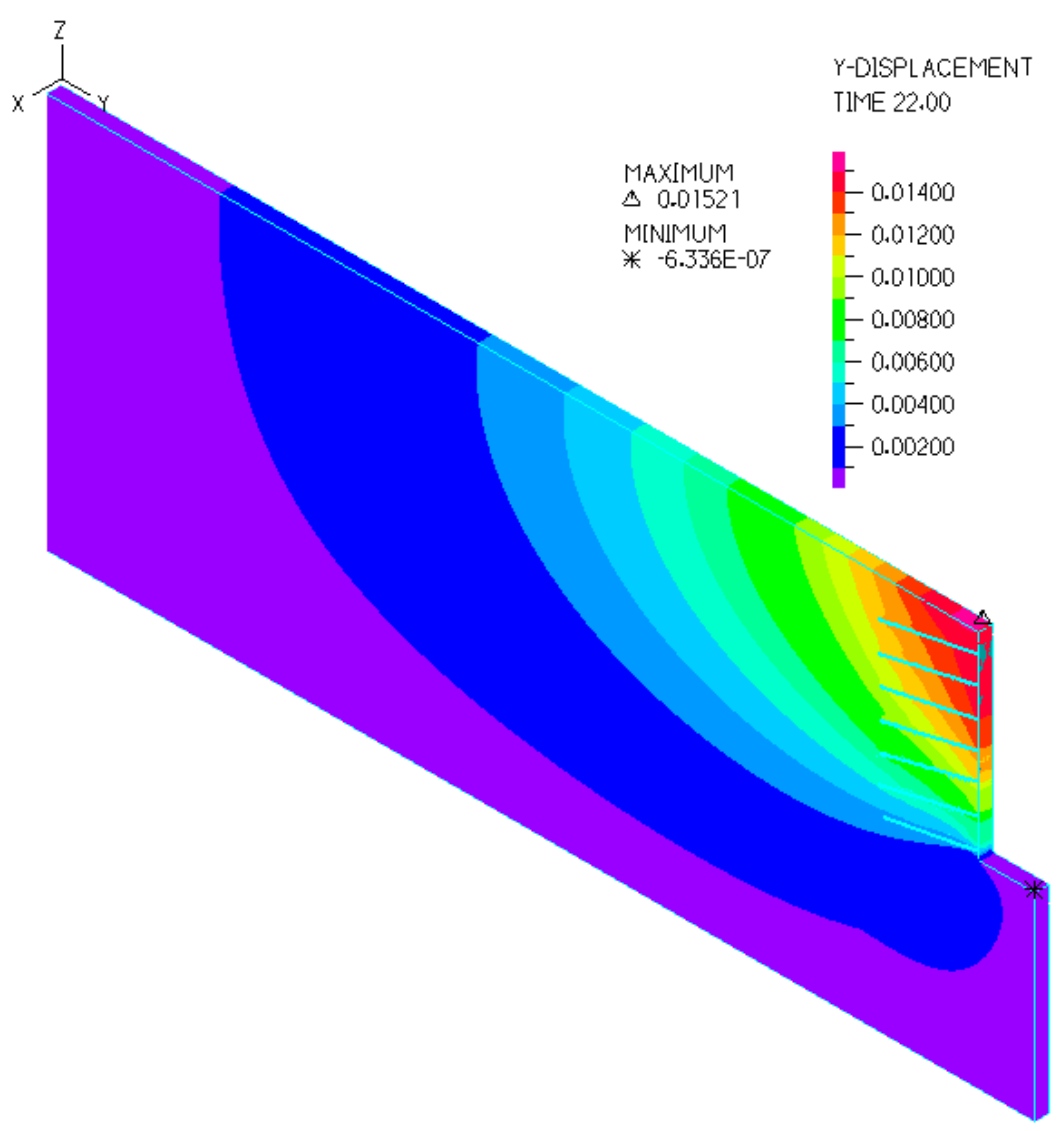

Figura 5.5 - Campo de deslocamentos horizontais obtidos no modelo 3D.

Na figura 5.6 ilustra-se o campo de deslocamentos verticais no maciço de solo na última etapa da escavação, na qual consegue-se notar que os valores máximos de deslocamento horizontal estão localizados no topo do talude escavado, sendo que estes também diminuem com a profundidade. Na mesma figura pode-se observar também, os deslocamentos verticais que ocorrem no fundo da vala, devidos ao alivio de tensões no solo durante as etapas de escavação. 


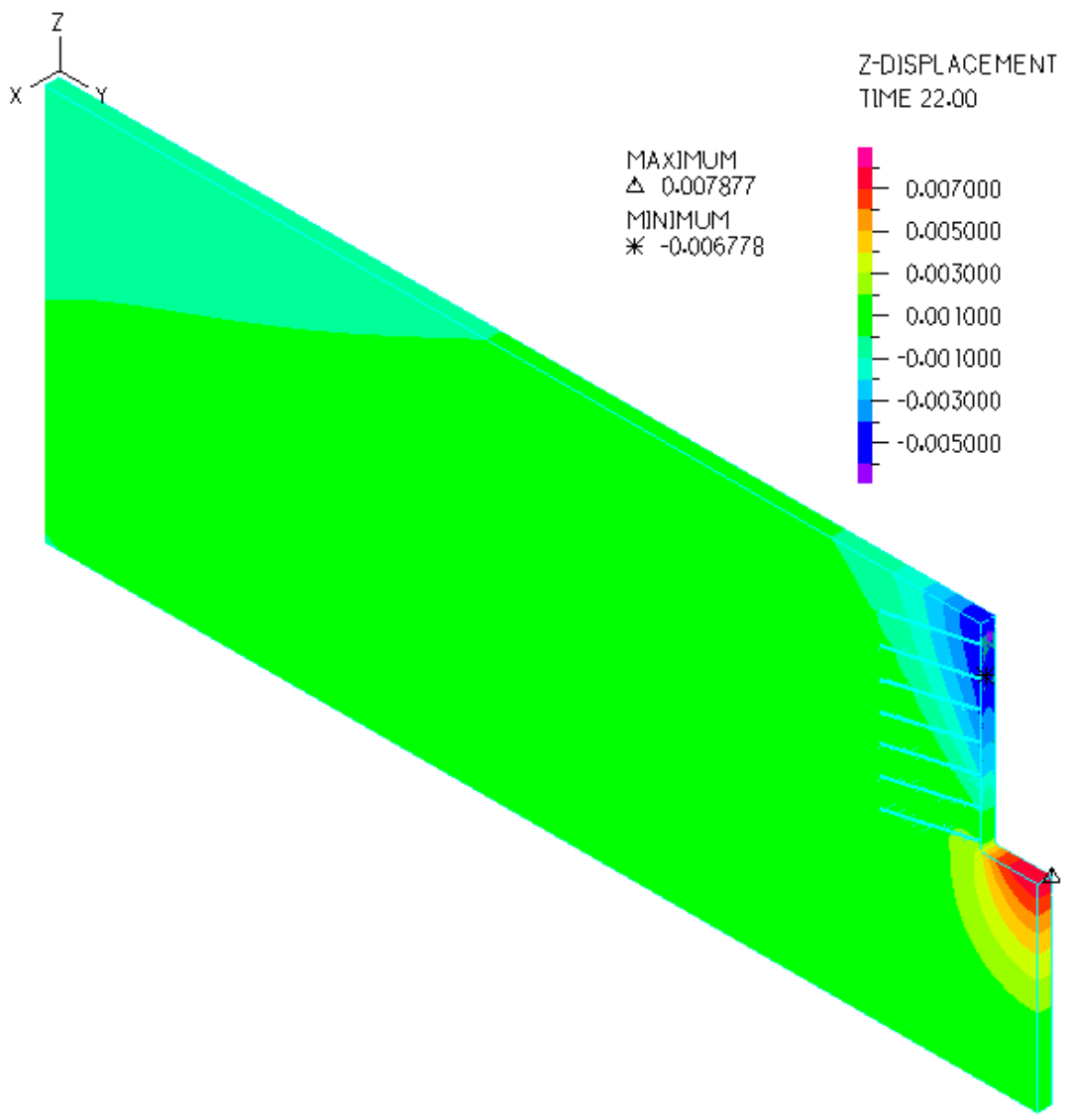

Figura 5.6 - Campo de deslocamentos verticais obtidos no modelo 3D.

Utilizando-se a mesma malha e a mesma configuração geométrica, realizaram-se também, modelagens numéricas bidimensionais com o objetivo de comparar resultados de modelos bidimensionais com tridimensionais. As figuras 5.7 e 5.8 mostram os campos de deslocamentos verticais e horizontais respectivamente.

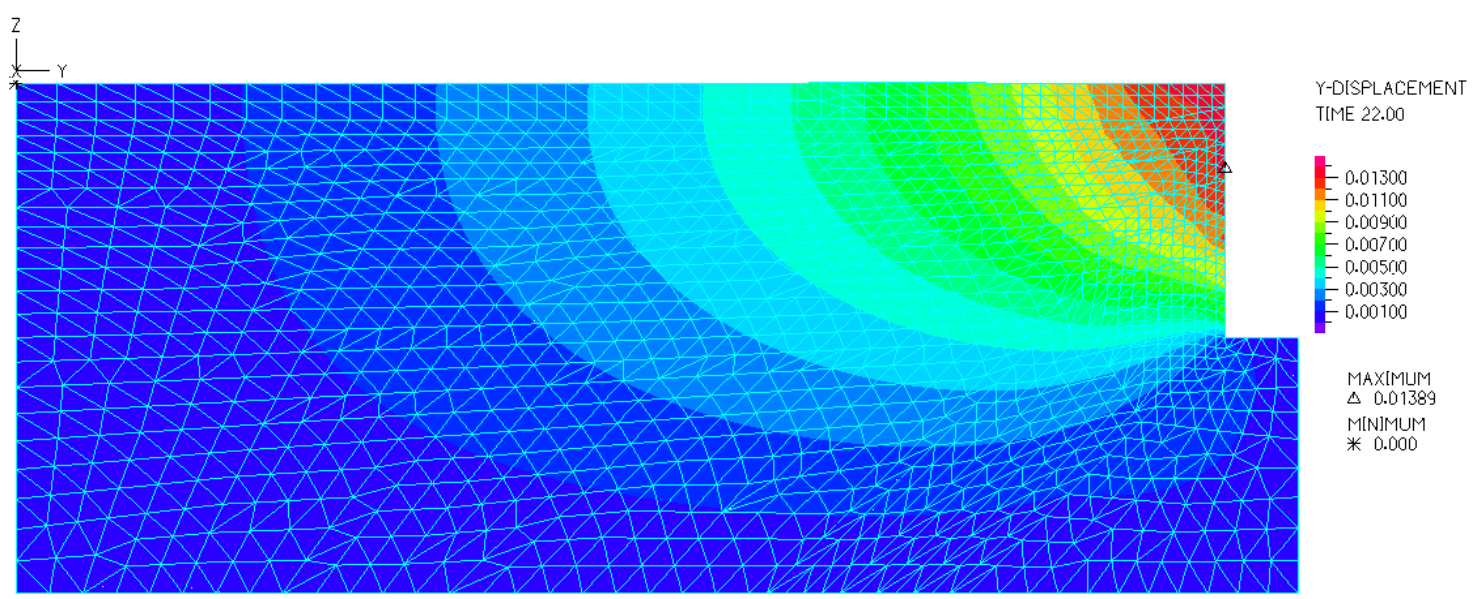

Figura 5.7 - Distribuição dos deslocamentos verticais obtidos no modelo 2D. 


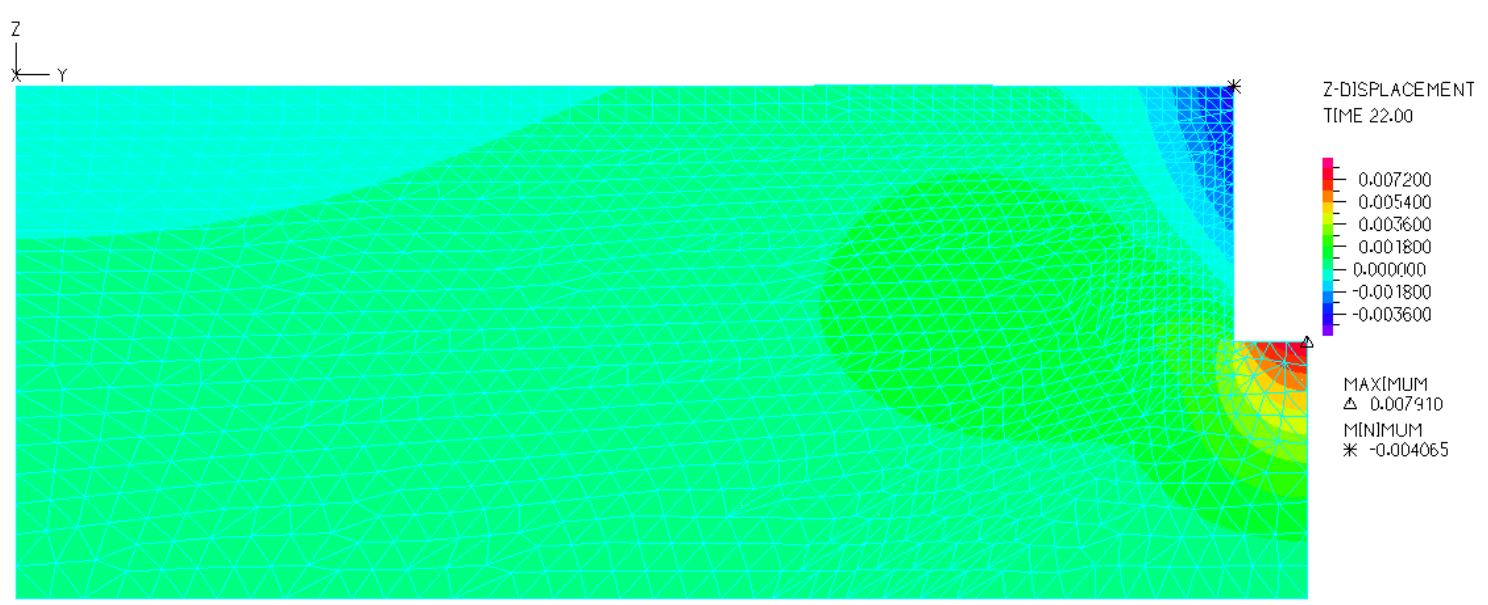

Figura 5.8 - Distribuição dos deslocamentos verticais obtidos no modelo 2D.

A comparação dos perfis de deslocamento horizontal, localizados a $1 \mathrm{~m}$ da parede da escavação nas modelagens numéricas: bidimensional, tridimensional e trabalho elaborado por Lima et. al (2002), está apresentada na figura 5.9. Nesta pode-se notar que os deslocamentos obtidos na modelagem numérica tridimensional são menores do que os encontrados por Lima et. al (2002). Acredita-se que esta diferença é causada por diversos fatores, sendo que os mais importantes são os seguintes: (1) utilização de diferentes tipos de modelos constitutivos, pois o modelo tridimensional empregou um modelo elástico-linear, enquanto que no exemplo de Lima et. al (2002) foi feito uso de um modelo elasto-plástico, delimitado pelo critério de ruptura de Mohr-Coulomb; (2) configuração geométrica das malhas adotadas nas análises $^{19}$; (3) hipóteses simplificadoras utilizadas em modelagens numéricas bidimensionais adotadas para problemas tridimensionais, no caso estudado por Lima et. al (2002); (4) diferenças na forma de representar o contato solo-grampo nas duas modelagens numéricas. Nessa Figura observa-se, também, que os valores de deslocamento horizontal (nos seis primeiros metros de profundidade de escavação) obtidos na modelagem tridimensional são maiores do que os encontrados na modelagem bidimensional, acredita-se que esta diferença é causada principalmente inadequada forma de representar os grampos em modelos bidimensionais, pois nesta condição o grampos é representado como uma laje, o que não é real, pois deveria ser considerado como um elemento unidimensional ${ }^{20}$.

\footnotetext{
${ }^{19}$ É importante comentar que na modelagem tridimensional foi utilizado o método dos elementos finitos, enquanto que a modelagem de Lima et. al (2002) empregou o método das diferenças finitas.

${ }^{20}$ A consideração do grampo como elemento unidimensional é valida somente para modelagens numéricas, pois se conhece que na realidade é um elemento sólido.
} 
Deslocamento Horizontal $(\% \mathrm{H})$

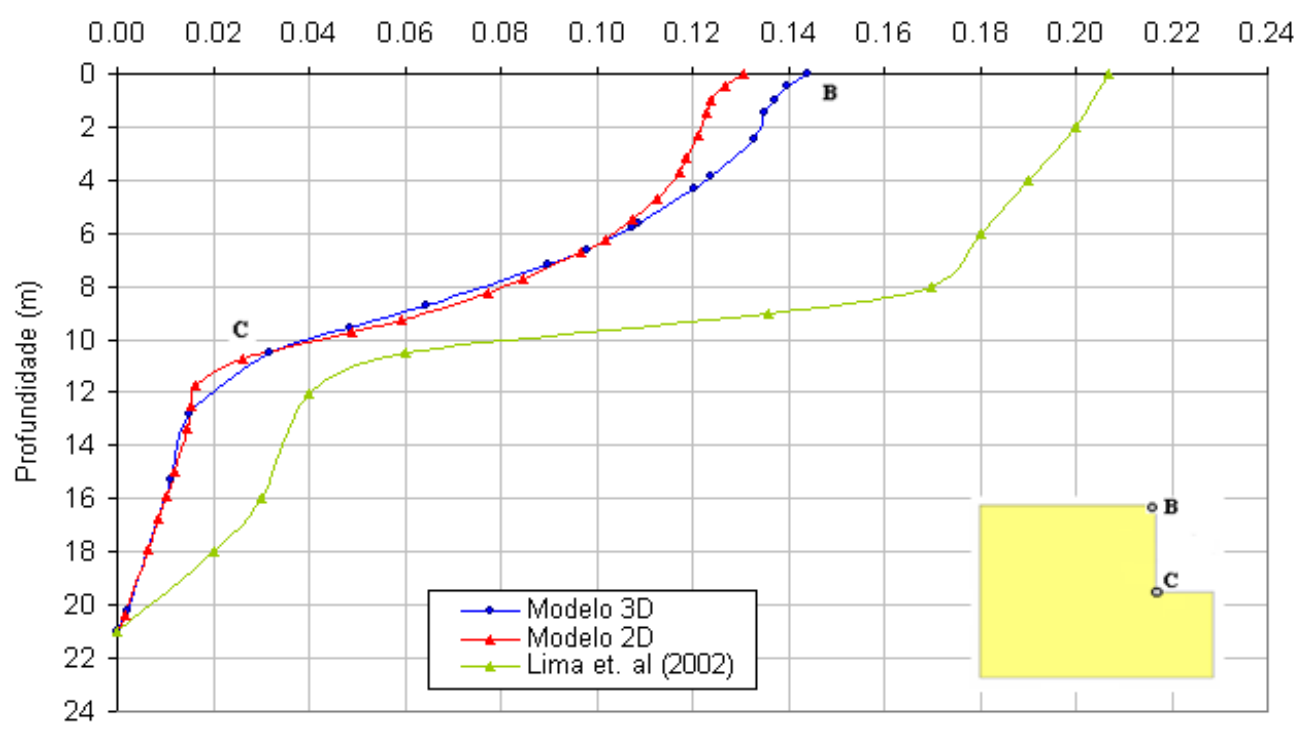

Figura 5.9 - Comparação dos perfis de deslocamentos horizontais obtidos no modelo 3D e no trabalho realizado por Lima et. al (2002).

Muito inobstante ao fato dos fatores terem influenciado os resultados de deslocamento horizontal, os valores do recalque no ponto B mostraram-se semelhantes (ver Figura 5.10). Contudo, os perfis de deslocamentos verticais obtidos nas modelagens numéricas bidimensionais e tridimensionais não apresentam semelhança geométrica com a curva encontrada por Lima et. al (2002).

Distância (m)

$\begin{array}{lllllllllllllllllllllllllll}0 & 2 & 4 & 6 & 8 & 10 & 12 & 14 & 16 & 18 & 20 & 22 & 24 & 26 & 28 & 30 & 32 & 34 & 36 & 38 & 40 & 42 & 44 & 46 & 48 & 50 & 52\end{array}$

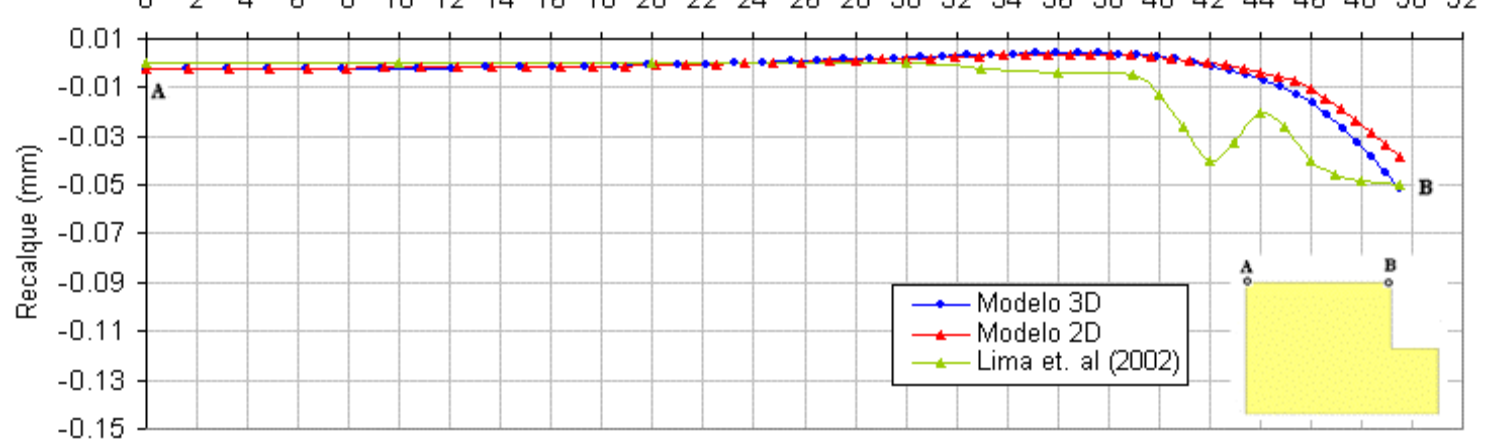

Figura 5.10 - Comparação dos perfis de recalques obtidos no modelo 3D e no trabalho realizado por Lima et. al (2002). 


\subsection{Caso da Escavação Instrumentada pelo Programa de Estudo Davis}

A modelagem numérica realizada neste item versa sobre uma descrição e comparação dos resultados obtidos mediante ${ }^{21}:$ (1) monitoração da escavação grampeada estudada por Shen et. al (1981); (2) modelagens numéricas tridimensionais realizadas por Zhang et. al (1999); (3) modelagens numéricas tridimensionais que aplicam a teoria da elasticidade, realizadas no presente trabalho. Os dois últimos itens representam uma tentativa de simular mediante elementos finitos, o comportamento da estrutura registrado em campo.

O programa de estudo Davis ${ }^{22}$ realizou a construção de um modelo físico a escala natural de uma escavação grampeada em talude vertical, com a finalidade de compreender o comportamento da técnica de solo grampeado como sistema de contenção de taludes escavados. Para tal objetivo, os autores realizaram a instrumentação do talude escavado com: inclinômetros ao longo do eixo central da escavação, registrando-se dessa forma os perfis de deslocamentos horizontais antes e depois de cada fase de escavação. Também foram instalados marcos superficiais e Strain Gauges para monitorar os recalques ao longo da crista do talude e determinar a distribuição de forças axiais em cada grampo, respectivamente.

O perfil típico de solo determinado mediante as sondagens está mostrado na figura 5.11a, na qual pode-se observar que o mesmo é muito variável. Shen et. al (1981) realizaram ensaios triaxiais $C D{ }^{23}$ de compressão por carregamento, em amostras representativas, na condição não drenada, os quais foram realizados para determinar a resistência ao cisalhamento dos diversos tipos de solos encontrados (ver Figura 5.11b).

\footnotetext{
${ }^{21}$ Para um melhor entendimento do caso de estudo, recomenda-se revisar os resumos dos trabalhos por Shen et. al (1981) e Zhang et. al (1999) apresentados no capitulo 3.

22 O Programa de Estudo Davis foi desenvolvido no ano 1979, no Campus Davis da Universidade de Califórnia, com uma duração de aproximadamente 3 anos.

${ }^{23}$ Para este caso deve-se entender CD como um ensaio triaxial realizado na condição adensada não drenada.
} 


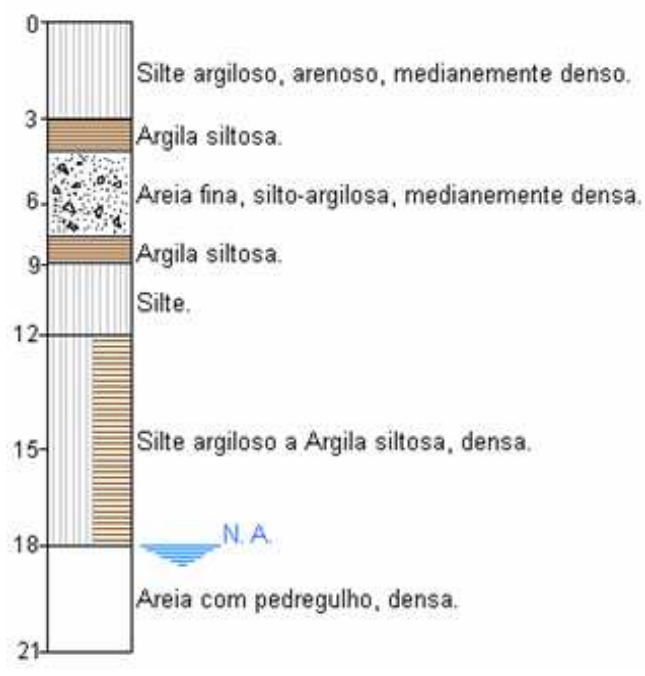

(a)

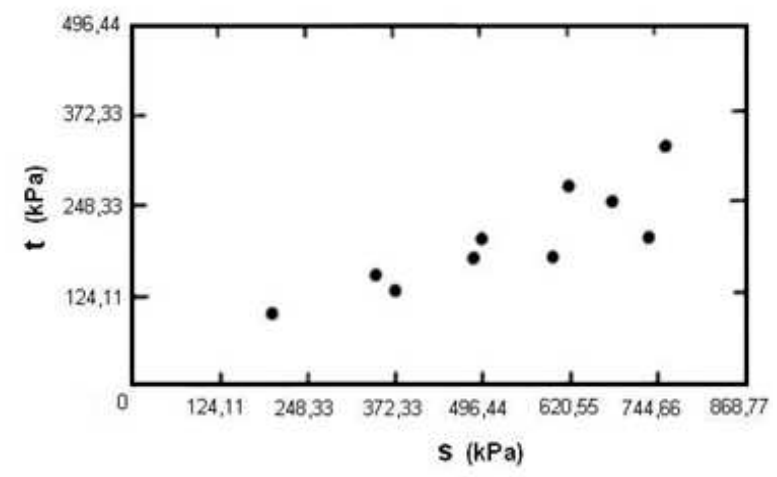

(b)

Figura 5.11 - Características do solo escavado: (a) perfil do solo encontrado nas sondagens; (b) resultados de ensaios de laboratório em amostras representativas.

A escavação apresentou uma altura de aproximadamente 9,2m de altura, construída em cinco fases, com grampos de 6,1m de comprimento, diâmetro do reforço igual a $25 \mathrm{~mm}$, diâmetro do grampo de $100 \mathrm{~mm}$, inclinação de 20, espaçamento horizontal e vertical de $1,83 \mathrm{~m}$ em cada grampo, e paramento de concreto projetado com espessura de $100 \mathrm{~mm}$ (ver Figura 5.12).
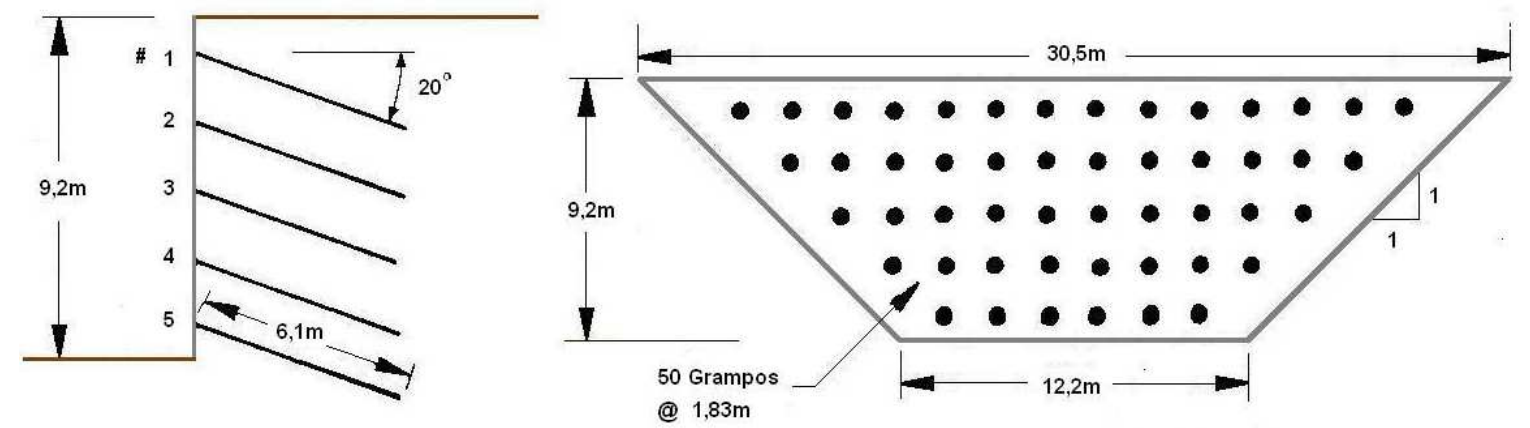

Figura 5.12 - Geometria e características do modelo físico de Shen et. al (1981).

O modelo tridimensional de elementos finitos foi criado para uma fatia de solo grampeado com espessura igual $0,915 \mathrm{~m}$ (metade do espaçamento horizontal entre grampos). A malha de elementos finitos empregada, junto com o processo construtivo em cada etapa (escavação, instalação do grampo e colocação do paramento de concreto projetado), encontram-se apresentados na figura 5.13. 

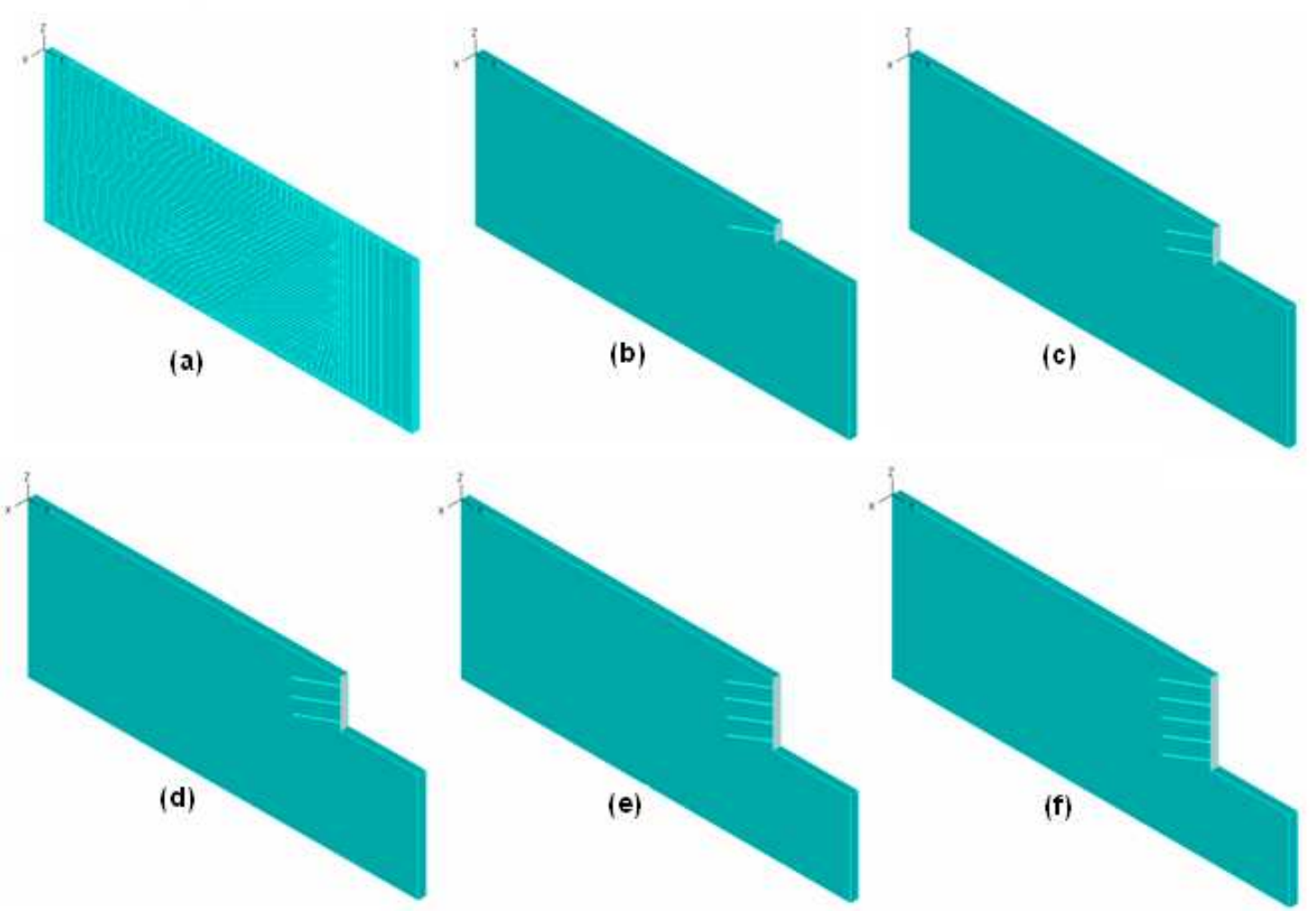

Figura 5.13 - Configuração da malha de elementos finitos e fases de construção: (a) Malha e estado inicial; (b) primeira fase; (c) segunda fase; (d) terceira fase; (e) quarta fase; (f) fase final.

É importante ressaltar alguns aspectos relacionados à análise numérica tridimensional realizada: (1) a análise numérica realizada não possui elementos de interface no contato solo-grampo, pois foi utilizado o elemento rebar para representar o grampo. Esta hipótese de comportamento supõe uma resistência ao arrancamento $\left(\mathrm{q}_{\mathrm{s}}\right)$ infinita, pois não haveria deslocamento entre os nós do solo com os do grampo;(2) não consideração de elementos de interface entre o solo e o paramento de concreto projetado, indicando que na superfície escavada não existe deslocamento relativo entre os nós dos elementos de casca que representam o paramento de concreto projetado e os nós dos elementos sólidos que representam o maciço de solo.

Para a determinação dos parâmetros utilizados nas análises numéricas foram utilizadas as equações do modelo hiperbólico de Duncan e Chang (1970), junto com os valores apresentados na tabela 5.2 obtidos por Shen et. al (1981) mediante os ensaios de laboratório apresentados na figura $5.11 \mathrm{~b}$ 
Tabela 5.2 - Parâmetros do modelo hiperbólico (Shen et. al, 1981).

\begin{tabular}{|c|c|}
\hline Parâmetro & Valor \\
\hline $\mathrm{K}$ & 500 \\
$\mathrm{~K}_{\mathrm{ur}}$ & 1370 \\
$n$ & 0,5 \\
$\phi\left({ }^{\circ}\right)$ & 36 \\
$\mathrm{c}(\mathrm{kPa})$ & 5 \\
$\mathrm{R}_{\mathrm{f}}$ & 0,79 \\
$\nu$ & 0,39 \\
$\gamma_{\mathrm{t}}\left(\mathrm{kN} / \mathrm{m}^{3}\right)$ & 19 \\
$\mathrm{p}_{\mathrm{a}}(\mathrm{kPa})$ & 103,31 \\
\hline
\end{tabular}

Para o cálculo dos módulos de elasticidade de compressão por carregamento utilizaram-se as equações propostas por Duncan e Chang (1970), as quais encontram-se reproduzidas no anexo A. Os valores dos módulos de elasticidade nas outras duas trajetórias de tensão (compressão por descarregamento e extensão por descarregamento) foram obtidos utilizando as proporções entre módulos de elasticidade para diferentes trajetórias de tensão descritas no capitulo anterior. $\mathrm{Na}$ tabela 5.3 pode-se observar os valores de módulos de elasticidade utilizados nas análises numéricas. Na aludida tabela nota-se que os valores de módulos de elasticidade foram calculados para uma altura media da camada de solo ${ }^{24}$ e para um valor de $50 \%$ da tensão desviadora.

Tabela 5.3 - Valores de módulos de elasticidade utilizados a diferentes profundidades para cada trajetória de tensão.

\begin{tabular}{|c|c|c|c|c|c|c|c|c|c|c|}
\hline $\begin{array}{c}\mathrm{H}_{\text {média }} \\
(\mathrm{m})\end{array}$ & $\begin{array}{c}\sigma_{1} \\
(\mathrm{kPa})\end{array}$ & $\mathrm{K}_{0}$ & $\begin{array}{c}\sigma_{3}(\mathrm{kPa}) \\
(\mathrm{kPa})\end{array}$ & $\begin{array}{c}\left(\sigma_{1}-\sigma_{3}\right)_{f} \\
(\mathrm{kPa})\end{array}$ & $\begin{array}{c}\mathrm{E}_{\mathrm{i}} \\
(\mathrm{kPa})\end{array}$ & $\begin{array}{c}\mathrm{E}_{\mathrm{t}} \\
(\mathrm{kPa})\end{array}$ & $\begin{array}{c}\left(\sigma_{1}-\sigma_{3}\right)_{50 \%} \\
(\mathrm{kPa})\end{array}$ & $\begin{array}{c}E_{\text {sec }-50 \gamma-C C} \\
(k P a)\end{array}$ & $\begin{array}{c}E_{\text {sec }-50 \alpha-C D} \\
(k P a)\end{array}$ & $\begin{array}{c}E_{\text {sec }-50}-E D \\
(k P a)\end{array}$ \\
\hline 0,000 & 0,00 & 0,64 & 0,00 & 19,63 & 0 & 0,00 & 9,81 & 0,00 & & \\
\hline 0,915 & 17,39 & 0,64 & 11,12 & 51,32 & 16943 & 13830,66 & 25,66 & 10251 & 30752 & 92256 \\
\hline 2,745 & 52,16 & 0,64 & 33,35 & 114,72 & 29347 & 22236,33 & 57,36 & 17755 & 53264 & 159792 \\
\hline 4,575 & 86,93 & 0,64 & 55,58 & 178,12 & 37886 & 28082,82 & 89,06 & 22921 & 68763 & 206290 \\
\hline 6,405 & 121,70 & 0,64 & 77,81 & 241,51 & 44828 & 32880,08 & 120,76 & 27121 & 81362 & 244086 \\
\hline 8,235 & 156,47 & 0,64 & 100,04 & 304,91 & 50830 & 37052,99 & 152,45 & 30752 & 92256 & 276767 \\
\hline 10,065 & 191,24 & 0,64 & 122,27 & 368,31 & 56194 & 40797,66 & 184,15 & 33998 & 101993 & 305978 \\
\hline 11,895 & 226,01 & 0,64 & 144,50 & 431,70 & 61090 & 44224,52 & 215,85 & 36959 & 110878 & 332633 \\
\hline 13,725 & 260,78 & 0,64 & 166,73 & 495,10 & 65621 & 47403,23 & 247,55 & 39701 & 119102 & 357305 \\
\hline 15,555 & 295,55 & 0,64 & 188,96 & 558,50 & 69859 & 50381,13 & 279,25 & 42265 & 126794 & 380381 \\
\hline 17,385 & 330,32 & 0,64 & 211,19 & 621,89 & 73854 & 53192,14 & 310,95 & 44682 & 134045 & 402134 \\
\hline
\end{tabular}

O campo de tensões iniciais foi imposto mediante a utilização do coeficiente de empuxo em repouso e o peso unitário do solo (ver Figura 5.14). As condições de contorno utilizadas não permitem nenhum tipo de deslocamento na superfície de

\footnotetext{
${ }^{24}$ Considerou-se como altura da camada o valor igual a $1,83 \mathrm{~m}$, que coincide com a altura de escavação em cada etapa.
} 
contorno inferior. As superfícies situadas nos contornos laterais apresentam impedimento para se deslocar nas direções $X$ e $Y$, porém, é permitido o deslocamento na direção Z
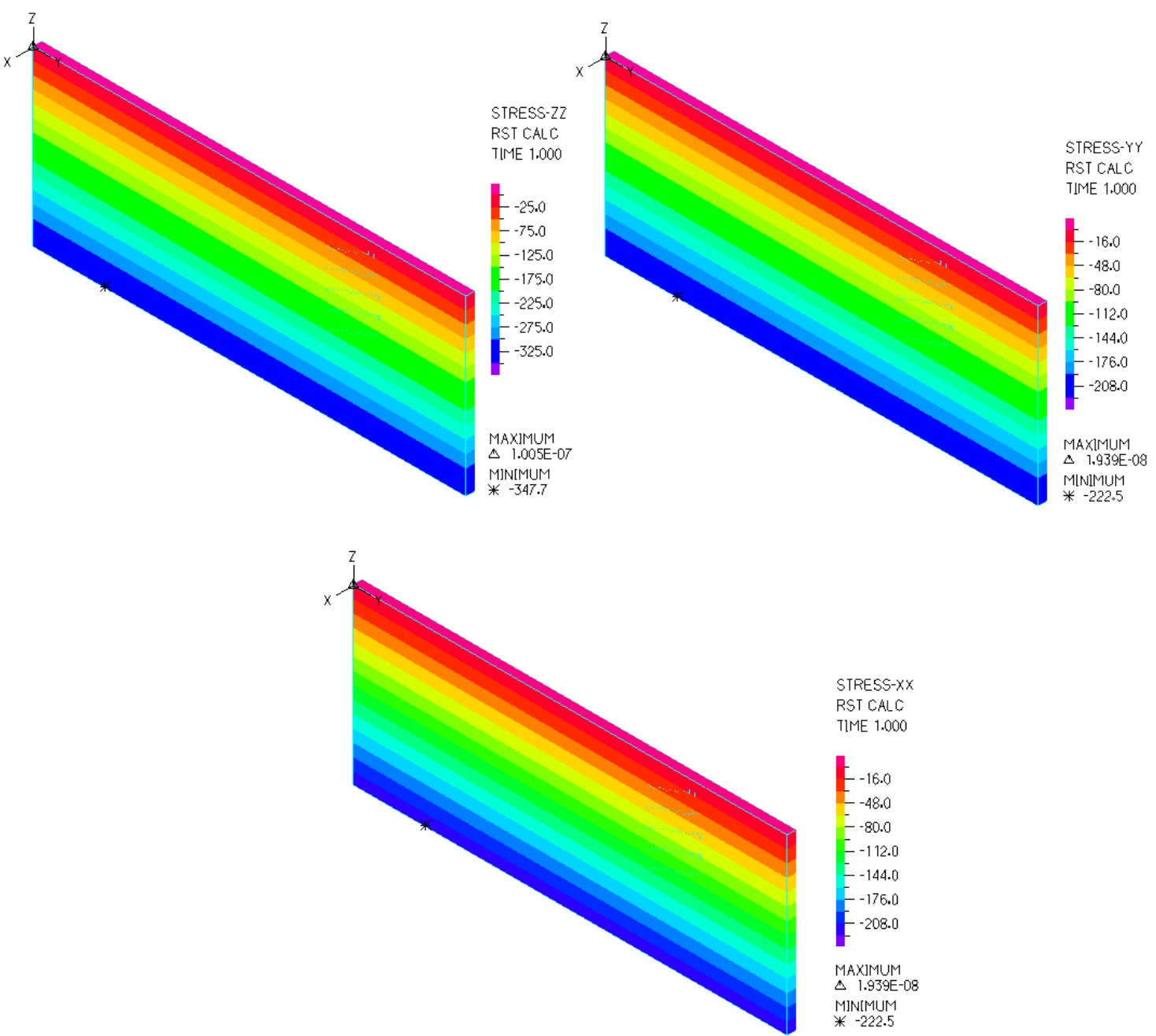

Figura 5.14 -Campos de tensões inicias nas direções z, y e x respectivamente.

O processamento computacional considerou dois fatores importantes que influenciam o comportamento do maciço escavado: (1) variação do módulo de elasticidade com a tensão de confinamento; (2) variação do módulo de elasticidade com tipo de trajetória de tensão no solo ao redor da escavação. O processamento computacional foi realizado em varias etapas, sendo que em cada etapa o módulo de elasticidade foi modificado em cada região, em função dos dois fatores descritos acima. A figura 5.15 apresenta a divisão do maciço de solo para modificação dos parâmetros elásticos durante o processamento computacional. 


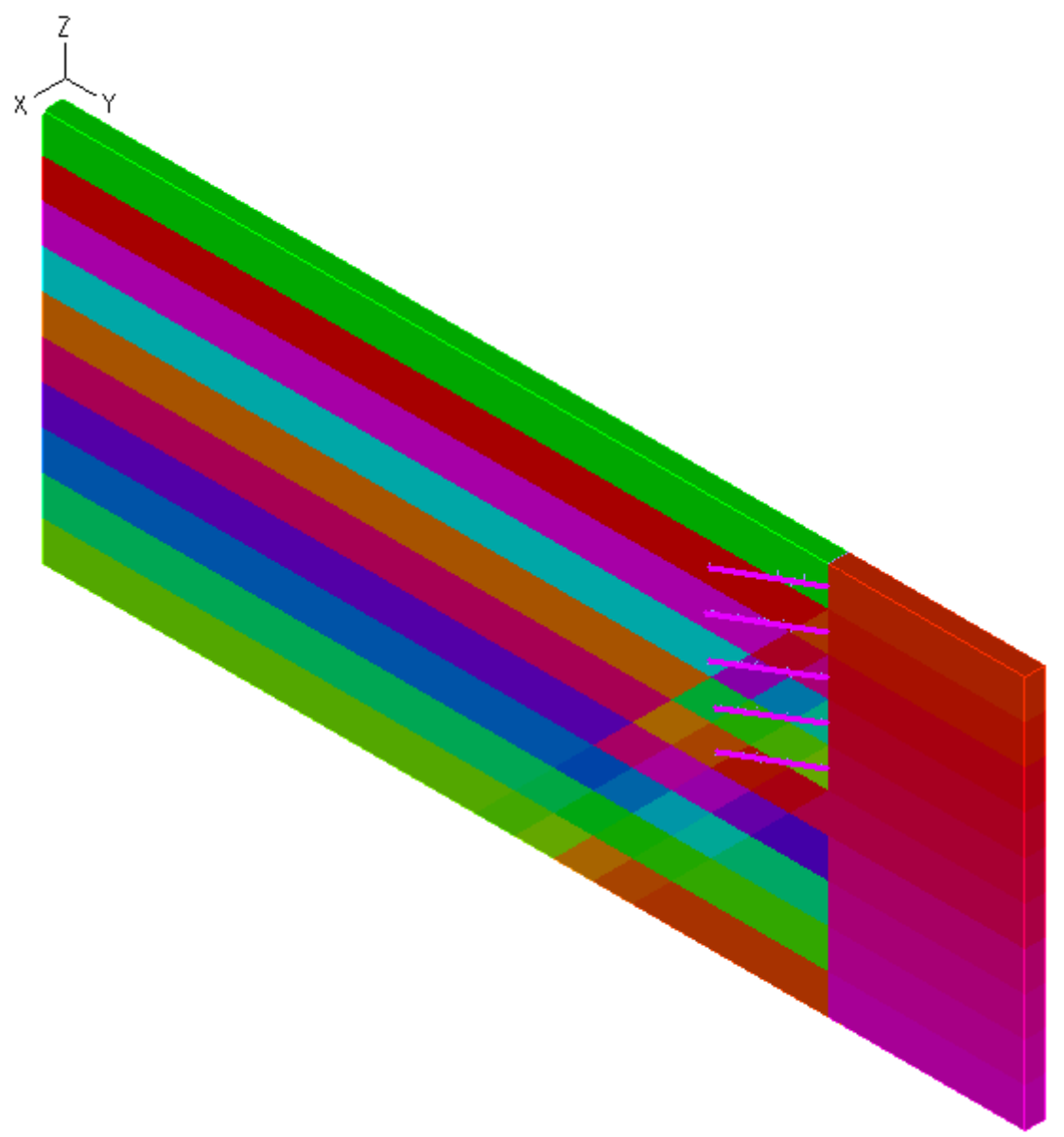

Figura 5.15 -Divisão do maciço de solo em regiões para atualização dos parâmetros elásticos durante o processamento computacional.

A figura 5.16 apresenta a deformada (onde os valores dos deslocamentos foram aumentados em 1000 vezes seu valor, para efeitos de visualização) da estrutura na última etapa da escavação. Esta deformação foi provocada pelo alívio de tensões nos maciços localizados detrás da face escavada e embaixo do fundo da vala.

Os campos de deslocamentos horizontais e verticais no maciço de solo na última etapa de escavação podem ser observados nas figuras 5.17 e 5.18 respectivamente. Nessas figuras pode-se notar que os valores máximos de deslocamento horizontal e vertical estão localizados próximos à crista do talude escavado. Tanto o campo de deslocamentos horizontais como verticais apresentaram cunhas de deslizamento. 


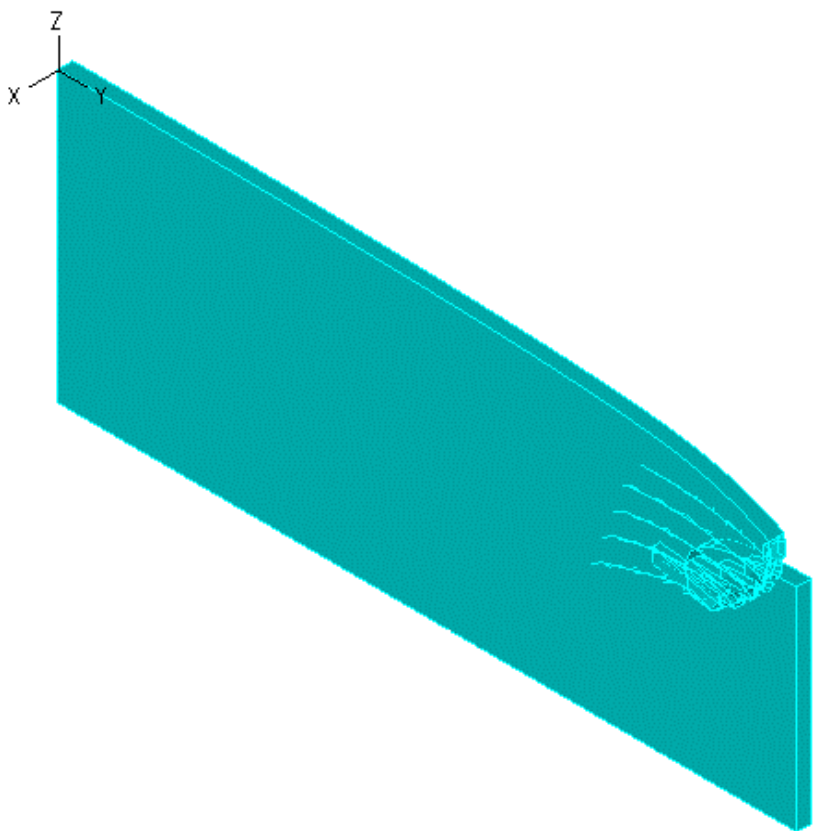

Figura 5.16 - Aspecto da deformada da escavação grampeada na última etapa de escavação.

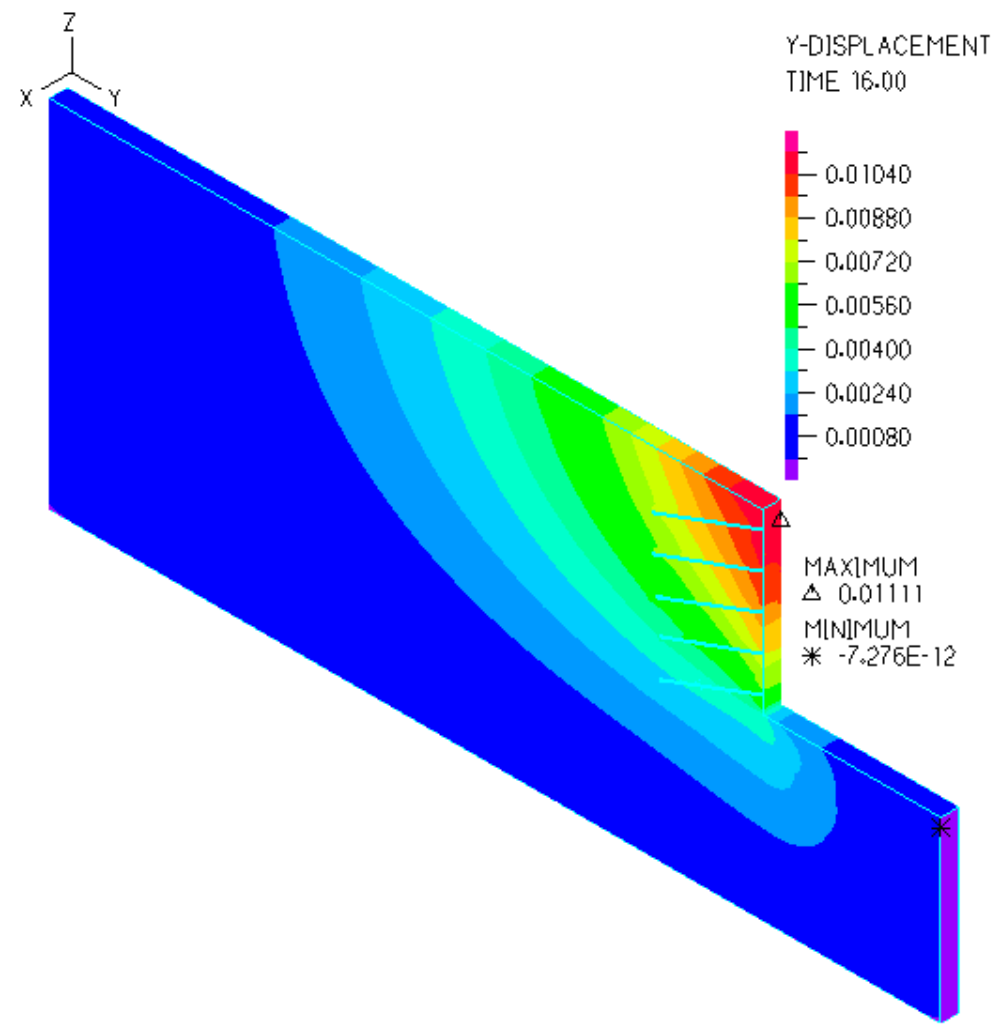

Figura 5.17 - Campo de deslocamentos horizontais. 


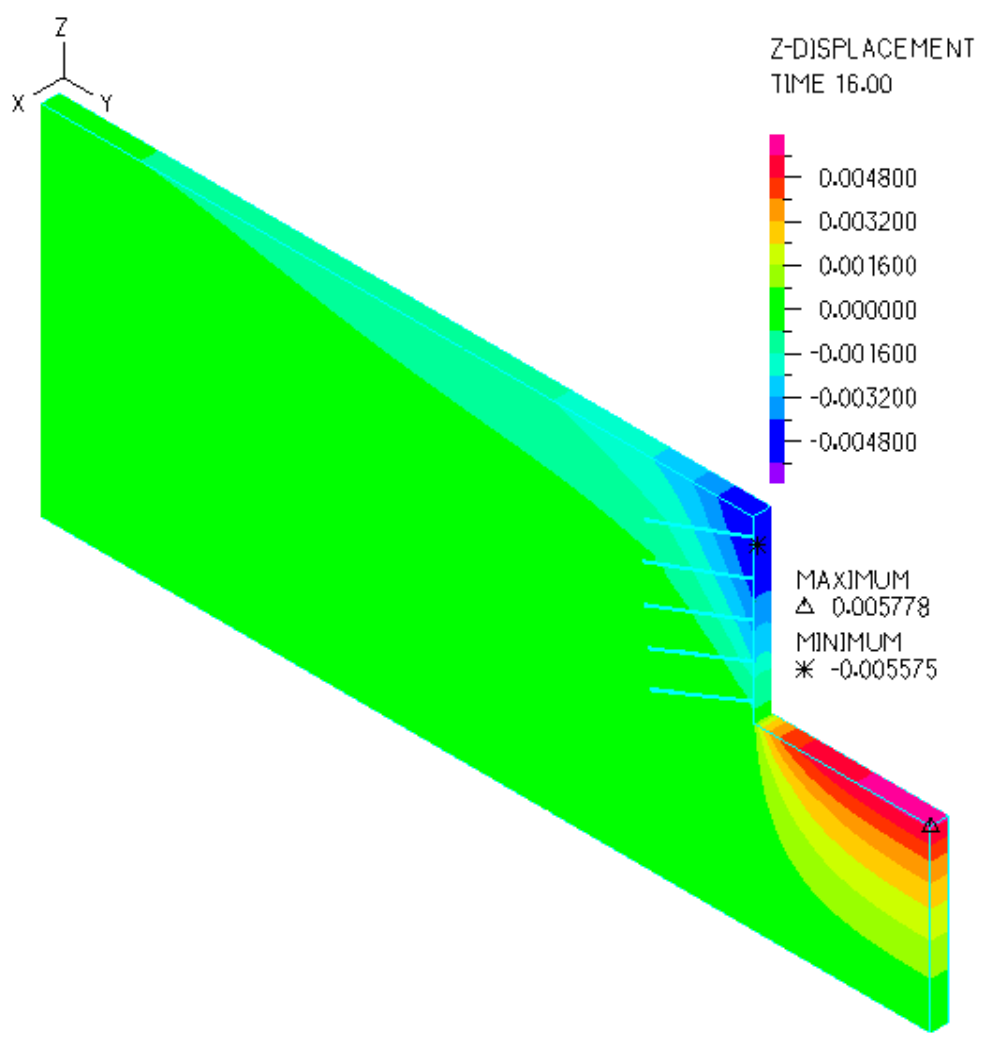

Figura 5.18 - Campo de deslocamentos verticais.

A comparação dos perfis de deslocamento horizontal situados a $1,5 \mathrm{~m}$ da parede escavada dos registros da instrumentação realizados por Shen et. al (1981), resultados da modelagem de Zhang et. al (1999) e do modelo tridimensional elaborado no presente trabalho, podem ser observados na figura 5.19. Nota-se que: (1) os maiores deslocamentos foram os registrados por Shen et. al (1999) duas semanas depois de finalizada a escavação; (2) o perfil de deslocamento horizontal obtido no modelo tridimensional aplicando a teoria da elasticidade é semelhante ao encontrado por Zhang et. al $(1999)^{25}$, porém, o valor do máximo deslocamento horizontal foi $2 \mathrm{~mm}$ maior do que obtido por Zhang et. al (1999); (3) os deslocamentos horizontais registrados mediante instrumentação na etapa final da escavação são menores do que os encontrados no modelo tridimensional, contudo as duas curvas apresentam-se semelhantes; (4) de acordo com perfil geotécnico apresentado na figura 5.11a mostra-se que a heterogeneidade do maciço de solo impossibilita a determinação adequada dos parâmetros, pois isto têm influência nos resultados das modelagens numéricas; (5) as duas análises numéricas mostraram

\footnotetext{
${ }^{25}$ Na modelagem numérica de Zhang et. al (1999) foi utilizado o modelo hiperbólico de Duncan e Chang (1970) para representação do comportamento do maciço de solo.
} 
que o maciço situado embaixo do fundo da vala apresenta um deslocamento maior do que o registrado na instrumentação, fato que poderia ser atribuído à rigidez do maciço utilizada nas análises.

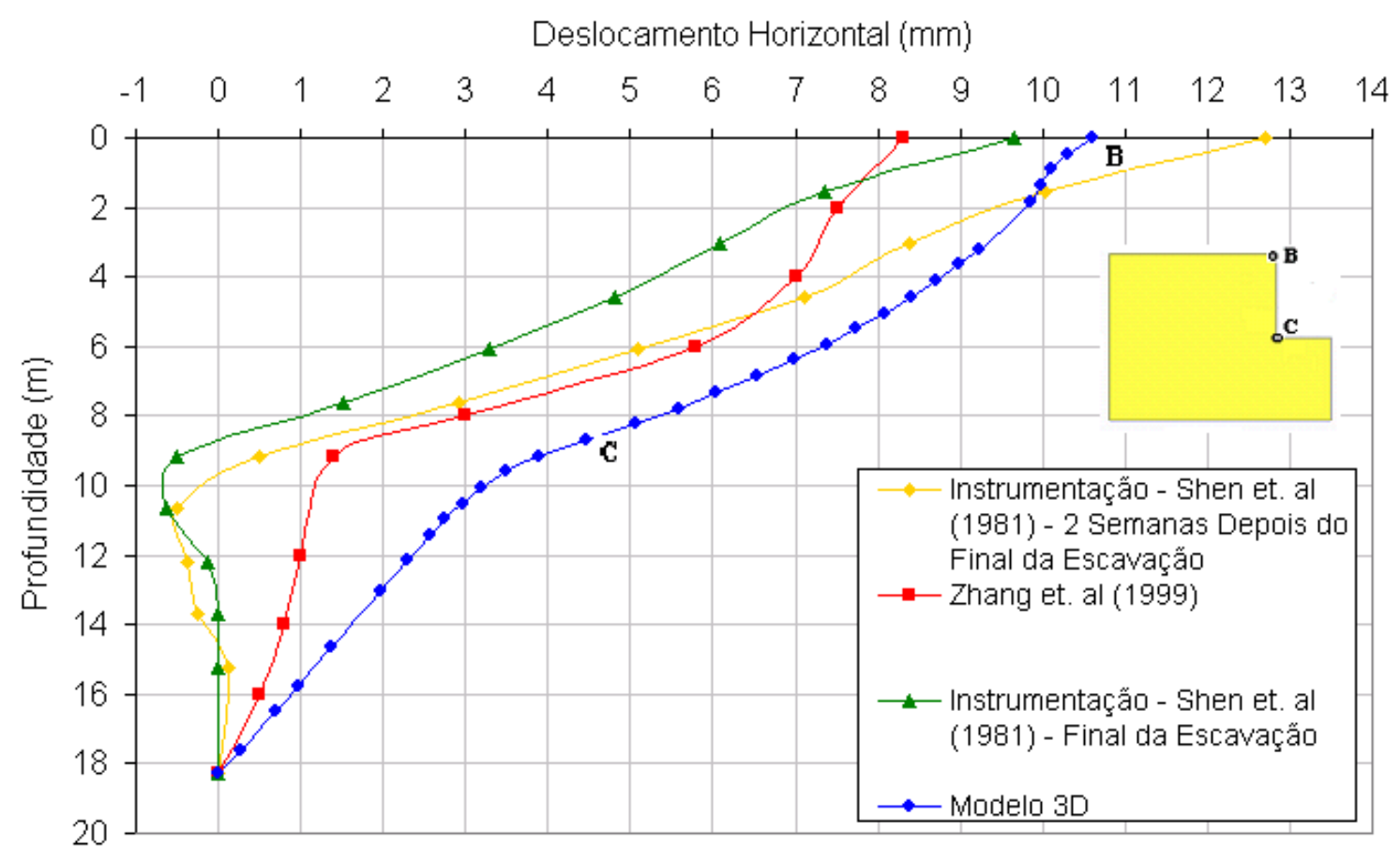

Figura 5.19 - Comparação dos perfis de deslocamentos horizontais.

A comparação dos perfis de recalques apresentados na figura 5.21, mostrou o seguinte: (1) no perfil de recalque obtido por Shen et. al (1981) mediante instrumentação do talude escavado registrou-se os maiores valores de recalques, este comportamento este que foi atribuído ao desenvolvimento de trincas ao longo da crista do talude, durante o processo de escavação; (2) a diferença entre os resultados dos máximos deslocamentos nas duas modelagens numéricas é de $2 \mathrm{~mm}$; (3) semelhança nos dois perfis de recalque das análises numéricas tridimensionais 
Distância (m)

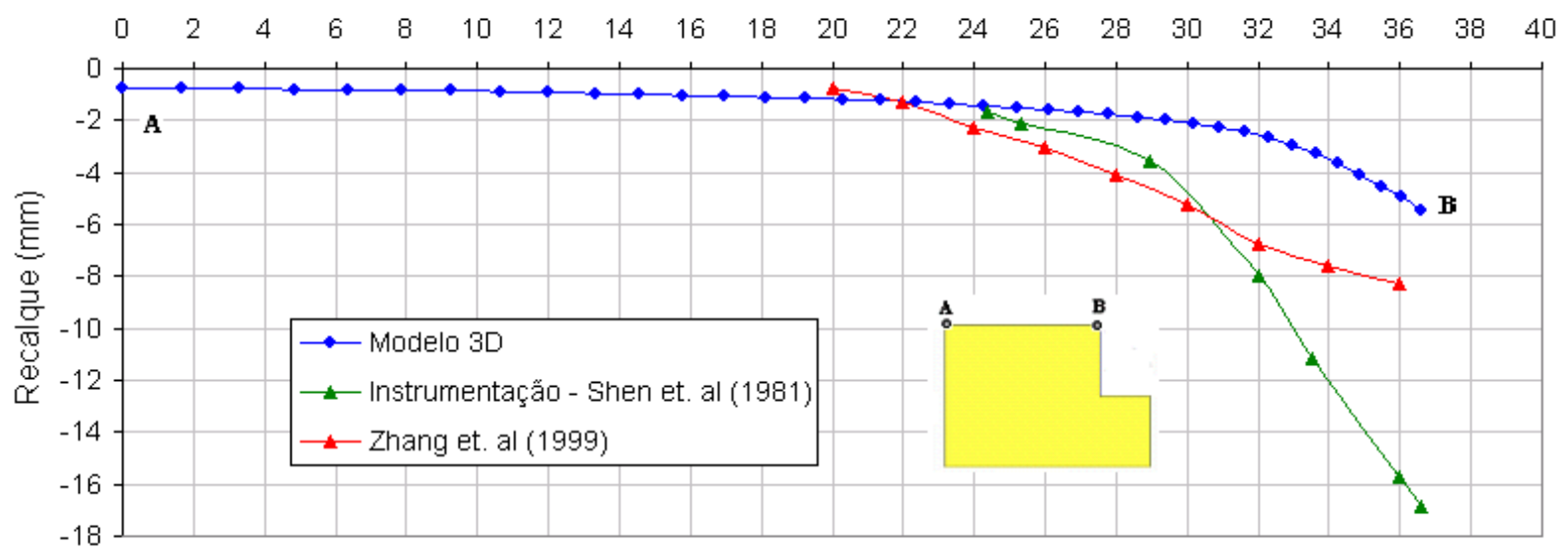

Figura 5.20 - Comparação dos perfis de recalques . 


\section{Capitulo 6 - CONCLUSÕES E RECOMENDAÇÕES}

A partir dos resultados das análises realizadas são efetuadas as seguintes conclusões:

- O número de etapas de escavação não tem influência em modelagens numéricas que utilizam a teoria da elasticidade para a condição de módulo de elasticidade único e constante. Fato que é validado pelo trabalho de Ishihara (1971), que versa sobre a demonstração teórica da existência de uma solução única nos processos de escavação em materiais elástico-lineares.

- Segundo os resultados apresentados no item 4.6 as análises numéricas de escavações a céu aberto realizadas em um meio contínuo, isotrópico (utilização de um único módulo de elasticidade para todo o maciço de solo) e homogêneo não simulam adequadamente o comportamento do maciço, pois não consideram a variação do módulo de elasticidade em função do tipo de trajetória de tensão no solo, levando a resultados incompatíveis com a realidade observada (Figura 4.4).

- Análises numéricas realizadas com a teoria da elasticidade mostraram que a proximidade das condições de contorno influencia muito os resultados. Portanto, recomenda-se a seguinte configuração geométrica, $W=4 \mathrm{H}$ e $\mathrm{D}=2 \mathrm{H}$ (Figuras 4.6, a 4.9).

- De acordo com a comparação de resultados (Figuras 5.9 e 5.10) entre as análises numéricas bidimensionais e tridimensionais realizadas no estudo de caso hipotético da escavação grampeada de Lima et. al (2002), conclui-se que a seção entre grampos do modelo tridimensional apresenta maiores deslocamentos horizontais do que o modelo bidimensional, pois neste último, os grampos são representados como elementos contínuos na direção longitudinal. 
- A revisão bibliográfica realizada sobre os valores de módulos de elasticidade para diferentes trajetórias de tensão permitiu conhecer algumas correlações entre módulos de elasticidade em diferentes trajetórias de tensão. Os estudos de caso apresentados no Capitulo 5 mostraram que as correlações entre valores de módulos de elasticidade utilizados nas modelagens numéricas representaram adequadamente o comportamento das escavações reforçadas com a técnica de solo grampeado. Portanto, verificou-se que a adoção das seguintes proporções: valor do módulo de elasticidade em compressão por descarregamento três vezes superior ao valor do módulo em compressão por carregamento, o valor do módulo de elasticidade obtido para uma trajetória de extensão por carregamento três vezes superior ao módulo encontrado em uma trajetória de compressão por descarregamento, representaram de maneira adequada o comportamento das escavações grampeadas.

- Os estudos realizados nos itens 4.11 e 4.13 mostraram que a escolha dos parâmetros elásticos (módulo de elasticidade e coeficiente de Poisson) para análises numéricas de escavações a céu aberto deve ser muito cuidadosa, pois os valores de deslocamentos horizontais da parede escavada e deslocamentos verticais ao longo da crista do talude, dependem dessa escolha.Esses estudos também permitiram definir que maciços de escavações grampeadas podem ser simulados adequadamente com a Teoria da Elasticidade, embora, deva ser considerada uma divisão do maciço em regiões em função do tipo de trajetória em cada região, para a realização da análise incremental (Figuras 5.3 e 5.15).

- O ajuste iterativo dos parâmetros elásticos de cada elemento do maciço de solo ao redor da escavação, em função das trajetórias de tensão, nas etapas final e intermediária da escavação, permite determinar uma distribuição típica das trajetórias de tensão em cada região do maciço (ver Figuras 4.14 e 4.17). Os resultados obtidos com adoção das distribuições típicas (sem iterações) foram conferidos mediante comparação dos deslocamentos horizontais e verticais, os quais mostraram pouca variação em relação em relação aos resultados das iterações (Figuras 4.15, 4.16, 4.18 e 4.19) Portanto, pode-se concluir que a divisão do maciço em regiões em função das trajetórias de 
tensão é necessária quando realizadas análises numéricas de escavações a céu aberto que aplicam a teoria da elasticidade, e pode ser simplificado por distribuições típicas de trajetórias de tensão, dispensando o cálculo iterativo.

- O estudo de caso hipotético realizado no item 5.2 permitiu realizar uma comparação entre o comportamento de uma escavação grampeada simulada com os modelos elástico-linear e elasto-plático (ver Figuras 5.9 e 5.10). Desta comparação pode-se concluir que os valores de deslocamentos horizontais obtidos com um modelo elasto-plástico são maiores do que os encontrados em uma análise numérica que aplica a teoria da elasticidade.

- A comparação dos resultados das modelagens numéricas que utilizaram a teoria da elasticidade e modelo hiperbólico de Duncan e Chang (1970), com os registros da instrumentação realizada por Shen et. al (1981) (ver Figuras 5.20 e 5.21), permitiram concluir que a correta aplicação da teoria da elasticidade permite representar bem o comportamento de escavações grampeadas.

- Resultados das duas análises numéricas apresentadas no estudo de caso do Programa Davis, apresentados no Capitulo 5, mostraram, que o maciço situado embaixo do fundo da vala apresenta um deslocamento maior do que o registrado na instrumentação.Isto poderia ser atribuído à rigidez do maciço utilizada nas análises (ver Figura 5.20).

- No estudo de caso do Programa Davis, mostrou-se que o perfil de recalque medido por Shen et. al (1981) mediante a instrumentação apresentou valores superiores aos encontrados na modelagem numérica (Figura 5.21). Esta diferença foi atribuída ao desenvolvimento de trincas ao longo da crista do talude durante o processo da escavação.

- Os resultados das simulações numéricas realizadas no Capitulo 5 mostraram que o máximo valor de deslocamento horizontal é aproximadamente o dobro do máximo valor de deslocamento vertical em escavações grampeadas. 
Clouterre (1991) reporta, mediante observações de campo, deslocamentos muito próximos. A diferença talvez possa ser explicada pelas trincas mencionadas no parágrafo anterior.

Com base nestas conclusões apresentam-se a seguir algumas sugestões de pesquisas futuras que podem complementar e melhorar a metodologia proposta:

- Realização de um modelo tridimensional de elementos finitos que considere a representação do grampo como um sólido, com interface solo-grampo representada de maneira mais realista por elementos de contato. Com isso poderia-se entender melhor o desenvolvimento das forças de contato que ocorrem nas zonas passivas e ativas do maciço reforçado.

- Segundo as análises numéricas realizadas, mostrou-se no item 4.13 que existe uma forte influência do valor do Coeficiente de Poisson utilizado nos resultados de modelagens numéricas. Portanto, recomenda-se realizar um estudo aprofundado sobre a variação do Coeficiente de Poisson com o tipo de trajetória de tensão que sofre o solo, e a influência dessa variação nos resultados de modelagens numéricas de escavações a céu aberto. 


\section{REFERÊNCIAS}

ANN, T. S. et al. Finite element of a soil nailed slope: some recent experience. Singapore, 2006. Disponível em:

<www.geosynthetica.net/tech_docs/GeoAsia04Ann.pdf>. Acesso em: 15 nov. 2005.

BATHE, K. J. Finite element procedures. Englewood Cliffs, N.J.: Pretince Hall, 1996. xiv, $1037 \mathrm{p}$.

BOWLES, J. E. Analytical and computer methods in foundation engineering. Tokyo: McGraw-Hill, 1974. 519 p.

BRIAUD, J. L.; LIM, Y. Soil-nailed wall under piled bridge abutment: simulation and guidelines. Journal of Geotechnical and Geoenvironmental Engineering, New York, v. 123, n. 11, p. 1043-1050, 1997.

BRUCE, D. A.; JEWELL, R. A. Soil nailing: application and practice: part I. Ground Engineering, London, v. 19, n. 8, p. 10-15, 1986.

BRUCE, D. A.; JEWELL, R. A. Soil nailing: application and practice: part II. Ground Engineering, London, v. 20, n. 1, p. 21-33, 1987.

BUSTAMANTE, M.; DOIX, B. Une méthode pour le calcul dês tyrants et des micropieux injectées. Bulletin dês Liaison dês Laboratoire dês Ponts et Chaussées, Paris, n. 140, 1985.

BYRNE, R. J. et al. Manual for design and construction monitoring of soil nail wall. Washington, DC: Federal Highway Administration, U. S. Department of Transportation, 1998. v. 1, 530 p.

CAMARGO, V. E. Comparação de métodos de análise de estruturas de solo grampeado. 2005. 118 p. Dissertação (Mestrado) - Escola Politécnica, Universidade de São Paulo, São Paulo, 2005.

CARDOSO, A. S.; CARRETO, A. P. Performance and analysis of a nailed excavation. In: INTERNATIONAL CONFERENCE ON SOIL MECHANICS AND FOUNDATION ENGINEERING, 12., Rio Janeiro, 1989. Proceedings... Rio de Janeiro, 1989. v. 2, p. 1233-1236. 
CHARLES, W. W. Stress paths in relation to deep excavations. Journal of Geotechnical and Geoenvironmental Engineering, New York, v. 125, n. 5, p. 357363, 1999.

CHEANG, W. L. et al. Lateral bending of soil-nails in an excavation. Australia, 2000. Disponível em:

$<$ www.plaxis.nl/upload/bulletins/12\%20PLAXIS\%20Bulletin.pdf>. Acesso em: 17 set. 2006.

CHRISTIAN, J. T.; WONG, I. H. Errors in simulating excavation in elastic media by finite elements. Soils and Foundations, Tokyo, v. 13, n. 1, p. 1-10. 1973.

UNITED STATES. Department of Transportation. Federal Highway Administration. Soil nailing recommendations, 1991: for designing, calculating, constructing and inspecting earth support systems using soil nailing. Washington, D.C., 1991. 302 p.

DÉCOURT, L.; ZIRILIZ, A.; PITTA, C. A. Projeto e comportamento de escavações estabilizadas com solo grampeado em São Paulo. In: WORKSHOP SOLO GRAMPEADO - PROJETO, EXECUÇÃO, INSTRUMENTAÇÃO E COMPORTAMENTO, 1., 2003, São Paulo. Anais... São Paulo: ABMS; SINDUSCONSP, 2003. p. 57-104.

DUNCAN, J. M.; CHANG, C. Y. Nonlinear analysis of stress and strain in soils. Journal of Soil Mechanics and Foundation Division, New York, v. 96, n. 5, p. 1629-1653, 1970.

DUNLOP, P.; DUNCAN, J. M. Development of failure around excavated slopes. Journal of Soil Mechanics and Foundation Division, New York, v. 96, n. 2, p. 471493.

EHRLICH, M.; ALMEIDA, M. S. S.; LIMA, A. M. Parametric numerical analysis of soil nailing systems. In: INTERNATIONAL SYMPOSIUM ON EARTH REINFORCEMENT, 2., 1996, Fukuoka, Japan. Proceedings... Fukuoka, Japan, 1996. p. 747-752.

EHRLICH, M.; DANTAS, B. T. Aplicação da análise dimensional a estruturas de contenção de solo reforçado. In: CONGRESSO BRASILEIRO DE ESTABILIDADE DE ENCOSTAS, 3., Rio de Janeiro, 2001. Anais... Rio de Janeiro: ABMS, 2001. p. 457-463 
EISENSTTEIN, Z.; MEDEIROS, L. V. A deep retaining structure in till and sand: part 2: performance and analysis,1983. Canadian Geotechnical Journal, Ottawa, CA, v. 20, n. 1, p. 120-130, Fev. 1983.

FRANÇA, P. T. Estudo do comportamento de túneis: análise numérica tridimensional com modelos elasto-plásticos. 2006. 185 p. Dissertação (Mestrado) Escola Politécnica, Universidade de São Paulo, São Paulo, 2005.

GASSLER, G.; GUDEHUS, G. Soil nailing: some aspects of a new technique. In: INTERNATIONAL CONFERENCE ON SOIL MECHANICS AND FOUNDATION ENGINEERING, 10., 1981, Stockholm. Proceedings... Stockholm, 1981. v. 3, session 12, p. 665-670.

GASSLER, G.; GUDEHUS, G. Soil nailing: statistical design. In: EUROPEAN CONFERENCE ON SOIL MECHANICS AND FOUNDATION ENGINEERING, 8., 1983, Helsinki. Proceedings... Rotterdam: A. A. Balkema, 1983. v. 2, p. 491-494.

GUIMARÃES FILHO, J. D. O alívio controlado de tensões na técnica de solo grampeado. Solos e Rochas, Rio de Janeiro, v. 17, n. 3, p. 195-201, 1994.

HACHICH, W. et al. Fundações teoria e prática. 2. ed. São Paulo: PINI, 1999. 751 p.

HACHICH, W. C.; CAMARGO, V. E. L. B. Comparação de processos de dimensionamento de estruturas em solo grampeado. . In: WORKSHOP SOLO GRAMPEADO - PROJETO, EXECUÇÃO, INSTRUMENTAÇÃO E COMPORTAMENTO, 1., 2003, São Paulo. Anais... São Paulo: ABMS; SINDUSCONSP, 2003. p. 179-185.

HACHICH, W.; CAMARGO, V. E. L. B. Sobre a contribuição dos grampos à estabilidade de estruturas de solo grampeado. In: CONGRESSO BRASILEIRO DE MECÂNICA DOS SOLOS E ENGENHARIA GEOTÉCNICA, 12., 2006, Curitiba. Anais... Curitiba, 2006. v. 4, p.2297-2302.

HO, D. K. H.; SMITH, I. M. Modeling of soil nailing construction by 3-dimensional finite element analysis. In: CONFERENCE RETAINING STRUCTURES, 1993, London. Proceedings... London: T. Telford, 1993. p. 515-528.

ISHIHARA, K. Relations between process of cutting and uniqueness of solutions. Soils and Foundations, Tokyo, v. 10, n. 3, p. 50-65, 1970. 
JEWELL, R. A. et al. Design methods for steep reinforced embankments. In: INTERNATIONAL CONFERENCE ON POLYMER GRID REINFORCEMENT IN CIVIL ENGINEERING, 1984, London. Proceedings... London: Thomas Telford, 1984. p. $70-81$.

JURAN, I. et al. Kinematical limit analysis approach for the design of nailed soil retaining structures. In: GEOTECHNICAL SYMPOSIUM ON THEORY AND PRACTICE OF EARTH REINFORCEMENT, 1988, Fukuoka, Japan. Proceedings... Rotterdam; Brookfield [Vt.]: A.A. Balkema, 1988. p. 301-306.

JURAN, I. et al. Kinematical limit analysis for design of soil-nailed structures. Journal of Geotechnical Engineering, New York, v. 118, n. 10, 1992.

KIM, J. S.; KIM, J. Y.; LEE, S. R. Analysis of soil nailed earth slope by discrete element method. Computers and Geotechnics, Barking Essex, v. 20, n. 1, p. 1-14, 1997.

LADE, P. V.; NELSON, R. B. Modelling the elastic behaviour of granular materials. International journal numerical and analytical methods in geomechanics, Chichester, v. 11, p. 521-542, 1987.

LADE, P. V. Overview of constitutive models for soils. In: YAMAMURO, J. A.; KALIANKIN, V. N. (Ed.). Soil constitutive models: evaluation, selection, and calibration. Texas: ASCE, 2005. p. 1-34. (Geotechnical special publication, n. 128).

LAMBE, T W.; WHITMAN, R. V. Soil mechanics. New York: John Wiley \& Sons, 1969. ix, $553 \mathrm{p}$.

LAMBE, T. W. Stress path method. Journal of the soil mechanics and foundations division, New York, v.93, n. sm6, p. 306-309, 1967.

LIMA, A. M. L. Análise numérica do comportamento de solos grampeados. 1996. 85 p. Dissertação (Mestrado) - Universidade Federal de Rio de Janeiro, Rio de Janeiro, 1996.

LIMA, A. P. Comportamento de uma escavação grampeada em solo residual de gnaisse. 2007. 428 p. Tese (Doutorado) - Pontifícia Universidade Católica de Rio de Janeiro, Rio de Janeiro, 2007. 
LIMA, A. P. Deformabilidade e estabilidade de taludes em solo grampeado. 2002. 85 p. Dissertação (Mestrado) - Pontifícia Universidade Católica de Rio de Janeiro, Rio de Janeiro, 2002.

LIMA FILHO, S. C. P; BORGES,J. B.; LIMA, A. P. Aplicação da técnica de solo grampeado para estabilização de áreas urbanas carentes. In: CONFERÊNCIA BRASILEIRA SOBRE ESTABILIDADE DE ENCOSTAS, 4., 2005, Salvador. Anais... Salvador: ABMS, 2005. v. 2, p. 657-663.

MALVERN, E. L. Introduction to the mechanics of a continuous medium. Englewood Cliffs, N.J: Pretince Hall, 1996. xii, 713 p.

MEDEIROS, L. V.; EISENSTTEIN, Z. A deep retaining structure in till and sand: part 1: stress path effects. Canadian Geotechnical Journal, Ottawa, CA, v. 20, n. 1, p. 121-130, 1983.

MITCHELL, J. K.; VILLET, W. C. B. (Ed.). Reinforcement of earth slopes and embankments. Washington, D.C.: Transportation Research Board, National Research Council, 1987. 323 p.

MORETRENCH GEOTEC. Case studies: soil nail. New Jersey, 2005. Disponível em: <www.moretrench.com>. Acesso em: 10 mar. 2006.

MORGENSTERN, N. R.; EISENSTEIN, Z. Methods of estimating lateral loads and deformations. In: SPECIALTY CONFERENCE ON LATERAL STRESSES IN THE GROUND AND DESIGN OF EARTH RETAINING STRUCTURES, 1970, New York. Proceedings... New York: ASCE; Cornell University, 1970. p. 51-102.

OLIVEIRA, V. S.; FERREIRA, R. S. Análise bidimensional e tridimensional em talude estabilizado com solo grampeado. In: CONGRESSO BRASILEIRO DE MECÂNICA DE SOLOS E ENGENHARIA DE GEOTÉCNICA, 12., 2006, Curitiba. Anais... Curitiba, 2006. 1 CD-ROM.

ORTIAGÃO, J. A. R.; ZIRLIS, A. C.; PALMEIRA, E. M. Experiência com solo grampeado no Brasil: 1970-1993. São Paulo: Solos e Rochas, Rio de Janeiro, v. 25, n. 4, p. 291-304, dez. 1993.

ORTIGÃO, J. A. R.; PLAMEIRA, E. M.; ZIRILIS, A. Optimised design for soil nailed walls. In: INTERNATIONAL CONFERENCE ON GROUND IMPROVEMENT GEOSYSTEMS, 3., London. Proceedings... London: T Telford, 1997. p. 368-374. 
ORTIGÃO, J. A. R.; SAYÃO, A. S. F. J. (Ed.). Manual técnico de encostas: ancoragens e grampos. 2. ed. Rio de Janeiro: GeoRio, 2000. v. 4, 184 p.

PINTO, C. S. Curso básico de mecânica dos solos. 2. ed. São Paulo: Oficina de Textos, 2002. viii, $355 \mathrm{p}$.

PITTA, C. A.; SOUZA, G. J. T.; ZIRILIS, A. C. Solo grampeado, alguns detalhes executivos, ensaios - casos de obras. . In: WORKSHOP SOLO GRAMPEADO PROJETO, EXECUÇÃO, INSTRUMENTAÇÃO E COMPORTAMENTO, 1., 2003, São Paulo. Anais... São Paulo: ABMS; SINDUSCONSP, 2003. p. 1-20.

POULOS, H. G.; DAVIS, E. H. Elastic solutions for soil rock mechanics. New York: J. Wiley, 1974. 411 p.

RESENDIZ, D.; ZONANA, J. La estabilidad a corto plazo de excavaciones a cielo abierto en la arcilla de la ciudad de México. In: CARRILLO, N. Hundimiento de la ciudad de Mexico y proyecto texcoco. Mexico: Secr. Hacienda Credito Publico, 1969. p. 203-228.

ROGBECK, Y. et al. Nordic guidelines for reinforced soils an fills. Dinamarca, 2004. Disponível em:

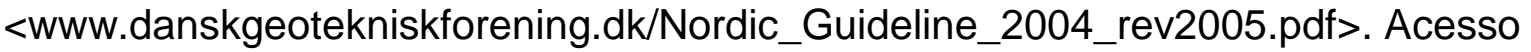
em: 20 jun. 2005.

SHEN, C. K. et al. Field measurements of earth support system. Journal of the Geotechnical Engineering Division, New York, v. 107, n. 12, p. 1625-1642, 1981.

SHEN, C. K.; BANG, S.; HERRMAN, L. R. Ground movement analysis of earth support system. Journal of the Geotechnical Engineering Division, New York, v. 107, n. 12, p. 1609-1624, 1981.

SHIU, Y. K.; CHANG, G. W. K. Effects of inclination, length pattern and bending stiffness of soil nails on behaviour of nailed structures. Kowloon, Hong Kong: Civil Engineering and Development Building, 2005. 116 p. (Special Project Report).

SMITH, I. M.; SU, N. Three-dimensional FE analysis of a nailed soil wall curved in plan. International Journal and Analytical Methods in Geomechanics, London, v. 21, p 583-597, 1997. 
SPRINGER, F. O. Ensaios de arrancamento de grampos em solo residual de ganaisse. 2006. 310 p. Tese (Doutorado) - Pontifícia Universidade Católica de Rio de Janeiro, Rio de Janeiro, 2006.

SPRINGER, F. O. Estudos de deformabilidade de escavações com solo grampeado. 2001. 95 p. Dissertação (Mestrado) - Pontifícia Universidade Católica de Rio de Janeiro, Rio de Janeiro, 2001.

STOCKER, M. F. et al. Soil nailing. In: INTERNATIONAL CONFERENCE ON SOIL REINFORCEMENT: REINFORCED EARTH AND OTHER TECHNIQUES = COLLOQUE INTERNATIONAL SUR LE RENFORCEMENT DES SOLS: TERRE ARMÉE ET AUTRES TECHNIQUES, 1979, Paris. Proceedings... Paris: Association amicale des ingenieurs anciens eleves de l'École nationale des ponts et chaussées, 1979. p. 469-474.

TEXEIRA et al. Um caso de obra: aeródromo caiapó - Mococa - SP. Disponível em: <http://www.solotrat.com.br>. Acesso em: 20 out. 2006.

TEZAGHI, K. Theoretical soil mechanics. New York: John Wiley \& Sons, 1943. 510 p.

THE SOIL NAIL LAUNCHER. Estados Unidos. Apresenta a metodologia de construção e alguns casos de obra. Disponível em:

<http://www.soilnaillauncher.com>. Acesso em: 06 maio 2007.

PROTO, T. S. et al. Avaliação semi-empírica da resistência ao arrancamento de grampos. In: CONGRESSO BRASILEIRO DE MECÂNICA DE SOLOS E ENGENHARIA DE GEOTÉCNICA, 12., 2006, Curitiba. Anais... Curitiba, 2006. 1 CDROM.

UNTERREINER, P.; SCHLOSSER, F.; BENHAMIDA, B. Calculation of displacements of a full-scale experimental soil nailed wall - French National Research Project Clouterre. In: SYMPOSIUM [OF THE] THE PRACTICE OF SOIL REINFORCING IN EUROPE, 18., 1995, London. [Trabalhos apresentados]. New York: ASCE, 1995. $20 \mathrm{p}$.

YU, S.; DAKOULAS, P. General stress-dependent elastic moduli for crossanisotropic soils. Journal of Geotechnical Engineering, New York, v. 119, n. 10, p. 1568-1586, 1993. 
ZHANG, M.; SONG, E.; CHEN, Z. Ground movement analysis of nailing construction by three-dimensional (3-D) finite element modeling (FEM). Journal of Computers and Geotechnics, Barking Essex, v. 25, p 191-204, 1999. 


\section{Apêndice A - TENSORES DE TENSÃO EM ELEMENTOS PRÓXIMOS A UMA ESCAVAÇÃO}

Neste apêndice são apresentados os tensores de tensão antes e depois da escavação, para três elementos (elementos 120, 288 e 376) situados ao redor da escavação (ver Figura A.1) Este estudo tem como objetivo mostrar a existência de uma variação da tensão na direção x perpendicular à fatia da escavação analisada, sendo que nessa direção a condição de contorno imposta não permite deslocamentos.em $x$, porém os deslocamentos nas outras duas direções não estão impedidos.

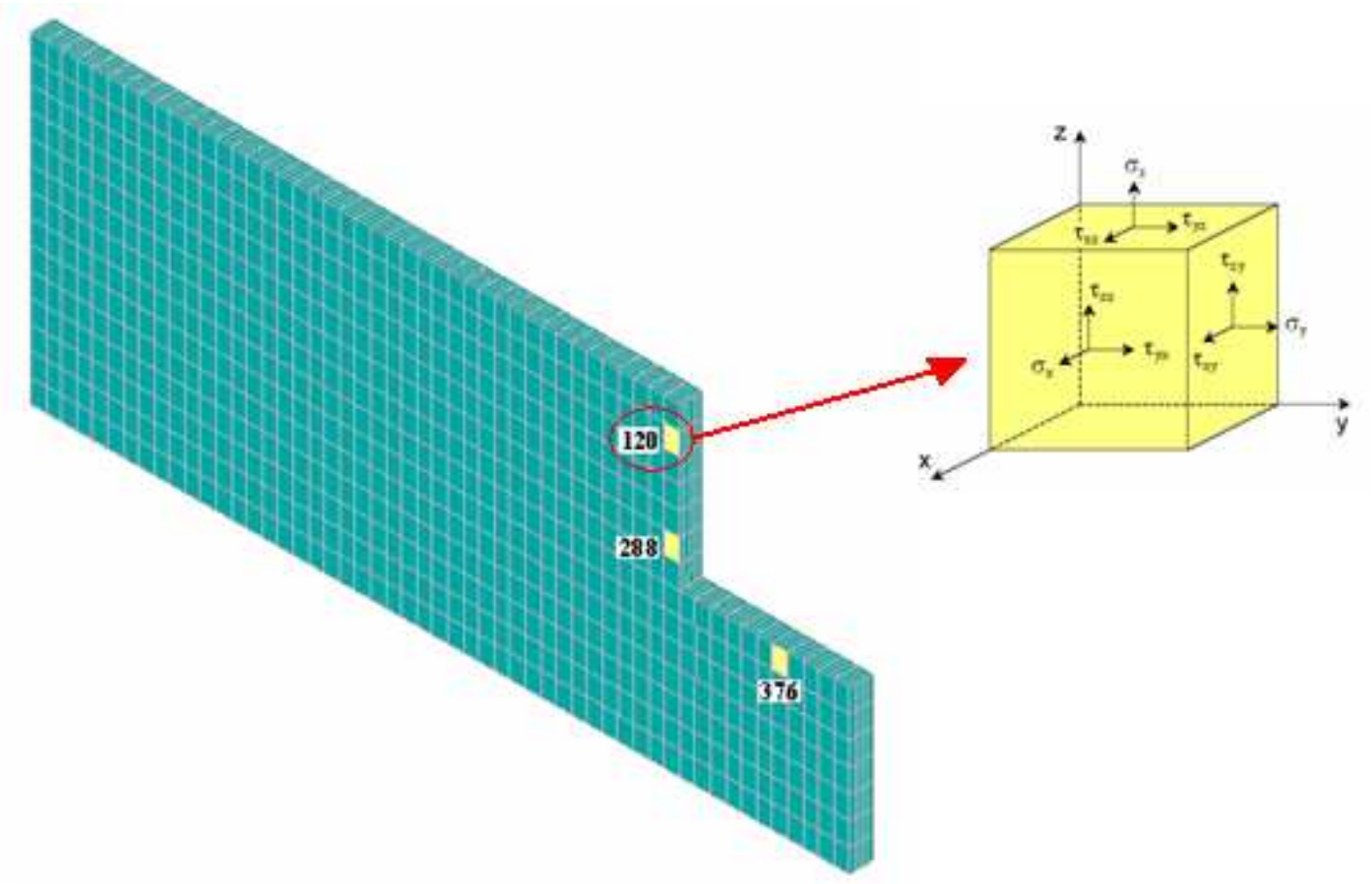

Figura A.1 - Modelo tridimensional de uma escavação e localização dos elementos estudados.

Os parâmetros geométricos, físicos e mecânicos utilizados na análise numérica da escavação estão apresentados na Tabela A.1. 
Tabela A.1 - Parâmetros utilizados na análise numérica para o estudo dos tensores de tensão em elementos próximos à escavação.

\begin{tabular}{|c|c|}
\hline Parâmetro & Valor \\
\hline Peso Unitário $\gamma(\mathrm{kN} / \mathrm{m} 3)$ & 18,5 \\
\hline Modulo de Young - $E(\mathrm{kPa})$ & 45.000 \\
\hline Coeficiente de Poisson $v$ & 0,3 \\
\hline Coeficiente de Empuxo em Repuso - $K_{o}$ & 0,5 \\
\hline Altura da Escavação - $H(\mathrm{~m})$ & 10,5 \\
\hline Largura da Vala - $B(\mathrm{~m})$ & 10,5 \\
\hline Profundidade elemento $120-z(\mathrm{~m})$ & 2,25 \\
\hline Profundidade elemento $288-z(\mathrm{~m})$ & 8,25 \\
\hline Profundidade elemento $376-z(\mathrm{~m})$ & 11,25 \\
\hline
\end{tabular}

Os tensores de tensões principais antes de iniciar a escavação e os tensores de tensões orientados segundo o sistema de eixos cartesianos depois da escavação, encontram-se apresentados a seguir:

$$
[\sigma]_{\text {Inicial }}=\left[\begin{array}{ccc}
\sigma_{1} & 0 & 0 \\
0 & \sigma_{2} & 0 \\
0 & 0 & \sigma_{3}
\end{array}\right] \quad[\sigma]_{\text {Final }}=\left[\begin{array}{ccc}
\sigma_{x} & \tau_{x y} & \tau_{x z} \\
\tau_{y x} & \sigma_{y} & \tau_{y z} \\
\tau_{z x} & \tau_{z y} & \sigma_{z}
\end{array}\right]
$$

- Elemento 120

$$
[\sigma]_{\text {Inicial }}=\left[\begin{array}{ccc}
41,6 & 0 & 0 \\
0 & 20,8 & 0 \\
0 & 0 & 20,8
\end{array}\right] \quad[\sigma]_{\text {Final }}=\left[\begin{array}{ccc}
14,5 & 0 & 0 \\
0 & -0,17 & 4,17 \\
0 & 4,17 & 41,7
\end{array}\right]
$$

- Elemento 288

$$
[\sigma]_{\text {Inicial }}=\left[\begin{array}{ccc}
152,6 & 0 & 0 \\
0 & 76,3 & 0 \\
0 & 0 & 76,3
\end{array}\right] \quad[\sigma]_{\text {Final }}=\left[\begin{array}{ccc}
60,3 & 0 & 0 \\
0 & 4,1 & -7,5 \\
0 & -7,5 & 171,5
\end{array}\right]
$$


- Elemento 376

$$
[\sigma]_{\text {Inicial }}=\left[\begin{array}{ccc}
208 & 0 & 0 \\
0 & 104 & 0 \\
0 & 0 & 104
\end{array}\right] \quad[\sigma]_{\text {Final }}=\left[\begin{array}{ccc}
30,6 & 0 & 0 \\
0 & 48,3 & 0,05 \\
0 & 0,05 & 18,8
\end{array}\right]
$$

Nota-se que existe um decréscimo da tensão $\Delta \sigma_{2}{ }^{26}$, o qual indicaria uma tendência de contração na fatia da escavação analisada. No entanto, as condições de contorno no modelo utilizadas no modelo tridimensional não permitem nenhum tipo de deformação nessa direção.Este comportamento pode ser explicado pela ocorrência do efeito de Poisson na direção $x$, pois o elemento sólido esta sendo tracionado no plano $\mathrm{YZ}$.

${ }^{26}$ Observado mediante a comparação de $\sigma_{3}$ antes do inicio da escavação, com $\sigma_{\mathrm{x}}$ na última etapa da escavação. 


\section{Anexo A - EQUAÇÕES DO MODELO HIPERBÓLICO DE DUNCAN E CHANG (1970)}

No presente anexo serão apresentadas as equações do modelo hiperbólico de Duncan e Chang (1970),

- Módulo de elasticidade inicial.

$$
E_{i}=K p_{a}\left(\frac{\sigma_{3}}{p_{a}}\right)^{n}
$$

- Tensão desviadora na ruptura.

$$
\left(\sigma_{1}-\sigma_{3}\right)_{f}=\frac{2 c \cos \phi+2 \sigma_{3} \operatorname{sen} \phi}{1-\operatorname{sen} \phi}
$$

- Módulo de elasticidade secante

$$
E_{g e c}=E_{i}\left\lfloor 1-\frac{R_{f}(1-\operatorname{sen} \phi)\left(\sigma_{1}-\sigma_{3}\right)}{2 c \cos \phi+2 \sigma_{3} \operatorname{sen} \phi}\right\rfloor
$$

- Módulo de elasticidade tangente

$$
E_{t}=E_{i}\left[1-\frac{R_{f}\left(1-\operatorname{sen} \phi^{2}\right)\left(\sigma_{1}-\sigma_{3}\right)}{2 c \cos \phi+2 \sigma_{3} \operatorname{sen} \phi}\right]^{2}
$$

